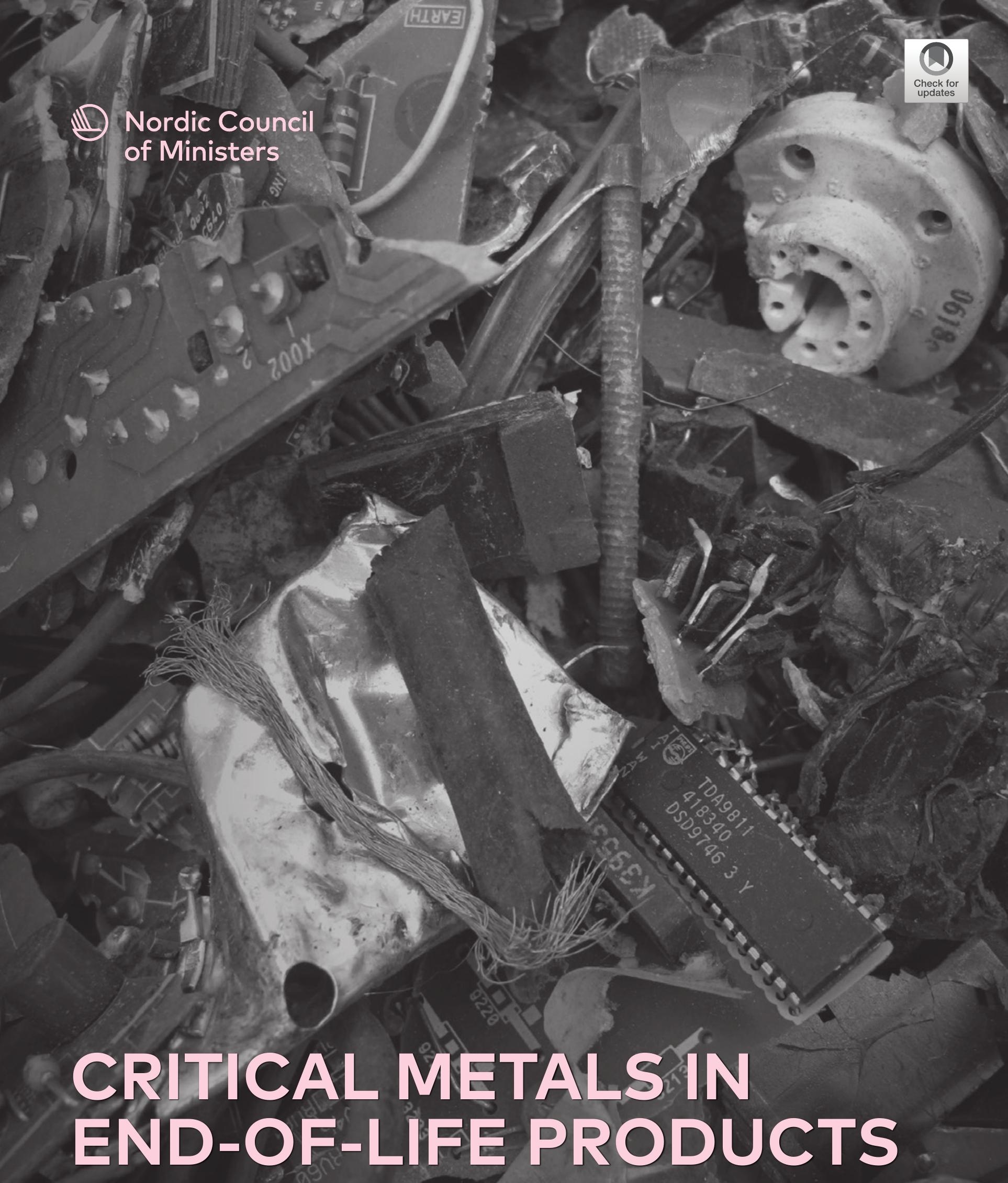

Recovery potential and opportunities for removal of bottlenecks of recycling 



\section{Critical metals in end-of-life products}

Recovery potential and opportunities for removal of bottlenecks of recycling

Henna Punkkinen, Ulla-Maija Mroveh, Margareta Wahlström, Lena Youhanan and Åsa Stenmarck

TemaNord 2017:531 


\section{Critical metals in end-of-life products}

Recovery potential and opportunities for removal of bottlenecks of recycling

Henna Punkkinen, Ulla-Maija Mroueh, Margareta Wahlström, Lena Youhanan and Åsa Stenmarck

ISBN 978-92-893-4988-8 (PRINT)

ISBN 978-92-893-4989-5 (PDF)

ISBN 978-92-893-4990-1 (EPUB)

http://dx.doi.org/10.6027/TN2017-531

TemaNord 2017:531

ISSN 0.908-6692

Standard: PDF/UA-1

ISO 14289-1

(c) Nordic Council of Ministers 2017

Cover photo: unsplash.com

Print: Rosendahls

Printed in Denmark

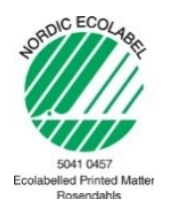

Although the Nordic Council of Ministers funded this publication, the contents do not necessarily reflect its views, policies or recommendations.

\section{Nordic co-operation}

Nordic co-operation is one of the world's most extensive forms of regional collaboration, involving Denmark, Finland, Iceland, Norway, Sweden, the Faroe Islands, Greenland, and Åland.

Nordic co-operation has firm traditions in politics, the economy, and culture. It plays an important role in European and international collaboration, and aims at creating a strong Nordic community in a strong Europe.

Nordic co-operation seeks to safeguard Nordic and regional interests and principles in the global community. Shared Nordic values help the region solidify its position as one of the world's most innovative and competitive. 


\section{Contents}

Preface

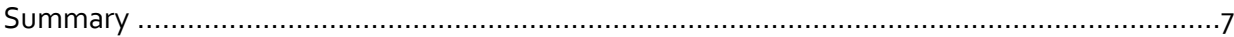

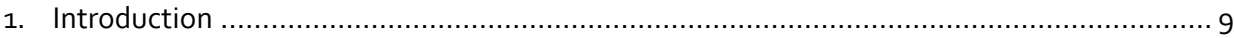

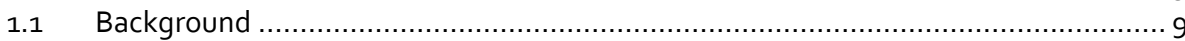

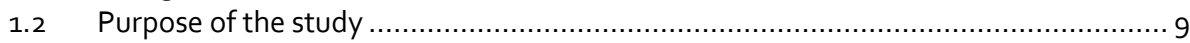

1.3 Selection of end-of-life product types .......................................................

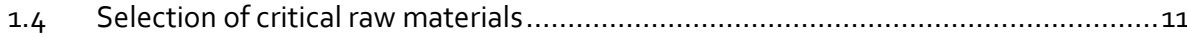

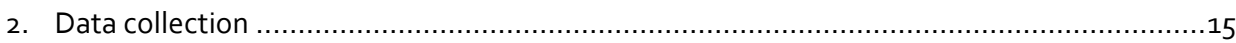

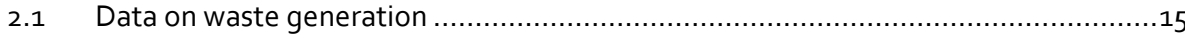

2.2 Data on critical raw material content of the selected products............................. 20

3. Critical raw materials in the selected applications in the Nordic countries....................... 25

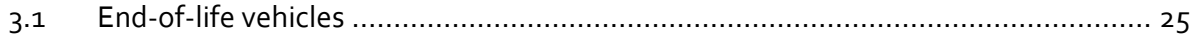

3.2 Lighting products........................................................................................ 27

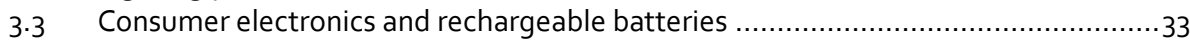

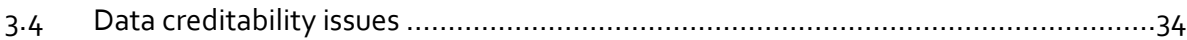

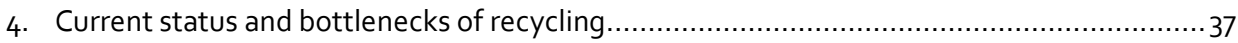

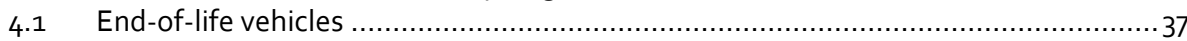

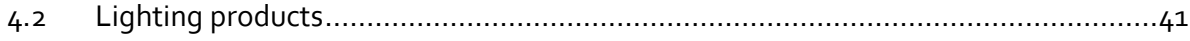

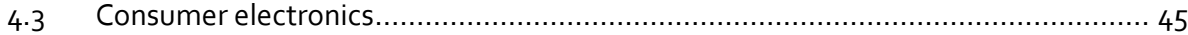

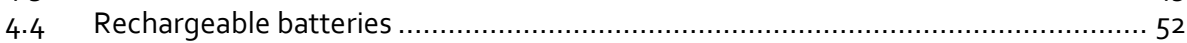

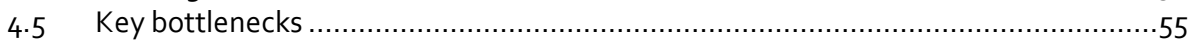

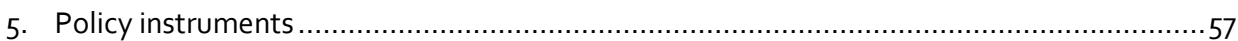

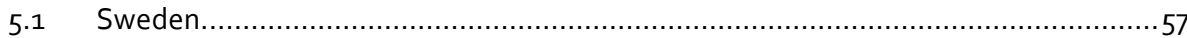

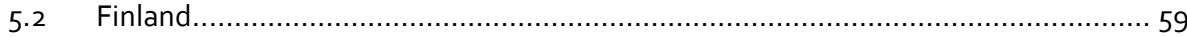

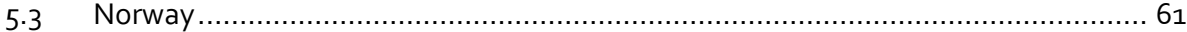

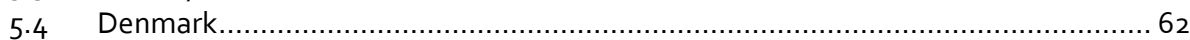

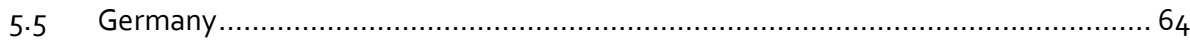

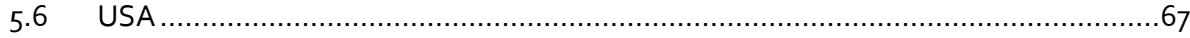

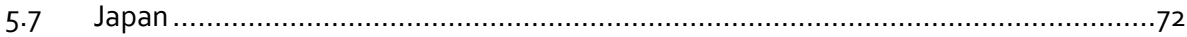

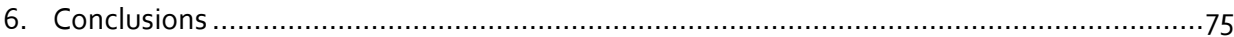

6.1 The availability and value of CRMs in selected product groups ............................75

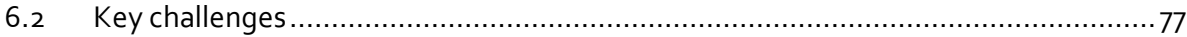

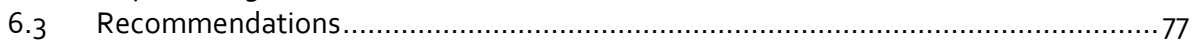

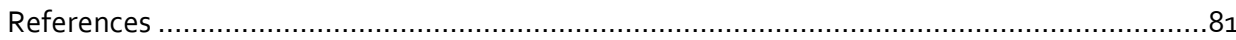

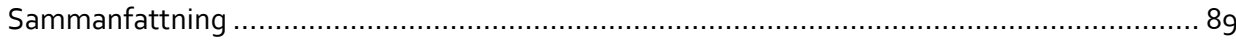

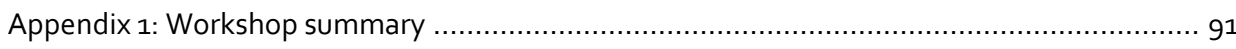

Appendix 2: CRM contents in generated ELV ...................................................... 95

Appendix 3: Identified bottlenecks for increased ELV recycling according to NEW_InnoNet

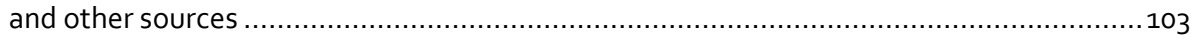





\section{Preface}

Critical raw materials (CRM) are used in a considerable number of different applications in different sectors, such as electrical and electronics, transport, energy, equipment manufacture and construction. It is projected that their consumption will further increase in the future. The threats caused by the limited availability and high prices of CRMs have led to discussion on the more efficient use of the resources available in Europe. Due to the limited availability of good-grade primary resources, improved recycling from end-of-life products is an opportunity for Europe.

This report is part of a report series of the Nordic Council of Ministers' Working Group on Environment and Economy (MEG) which focuses on the recycling potential of waste streams that contain critical raw materials as well as policy instruments for the efficient management of these resources. The first report, compiled by a consortium led by CRI (Bakas et al., 2016), focused on the recycling potential of selected consumer electronic applications and rechargeable batteries. Here, however, the focus is on the CRM potential of end-of-life vehicles (ELV) and lighting applications, as well as potential incentives that could enhance the sustainable recycling of CRMs from all the above mentioned end-of-life product groups.

This report was funded by the Environment and Economy Group (MEG) under the Nordic Council of Ministers (NCM) and prepared by researchers from VTT Technical Research Centre of Finland Ltd and IVL Swedish Environmental Research Institute.

May 2017

Signe Krarup

Chairman of the Working Group on Environment and Economy under the Nordic Council of Ministers 



\section{Summary}

Precious and Critical Raw Materials (CRMs) are widely used in different kinds of products. Their applications include, for example, transportation vehicles, electric and electronics products, low-carbon energy technologies and different industrial applications. Typically, CRMs are contained in components with high-performance requirements. Therefore, they are critical for the functioning of the product. From the recycling point of view, the challenge is that these materials are mostly used in small amounts in complex structures.

The project aimed to analyze the bottlenecks in CRM recycling and identify potential policy instruments to eliminate the barriers or reduce their impact. Based on the results, the report presents recommendations on key measures to enhance sustainable recycling of CRMs in the Nordic countries. The focus areas were end-of-life vehicles (ELV), lighting products, consumer electronics and rechargeable batteries. Estimates of the annually available CRM quantities in these end-of-life products during the period 2015-2020 give indications about the recycling potential in the Nordic countries (Denmark, Finland, Norway and Sweden).

The CRM quantities in ELV and lighting waste were calculated by combining estimates of waste generation and literature data on CRM quantities in products. For electronics and rechargeable batteries, the report uses the CRM potentials presented in the publication "Critical metals in discarded electronics" (Bakas et al. 2016), with the exception of gold and silver. The results show that there is a relatively significant potential of critical and precious metals available in these product groups, but it is scattered in a very large number of individual products under different regulations and subject to different collection and pretreatment systems.

One of the key challenges is to find economically effective solutions for recycling small quantities of materials integrated in alloys, composites or tightly packed structures and joined with methods, which complicate dismantling. In addition, the rapidly changing product design leads to continuously changing and heterogeneous input to recycling processes. The volatility of metal prices, lack of data about recyclable volumes and uncertainties about the future market of recovered CRMs further complicate estimation of the economic viability of the processing concepts.

Currently there are almost no incentives for manufacturers and designers to develop recyclable and reusable products. Instead, the trend to improve the technical performance and cost efficiency of products and components by miniaturization and tightly packing the components make the recycling even more challenging. In addition, the waste legislation is based on quantitative recycling targets, and gives no incentives for recycling materials in small quantities.

The recycling systems are optimized for base metals. A part of the most valuable precious metals, such as gold, silver, palladium, platinum and cobalt is also recovered. 
However, the losses of minor metals in the collection and treatment chains are quite high, and there is room for significant improvement of the recovery rates. Rare earth elements, especially permanent magnets containing neodymium and dysprosium are also interesting from the recycling point of view. Their total volumes in different endof-life (EoL) products are significant, and recycling rates are currently minimal. New kinds of recycling strategies and system-level solutions are needed to improve effectiveness and achieve economies of scale.

Since the total recycling potential of CRMs available in the Nordic countries is quite significant, actions to enhance recycling are well justified. Due to the similarity of challenges between different product groups and limited quantities available in individual countries, the planning and development of the actions are potential topics for collaboration on the Nordic and European level. The recommendations for policy instruments include:

- Improvement of knowledge and availability of up-to-date data on CRM availabilities in different EoL products. This could reduce uncertainties, which currently complicate assessment of the feasibility of different technical and system-level solutions.

- Development and evaluation of new recycling strategies to enable more efficient and economic recycling of minor metals. Dismantling and pooling the same types of components, such as printed circuit boards or permanent magnets in to specialized facilities is one potential example.

- Support to demonstration facilities and selected R\&D actions.

- Strengthening of Nordic influence on the development of European legislation and standards, which improve preconditions of CRM recycling. They include:

- Development of recycling targets which create incentives for improved recycling of minor metals, and

- Work on new European eco-design standards and legislation, which take into account recyclability and reusability. 


\section{Introduction}

\section{$1.1 \quad$ Background}

Raw materials are characterized as critical when their supply rates are low compared with an increasing demand. Other aspects of criticality include the metals' low dispersity around the world, low recycling rates and substitution potential as well as their importance in specific applications for which a threat to the supply from abroad could involve harm to the national economy (European Commission, 2010). Such sectors could involve, e.g., the energy, ICT, transport and manufacturing industries.

The European Commission has created a list of raw materials that are important to the European economy but at the same time associated with supply risks (European Commission, 2014). This list includes, for example, platinum group metals, rare earth metals, gallium, indium, niobium and cobalt. However, criticality may depend on sector-specific and local conditions, and therefore, for example, the US list of CRMs differs from the European one. In addition, certain materials can be more critical to a specific sector than to all of Europe. Due to the dynamic nature of criticality, the EU list will be updated biannually. The next update is expected to be published in 2017.

Increased recycling would be one opportunity to reduce dependence on imports, but also to improve material efficiency and reduce the life-cycle environmental impacts of the applications. Currently, the recycling rates of most CRMs are low (in many cases less than $1 \%$ ) due to several factors, such as low concentrations in complex products, a multitude of products with varying concentrations, limited knowledge of CRMs in endof-life waste, and limited or lacking recycling solutions. CRMs are economically important for Nordic countries, because Nordic industry actors are well represented in different parts of the CRM material life cycles. For example, the following sectors can be mentioned: end-use and manufacturing of transport and low-carbon energy applications and equipment, production of metals and alloys, as well as recycling industries including collection, mechanical processing and metallurgical recovery. Therefore, it would be important to determine the Nordic role in CRM recycling.

\subsection{Purpose of the study}

A better understanding of the current recycling potential, bottlenecks of recycling and administrative instruments to support the removal of bottlenecks are needed to create Nordic strategies and incentives for increased recycling of CRMs.

This study aims to identify the opportunities and potential administrative instruments to enhance recycling of CRMs in the Nordic countries, and thus support the development of Nordic strategies for CRM recycling. Information about the quantities of 
critical and precious raw materials in selected end-of-life product groups was collected in order to obtain indications about the recycling potential (Chapters 2 and 3 ). Together with the analysis of the bottlenecks of recycling (Chapter 4 ) and identification of potential policy instruments (Chapter 5 ), the data was used as a basis for recommendations on key measures to enhance sustainable recycling of CRMs (Chapter 6).

As part of the project, a Nordic workshop was organized on January 18, 2017 in Stockholm, Sweden. The workshop aimed at gathering information on bottlenecks of recycling of CRMs in WEEE and ELV, identifying policy instruments, and obtaining suggestions on how to increase the currently low recycling rates of CRMs. All together 24 experts representing six different countries registered in the workshop. A summary of the workshop is compiled in Appendix 1.

\subsection{Selection of end-of-life product types}

The data produced in this study is complementary to the already published TemaNord report on CRMs in consumer electronics by Bakas et al. (2016). Their report estimates the CRM recycling potential of the following end-of-life products: mobile phones, PCs, flat-screen TVs, laptops and notebooks, and rechargeable batteries. In the following, the term "Consumer electronics products/waste" is used for the four product/end-oflife (EoL) waste groups: mobile phones, PCs, flat-screen TVs, laptops and notebooks. The applications were selected based on the following criteria:

- Significant quantities of the selected critical metals are present in the product groups.

- The selected product groups represent a significant economic activity within the consumer electronics market in the Nordic region.

- Data should be available regarding the critical metals' content in the selected product groups.

To obtain additional information about CRM recycling potential, other end-of-life product types containing significant amounts of critical raw materials were screened. Based on the screening and the criteria mentioned above, end-of-life vehicles (ELV) and lighting products (Table 1 ) were selected for further analysis. In addition, low-carbon energy applications, particularly wind power, solar panels and fuel cells, were included in the screening. The market of these applications is growing, and they contain significant quantities of critical raw materials. However, the statistical data available does not enable estimation of the waste amounts. In addition, due to long lifespans of the low-carbon energy application devices, the waste quantities are currently low or almost non-existing. 
Table 1: End-of-life product types selected in the study. In addition, consumer electronics and rechargeable batteries analyzed by Bakas et al. (2016) were included in the analysis

\section{End-of-life product Justification}

End-of-life vehicles (ELV)

Significant quantities of ELV waste produced yearly

Contain significant amounts of different CRMs in components like catalysts, electric motors, body structure, lighting, electronics, etc. (same type of components are used also in several other applications)

CRM consumption has been significantly growing with increased safety, environmental and user comfort requirements and with the general automation and electrification of cars

Not much published data on development of CRM quantities in vehicles

Most of the CRMs are lost in current recycling processes

Vehicle manufacturing important for the Nordic (and several other European) countries

Lighting

Fluorescent lamps

LED lighting
Waste amounts are rapidly growing, because consumption of fluorescent and LED lighting in Europe has significantly grown after the 2012 ban of incandescent light bulbs. Same trend also in other countries

Contain several rare earth elements, such as yttrium, europium and gallium

Although the CRM quantities/product are small, evaluation of the potential is important due to the large amounts used

In addition to general lighting, light-emitting diodes (LEDs) are used in automotive lighting and as backlights in TV screens and mobile phones

Both the data on CRM potentials generated by Bakas et al. (2016) and the data on ELVs and lighting products were used as a basis to estimate the bottlenecks and potential instruments to enhance CRM recycling.

\subsection{Selection of critical raw materials}

The critical raw materials that are contained in the selected applications and considered in this study are presented in Table 2. The table also contains information on the CRMs analyzed by Bakas et al. (2016). The focus of their report was only on selected precious and critical compounds. 
Table 2: Use of critical metals in selected product groups. The table also includes consumer electronics and rechargeable batteries analyzed by Bakas et al. (2016)

\begin{tabular}{|c|c|c|c|c|c|}
\hline Critical raw material & LEDs & $\begin{array}{l}\text { Fluorescent } \\
\text { lamps }\end{array}$ & Vehicles & $\begin{array}{l}\text { Consumer } \\
\text { electronics }\end{array}$ & $\begin{array}{c}\text { Rechargeable } \\
\text { batteries }\end{array}$ \\
\hline Beryllium, Be & & & & + & \\
\hline Cerium, $\mathrm{Ce}$ & + & + & + & & \\
\hline Cobalt, Co & & & + & + & + \\
\hline Dysprosium, Dy & & & + & & \\
\hline Erbium, Er & & & + & & \\
\hline Europium, Eu & + & + & + & & \\
\hline Gadolinium, Gd & + & + & + & & \\
\hline Gallium, Ga & + & + & + & + & \\
\hline Gold, Au & & & + & + & \\
\hline Indium, In & + & & + & + & + \\
\hline Lanthanum, La & & + & + & & \\
\hline Lithium, Li & & & + & + & + \\
\hline Magnesium, Mg & & & + & & \\
\hline Manganese, $\mathrm{Mn}$ & & & + & & \\
\hline Molybdenum, Mo & & & + & & \\
\hline Neodymium, $\mathrm{Nd}$ & & & + & & \\
\hline Niobium, Nb & & & + & & \\
\hline Palladium, Pd & & & + & + & \\
\hline Platinum, Pt & & & + & & \\
\hline Praseodymium, $\mathrm{Pr}$ & & & + & & \\
\hline Rhodium, Rh & & & + & & \\
\hline Ruthenium, Ru & & & & + & \\
\hline Samarium, Sm & & & + & & \\
\hline Silver, Ag & & & + & + & + \\
\hline Tantalum, Ta & & & + & + & \\
\hline Terbium, Tb & & + & + & & \\
\hline Tungsten, W & & & & + & \\
\hline Ytterbium, Yb & & & + & & \\
\hline Yttrium, $\mathrm{Y}$ & + & + & + & & \\
\hline
\end{tabular}

Because there is no universal and static list of CRMs, the table is based on the EU list of critical raw materials (European Commission, 2014) and significant availability of the materials in the selected applications. In addition, application/sector-specific aspects and importance from the recycling point of view have been considered, and therefore precious metals like gold and silver, as well as manganese, magnesium and tantalum were added to the list.

In general, a definition of critical metals should include aspects such as (Bakas et al., 2016):

- Supply risks, denoting the concentration of the metal in a few countries, the physical and temporal scarcity

- Demand growth, denoting the prospects for increase in global demand

- Recycling restrictions, denoting the limitations in recycling of the metal

- Substitutability, no commercial substitutes available in near future. (Bakas et al., 2016).

\footnotetext{
${ }^{1}$ Selected product groups and metals, see Bakas et al. (2016).
} 
The European initiative on CRMs has considered criticality from European point of view, and has put strong emphasis on the Economic importance for European mass sectors (sectors where there is significant production in Europe) as one indicator of criticality. 



\section{Data collection}

\subsection{Data on waste generation}

This chapter estimates the amounts of ELV and lighting waste generated in Denmark, Finland, Norway and Sweden. For ELV, data on scrapped personal vehicles was collected from statistical bureaus or branch organizations. As far as possible the statistics reflect the definition of personal vehicles (weighing less than 3.5 tonnes) according to the ELV Directive (2000/53/EC): ${ }^{2}$

- Category M1. Motor vehicles with at least four wheels with the purpose of transporting passengers. Vehicles with maximum nine seats.

The number of vehicles in the statistics is multiplied with the average weight of a personal car in order to obtain the waste amount in tonnes. Estimates for ELV for 20162020 are given using linear extrapolation.

The category of lighting products contains both fluorescent and LED lamps as these two lamp types are currently dominating the general lighting markets. General lighting is the leading sector in the total lighting markets. However, lighting products are also used in automotive lighting, and backlighting on displays and mobile phones. Due to the lack of reported production or sales data on automotive lighting and backlighting, the focus is put on general lighting.

No accurate statistics on waste generation of different lamp types in the Nordic countries exist. Thus, the estimation on waste quantities within the lighting product group was generated by combining the trade data with the estimated product lifespans, similarly to the TemaNord publication "Critical metals in discarded electronics" by Bakas et al. (2016).

Estimates for fluorescent lamps are provided for the period 2015-2020. The waste generation of LED lamps is for the period 2017-2022, as there seems to be no significant waste generation before 2018. The data creditability issues are discussed in Section 3.4.2.

\footnotetext{
${ }^{2}$ In Directive (2000/53/EC) "vehicle" is defined as "any vehicle designed as category M1 or N1 defined in Annex A to Directive 70/156/EEC, and three-wheel motor vehicles as defined in Directive 92/61/EEC, but excluding motor tricycles." Category $\mathrm{M}_{1}$ is defined as "Vehicles used for the carriage of passengers and comprising no more than eight seats in addition to the driver's seat" and $\mathrm{N} 1$ as "Vehicles used for the carriage of goods and having a maximum weight not exceeding 375 metric tons" (Directive 70/156/EEC).
} 


\subsubsection{End-of-life vehicles}

Table 3 below shows the generated amount of ELV waste in Denmark, Finland, Norway and Sweden.

Table 3: Generated ELV waste in Denmark, Finland, Norway and Sweden 2010-2020 in tonnes. Data from 2016 to 2020 (italic) is extrapolated

\begin{tabular}{lcccc} 
Year & Denmark & Finland & Norway & Sweden \\
2010 & 143,526 & 77,298 & & \\
2011 & 162,491 & 91,308 & 136,137 & 223,773 \\
2012 & 179,397 & 91,353 & 161,681 & 257,838 \\
2013 & 188,253 & 85,998 & 20,060 & 259,617 \\
2014 & 175,304 & 86,180 & 196,859 & 265,772 \\
2015 & 153,272 & 92,016 & 183,849 & 241,562 \\
2016 & 173,899 & 91,134 & 201,862 & 264,929 \\
2017 & 176,643 & 92,644 & 212,938 & 263,899 \\
2018 & 179,386 & 94,154 & 224,014 & 268,559 \\
2019 & 182,130 & 95,664 & 235,090 & 273,219 \\
2020 & 184,873 & 97,174 & 246,166 & 287,879 \\
& & & & 282,539 \\
\hline
\end{tabular}

In Table 4, the waste amount from scrapped cars in 2015 is presented along with the used sources as well as explanations and comments on the collected data. 
Table 4: Generated ELV, population, sources and comments on the data in the studied Nordic countries 2015 (Globalis, 2016; Statistics Sweden, 2016a-b; Statistics Norway, 2016a; Trafi, 2016; Miljøordning for Biler, 2016; Autoretur, 2016)

\begin{tabular}{|c|c|c|c|c|}
\hline Country & $\begin{array}{r}\text { Population } \\
2015 \text { (million) }\end{array}$ & $\begin{array}{r}\text { Amount of scrapped } \\
\text { personal vehicles } \\
2015 \text { (tonnes) }\end{array}$ & Definitions and comments & Source \\
\hline Denmark & 5.7 & 153,300 & $\begin{array}{l}\text { Private cars (cars weighing less than } \\
3.5 \text { tonnes). }\end{array}$ & $\begin{array}{l}\text { Miljøordning for biler, } \\
2016\end{array}$ \\
\hline Finland & $5 \cdot 5$ & 92,000 & $\begin{array}{l}\text { Definition for personal cars is cars with } \\
\text { vehicle class } \mathrm{M}_{1} \text { or } \mathrm{M}_{1} \mathrm{G}_{3} \text {. Older } \\
\text { vehicles which have a vehicle class } \\
\text { "Other" and vehicle group "Personal } \\
\text { car", "Off-road personal car", "Motor } \\
\text { home" or "Special car with mass equal } \\
\text { to or less than } 3.5 \text { tonnes." }\end{array}$ & Trafi, 2016 \\
\hline Norway & 5.1 & 183,800 & $\begin{array}{l}\text { Including private cars and some work- } \\
\text { vans weighing less than } 3.5 \text { tonnes. } \\
\text { The data are up till now provided by } \\
\text { the Custom authorities. From } 2016 \text { the } \\
\text { data will be provided by the } \\
\text { Directorate of Taxes. } \\
\text { Not including Svalbard in Troms } \\
\text { county. }\end{array}$ & $\begin{array}{l}\text { Statistics Norway, } \\
2016 a\end{array}$ \\
\hline Sweden & 9.7 & 265,000 & $\begin{array}{l}\text { Category } M_{1} \text { and } M_{1} G \text {. Approximately } \\
3 \text { per cent of the registered cars are } \\
\text { campers. All vehicles included here } \\
\text { weigh less than } 3.5 \text { tonnes. }\end{array}$ & $\begin{array}{l}\text { Statistics Sweden, } \\
2016 a-b\end{array}$ \\
\hline
\end{tabular}

The amounts form scrapped cars presented in Table 4 are, however, most likely overestimated since new cars are heavier than older ones being scrapped today (BIL Sweden, 2016). Since the average life of a personal car is 16-20 years (Andersson et al., 2016; Miljøordning for Biler, 2016; Statistics Norway, 2016a), the amounts presented in the table can be expected in 16-20 years' time if the number of scrapped cars is constant. The average weight of a personal car used in the calculations is 1.5 tonnes (BIL Sweden, 2016; Cullbrand et al., 2015; SBR, 2016).

\subsubsection{Lighting products}

The consumption of fluorescent lamps in each of the Nordic countries examined was approximated based on the trade data (the net of import and export) and estimated product lifespans. The national central statistical offices in Sweden, Norway, and Denmark, and the Finnish Customs report the foreign trade statistics, i.e. exports and imports of different products, utilizing the 8-digit combined nomenclature (CN) codes. For fluorescent lamps, there are two CN categories (85393110 Discharge lamps, fluorescent, hot cathode, with double ended cap and 85393190 Discharge lamps, fluorescent, hot cathode (excl. with double ended cap) representing the linear fluorescent

3 Symbol G stands for off-road vehicles (Directive 70/156/EEC). 
lamps (LFLs) and the compact fluorescent lamps (CFLs), respectively. These two categories were included in the analysis. Similar to the reports of the European Lighting Companies' Federation (2003) and Guyonnet et al. (2015), a lifespan estimate of six years was used for the both lamp types.

In Table 5 the trade data is combined with the estimated product lifespan to derive the potential waste generation for the period 2015-2020.

Table 5: Estimated fluorescent lamp waste quantities (in tonnes) generated in the Nordic countries for 2015-2020 (Finnish Customs, 2017; Statistics Denmark, 2017; Statistics Norway, 2016b; Statistics Sweden, 2017, UN Comtrade, 2017)

\begin{tabular}{lllllrrr} 
Country & Product group & 2015 & 2016 & $\mathbf{2 0 1 7}$ & $\mathbf{2 0 1 8}$ & $\mathbf{2 0 1 9}$ & $\mathbf{2 0 2 0}$ \\
\hline DK* & Fluorescent lamps & 1,641 & 1,325 & 1,027 & 1,025 & 911 & 656 \\
FI & Fluorescent lamps & 1,451 & 1,440 & 1,423 & 1,132 & 1,039 & 927 \\
NO & Fluorescent lamps & 1,227 & 1,266 & 1,071 & 1,032 & 968 & 876 \\
SE & Fluorescent lamps & 1,950 & 2,163 & 1,853 & 1,569 & 1,375 & $1,896^{* *}$ \\
& & & & & & 1,196 \\
\hline
\end{tabular}

Note: *According to Eurostat (2016), there is also domestic production of fluorescent lamps in Denmark and the waste generation estimated based on import-export data is thus incorrect. However, based on the production quantities given in Eurostat database, the amount of the Danish production is rather small and its effect on waste quantities would be only some tonnes. Thus, the effect of domestic production is not acknowledged.

$* *$ The figure $1,896 \mathrm{t}$ for Sweden is not in line with the decreasing trend for fluorescent lamps that can be seen in all the other Nordic countries studied. Thus, it was decided to use the figure 1,196 t taken from UN Comtrade (2017) database representing similar statistical information.

Compared to fluorescent lamps, it was more challenging to generate estimates on the generation of LED lighting waste as their trade data could not be used (See Section 3.4 for more information). In addition, the market penetration of LEDs has just started a couple of years ago (after the year 2010), and due to their long lifespan expectancy (Table 6), there should not be considerable amounts of waste generated yet. 
Table 6: Average lifespans for LED lamps (in hours)

\begin{tabular}{|c|c|}
\hline LED lifespan estimate (h) & Sources \\
\hline 1,460-32,850 ("true" lifespans) & Casamayor et al., 2013 \\
\hline $\begin{array}{l}\text { Until 2013: 10,000 } \\
\text { 2014-2016: } 25,000 \\
\text { From 2017: } 45,000\end{array}$ & Confidential \\
\hline 20,000 & Clasp, 2013 \\
\hline 25,000 & Osram, 2009; Philips, 2016 \\
\hline $25,000-30,000$ & $\begin{array}{l}\text { Sähköturvallisuuden Edistämiskeskus Ry, 2016; Premium } \\
\text { Light Consortium, } 2016\end{array}$ \\
\hline $\begin{array}{l}25,000 \\
\text { From 2015: 40,000 }\end{array}$ & U.S. Department of Energy, 2012a \\
\hline $25,000-50,000$ & Motiva, 2014 \\
\hline 50,000 & McKinsey \& Company, 2012 \\
\hline
\end{tabular}

To be able to generate approximation on waste generation of LED lamps, confidential sales data obtained from Finland and Sweden was used. As corresponding data from Denmark and Norway was not available for this study, their figures are estimated based on the Finnish data and the populations of the countries, assuming that the markets in each country have been similar to Finland (Table 7). Due to the data confidentiality, neither the source data and lifespan estimate used, nor the other assumptions made are described in more detail. However, the lifespan of LEDs was estimated to be longer than the lifespan of fluorescent lamps.

It should be noted that the approach used to estimate the generation of LED lighting waste contains several uncertainty factors, which are described in Section 3.4.2 in more detail. Thus, the waste quantities in Table 7 should be considered indicative only.

Table 7: Estimated LED lighting waste quantities (in tonnes) generated in the Nordic countries for 2017-2022. Due to the confidentiality of the source data, the figures are rounded to the nearest $5 \mathrm{t}$

\begin{tabular}{llrrrrrr} 
Country & Product group & $\mathbf{2 0 1 7}$ & $\mathbf{2 0 1 8}$ & $\mathbf{2 0 1 9}$ & $\mathbf{2 0 2 0}$ & $\mathbf{2 0 2 1}$ & $\mathbf{2 0 2 2}$ \\
\hline \multirow{D}{*}{$E^{*}$} & LED & 0 & 5 & 20 & 45 & 100 & 180 \\
FI & LED & 0 & 5 & 20 & 45 & 95 & 175 \\
NO* & LED & 0 & 5 & 15 & 40 & 90 & 165 \\
SE & LED & 0 & 0 & 15 & 95 & 220 & 385 \\
\hline
\end{tabular}

Note: *Estimated based on the Finnish sales data. 


\subsection{Data on critical raw material content of the selected products}

In this section, the contents of relevant CRMs in ELVs and lighting products are presented within the limits of data availability. Data collected in previous and ongoing projects of VTT and IVL was mainly used. In these projects, data on CRMs in vehicles and lighting appliances have been collected from literature sources and available databases. If needed, additional literature searches were made. One challenge is that CRM contents of current products may differ from those in the end-of-life products if the lifespan of the product is long, but if possible, this was also considered.

\subsubsection{End-of-life vehicles}

Table 8 below shows the metal content in personal cars based on Cullbrand \& Magnusson (2011) cited in Andersson et al. (2016). The ranges represent variations in three different diesel-powered car models studied with weights ranging from 1.5 to 2.2 tonnes. The three models are the most commonly used in Sweden (Cullbrand \& Magnusson, 2011) and the CRM content is based on conditions in 2012 (Andersson et al., 2016). Since the studied cars in Andersson et al. (2016) are from the same brand and production period, it is clear that the variations will be larger when considering the entire car fleet.

The largest quantities of critical materials can be found in metallurgical, catalytic and electrical and electronic applications. The electrification of the car fleet will increase the use of neodymium, dysprosium, copper, samarium, silver, terbium, manganese, lithium, palladium and platinum, and higher equipment usage leads to an increased use of neodymium, dysprosium, copper, gallium, lithium, praseodymium, tantalum, niobium, palladium and platinum (Cullbrand \& Magnusson, 2011). Compared with conventional cars, hybrid cars contain at least double the amount of some critical metals (Söderman \& Ingemarsdotter, 2014).

There are other reasons behind the increased use of CRMs besides the electrification of the vehicles. In order to produce light-weight cars there is a need for strong and light materials such as aluminium, magnesium, and alloys, e.g., chromium, molybdenum, manganese and niobium. Decreasing emissions further with the use of catalysts and particle filters usually requires platinum group metals and rare earth metals (Söderman \& Ingemarsdotter, 2014). 
Table 8: CRM content in ELV. Based on three diesel-car models (from the same brand and production period) commonly used in Sweden (Adapted from Andersson et al. (2016), supplementary material. Cited sources: Cullbrand \& Magnusson, 2011; Söderman \& Ingemarsdotter, 2014; Geological Survey of Sweden, 2014; Widmer et al., 2015)

\begin{tabular}{|c|c|c|c|}
\hline Metal & $\begin{array}{r}\text { Content in personal } \\
\text { cars ( } g / c a r)\end{array}$ & $\begin{array}{r}\text { Number of } \\
\text { applications }\end{array}$ & Main applications \\
\hline Manganese & $6-7 e 3$ & n.a. & Steel alloys, Al alloys, micro condensers \\
\hline Magnesium & $3-9 e 3$ & n.a. & Mg alloys, Al alloys \\
\hline Molybdenum & $500-630$ & n.a. & Steel alloys \\
\hline Niobium & $63-90$ & $336-426$ & Steel alloys, Ni alloys \\
\hline Cobalt & $28-39$ & n.a. & Electrical and electronic equipment (EEE), Ferrous alloys \\
\hline Neodymium & $28-210$ & $26-70$ & Magnets, printed circuit boards (PCBs) \\
\hline Silver & $14-21$ & n.a. & PCBs \\
\hline Tantalum & $5.8-11$ & $60-119$ & PCBs \\
\hline Platinum & $5 \cdot 5^{-8.1}$ & $69-106$ & Catalytic converter, particulate filter \\
\hline Gold & $5-7$ & n.a. & PCBs \\
\hline Lithium & $1.4-10$ & $873-1105$ & Battery (car key), lubricants \\
\hline Palladium & $1.2-1.5$ & $58-227$ & Catalytic converter, particulate filter, PCBs \\
\hline Dysprosium & $0.83-27$ & $7-21$ & Magnets \\
\hline Praseodymium & $0.81-5.6$ & $4^{-13}$ & Magnets \\
\hline Samarium & $0.43-0.73$ & 2 & Magnets \\
\hline Cerium & $0.29-13$ & $4-7$ & Particulate filter \\
\hline Gallium & $0.08-0.56$ & $21-47$ & Magnets, LED \\
\hline Indium & $0.05-0.38$ & $82-174$ & PCBs \\
\hline Yttrium & $0.02-0.23$ & $12-23$ & Ceramics in electronics, LED, Ni alloys \\
\hline Lanthanum & $0-5.2$ & $0-5$ & Particulate filter, magnets \\
\hline Erbium & $0-0.18$ & $0-1$ & LCD \\
\hline Ytterbium & $0-0.16$ & $0-1$ & Ceramics in electronics \\
\hline Terbium & $<0.01-0$ & $0-1$ & Magnets \\
\hline Gadolinium & $<0.01$ & $8-11$ & Al alloys, LED \\
\hline Rhodium & $<0.01$ & 2 & Electronic wiring, $\mathrm{PCBs}$ \\
\hline
\end{tabular}

Due to the long usage time of cars, the cars that are scrapped today do not contain the same amounts or types of CRMs as those of newer models as shown in the table. As more electrical equipment is added into cars, new cars will most likely contain more CRMs than the ones being scrapped today. As a personal car's average lifetime is about 16-20 years (Andersson et al., 2016; Miljøordning for Biler, 2016; Statistics Norway, 2016a) and as the CRM content in Table 8 is based on car models from 2012, the specified contents shown in the table may be available in $16-20$ years' time.

\subsubsection{Lighting products}

Again, a method similar to Bakas et al. (2016) was used to report the results of data collection on critical raw material contents of lighting products. Since often differing values from different literature sources were identified, the contents in Tables 9-11 are presented as ranges consisting of minimum and maximum values. The approach used avoids giving the incorrect impression of data reliability, and it thus accounts for the variability of product weights within the same lighting product group. For certain elements, only one value was found. These single values are presented in the average content column, but without low and high ranges (Bakas et al., 2016). 
The contents of critical metals were presented in many different units in the source literature, e.g., as per cent of an item's weight, in grams per unit, in grams per LED diode, in milligrams per kilogram, or as ranges. Therefore, to be able to use the identified data, it was necessary to use an estimated average weight for an item in each lamp group.

The average weight of a compact fluorescent lamp was assumed to be $0.082 \mathrm{~kg}$ per unit (Tähkämö, 2013).

Table 9: Assumed content of critical metals in compact fluorescent lamps (Data from: U.S. Department of Energy, 2011; Lim et al., 2013; Castilloux, 2014; Ku et al., 2015; Machacek et al., 2015; Wu et al., 2014)

\begin{tabular}{lrrr}
\hline Critical metal & Average content (wt-\%) & Low range (wt-\%) & High range (wt-\%) \\
Cerium & 0.14560 & & \\
Europium & 0.05661 & 0.00096 & 0.08585 \\
Gadolinium & 0.00006 & 0.02195 & \\
Gallium & 0.00060 & & \\
Indium & n.d. & & \\
Lanthanum & 0.15549 & & \\
Terbium & 0.05514 & 0.03427 & 0.09146 \\
Yttrium & 0.62734 & 0.25400 & 1.13415 \\
\hline
\end{tabular}

The weight of LFL lamps varies widely from tens of grams to over half a kilogram according to lamp type. No literature references on lamp weight were found, but this lamp type was assumed as the heaviest of these three lamp types investigated. Thus, the average weight of a linear fluorescent lamp was assumed to be $0.200 \mathrm{~kg}$ per unit.

Table 10: Assumed content of critical metals in linear fluorescent lamps (Data from: U.S. Department of Energy, 2011; Lim et al., 2013; Castilloux, 2014; Machacek et al., 2015; Wu et al., 2014).

\begin{tabular}{lccc}
\hline Critical metal & Average content $(w t-\%)$ & Low range $(w t-\%)$ & High range (wt- $\%)$ \\
Cerium & 0.06041 & 0.03905 & 0.07605 \\
Europium & 0.03240 & 0.01500 & 0.05265 \\
Lanthanum & 0.25740 & & \\
Terbium & 0.03559 & 0.02189 & 0.05850 \\
Yttrium & 0.45808 & 0.28000 & 0.72540 \\
\hline
\end{tabular}

The average weight of an LED bulb was assumed to be $0.185 \mathrm{~kg}$ per unit (ELC, 2009; U.S. Department of Energy, 2012b; Tähkämö, 2013). In some of the references, CRM contents were expressed in the unit $\mathrm{mg} /$ diode. LED lamps usually contain more than just one diode, but the number of diodes varies between manufacturers and lamp types. For example, in the study by Buchert et al., (2012) three LED lamps were observed, one containing 132 diodes, the second 72 diodes, and the third just 12 diodes. However, there may also be just a few diodes in a lamp. In these cases, to be able to generate estimates of CRM content for the study, it was assumed that one lamp contains 72 diodes. 
Table 11: Assumed content of critical metals in LED lamps (Data from: Angerer et al., 2009; Buchert, et al. 2012; Lim et al., 2013; Castilloux, 2014; Wu et al., 2014; Ku et al., 2015; Machacek et al. 2015)

$\begin{array}{lrrr}\text { Critical metal } & \text { Average content }(w t-\%) & \text { Low range (wt- } \%) & \text { High range }(w t-\%) \\ \text { Cerium } & 0.00035 & 0.00008 & 0.00078 \\ \text { Europium } & 0.00026 & 0.00002 & 0.00057 \\ \text { Gadolinium } & 0.00030 & 0.00001 & 0.00058 \\ \text { Gallium } & 0.01090 & 0.00126 & 0.02063 \\ \text { Indium } & 0.00387 & 0.00113 & 0.00662 \\ \text { Yttrium } & 0.01584 & 0.00017 & 0.05730\end{array}$

It should be noted that most of the references present the CRM contents used in just phosphors and/or semiconductor materials, and do not take into account that other lamp components, such as the electronic parts, may contain CRMs as well. 



\section{Critical raw materials in the selected applications in the Nordic countries}

The total quantities of the selected CRMs in the target end-of-life product groups (ELV and lighting waste) were calculated by multiplying the content of critical metals in each product group with the annual discarded quantities of the product in the four Nordic countries. The data on discarded quantities of each CRM is presented per each end-oflife product and country. The available amounts of each metal are summarized. In addition, based on the report by Bakas et al. (2016), a summary of the total quantities of CRMs in consumer electronics products and rechargeable batteries is presented.

Due to the limited number of studies containing data on CRM contents in products and their development as well as limitations due, for example, to product categorization in statistics, it can be expected that there are uncertainties in the produced data. The sources of these uncertainties are discussed. However, it is not possible to make any numerical analysis of the uncertainties in this study.

\subsection{End-of-life vehicles}

As previously mentioned, the three most abundant CRMs in ELVs are manganese, magnesium and molybdenum. Figure 1 shows the total available CRM quantities in the four Nordic countries studied. Since 2010, the available CRM content of 5,175 tonnes has increased steadily and it is expected to rise to approximately 7,200 tonnes in 2020. 
Figure 1: Total available CRM quantities in tonnes, in the Nordic ELVs (Denmark, Finland, Norway and Sweden)

Total available CRM quantities in the Nordic ELV

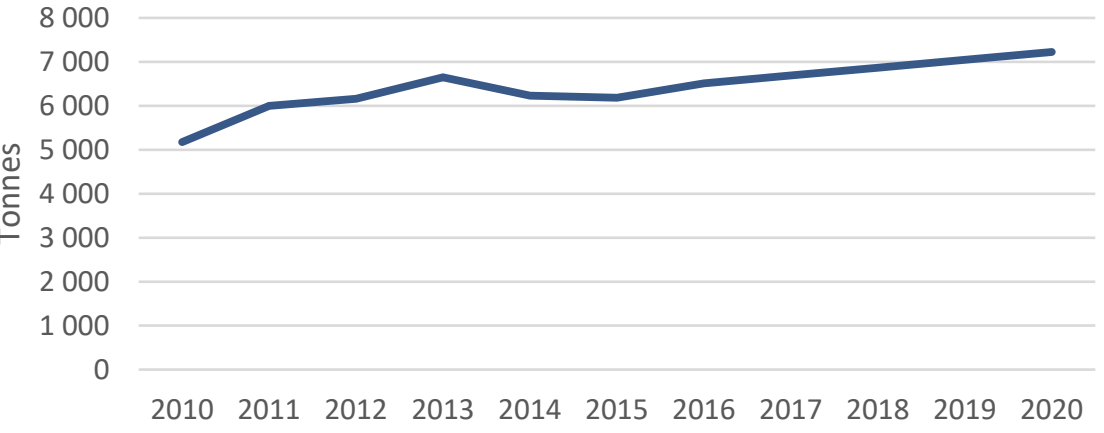

Figures 2-4 present the content of the three most abundant CRMs in estimated ELVs generated in the Nordic countries studied. All other CRM amounts in generated ELVs are presented in Appendix 2.

Figure 2: Manganese content in estimated ELV 2015-2020

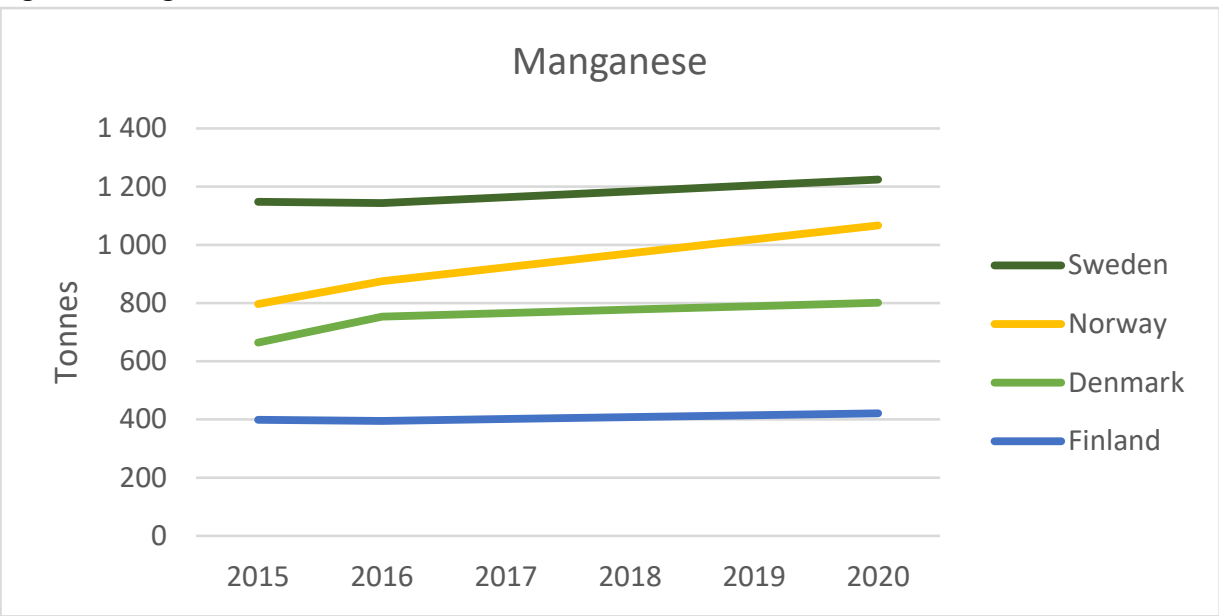


Figure 3: Magnesium content in estimated ELV 2015-2020

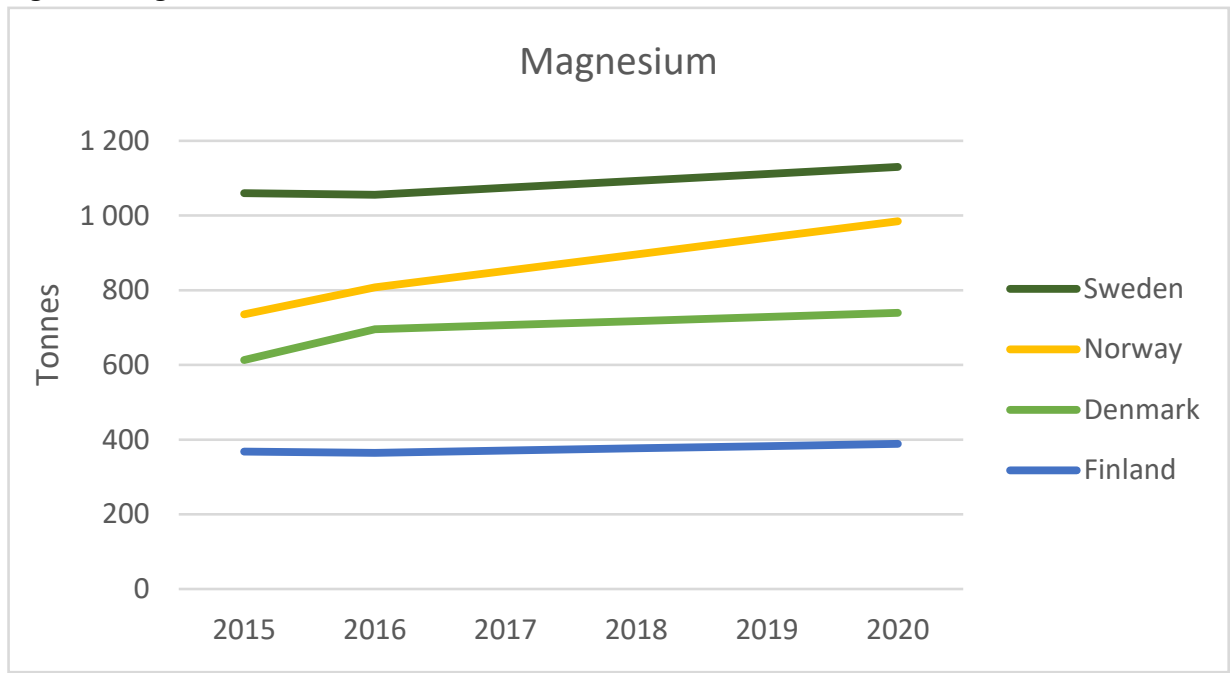

Figure 4: Molybdenum content in estimated ELV 2015-2020

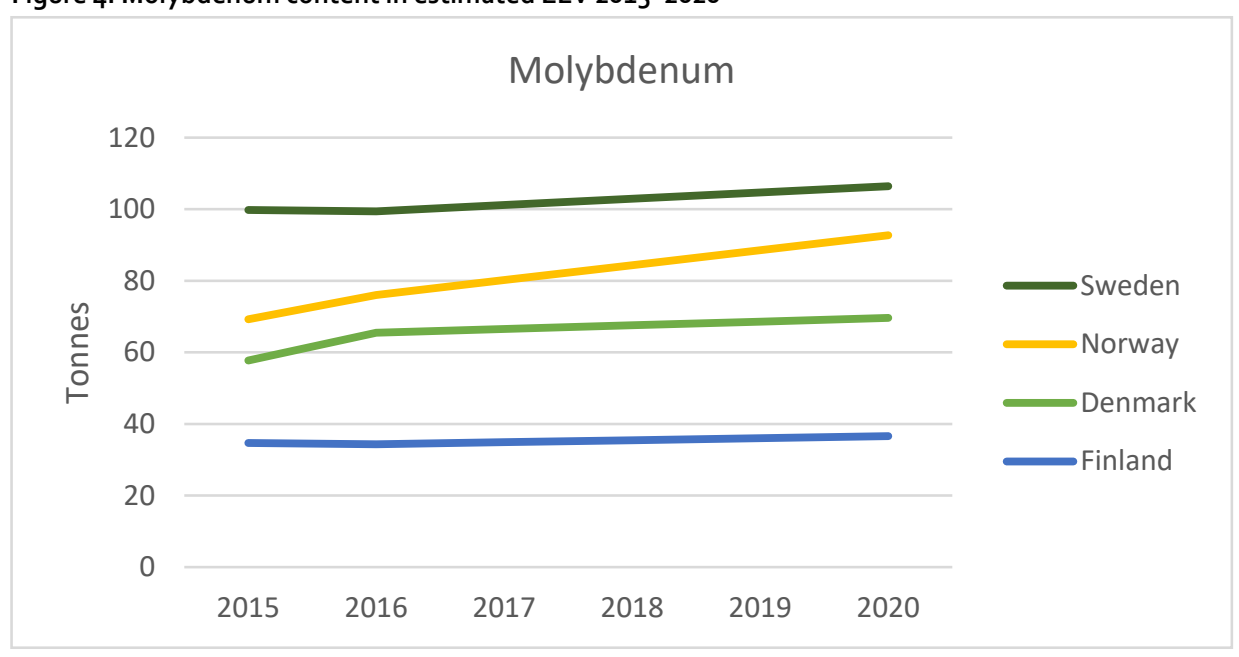

\subsection{Lighting products}

In general, fluorescent lamps contain more CRMs compared to LED bulbs, as can be seen from Tables 9-11. Fluorescent lamps have higher levels of lanthanum, cerium, yttrium, europium, and terbium. In contrast, the contents of gallium and gadolinium are higher in LED bulbs than with CFLs, and indium is only present in LEDs. Yttrium is the most abundant CRM in both lamp types. However, yttrium content is many times higher in fluorescent lamps than in LEDs. In addition, lanthanum and cerium are abundant in fluorescent lamps.

Figure 5 shows the total available CRM quantities in discarded lamps for the period 2015-2020 in the Nordic countries studied, and Table 12 summarizes the total available 
CRM quantities by each metal. The average metal contents presented in Tables 9-11 are used in the calculation of quantity estimates.

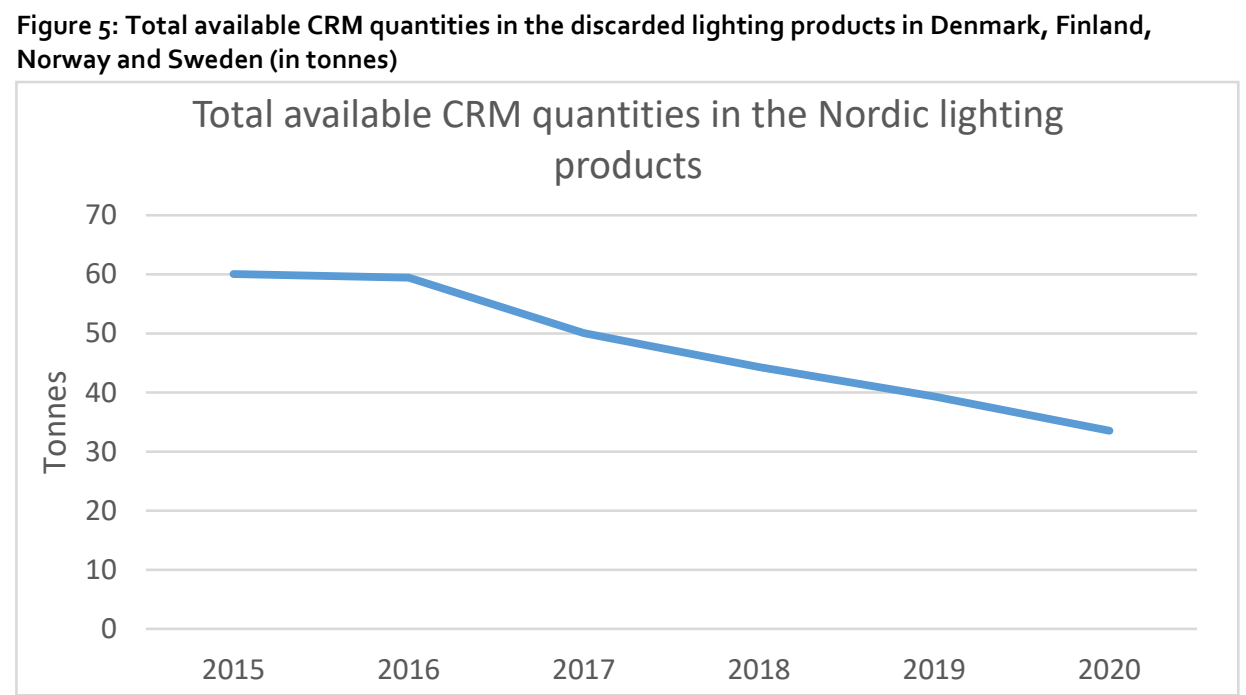

The available CRM content of around 63 tonnes in 2015 is expected to decrease to around 34 tonnes by 2020 . The period reflects a turning point in the lighting markets; the market penetration of LEDs has decreased the market share of the fluorescent lamps containing more CRMs. Due to the shorter average lifespan of the fluorescent lamps, their replacement with LEDs starts to decrease the waste quantities as well within the next few years. In addition, the LED waste generation remains small within the period under review due to their longer lifespan, and thus their CRMs do not show in the figures yet. Therefore, the longer time period, e.g. for the year 2030, would perhaps show the real trend in the CRM quantities better.

Table 12: Total available CRM quantities by each CRM in the Nordic EoL lighting products (in tonnes)

$\begin{array}{lrrrrrr}\text { CRM } & 2015 & 2016 & 2017 & 2018 & 2019 & 2020 \\ \text { Cerium } & 7 & 7 & 5 & 5 & 4 & 3 \\ \text { Europium } & 3 & 3 & 2 & 2 & 2 & 2 \\ \text { Gadolinium } & <0.01 & <0.01 & <0.01 & <0.01 & <0.01 & <0.01 \\ \text { Gallium } & 0.02 & 0.02 & 0.01 & 0.01 & 0.02 & 0.03 \\ \text { Indium } & 0 & 0 & 0 & <0.01 & <0.01 & 0.01 \\ \text { Lanthanum } & 12 & 12 & 11 & 10 & 9 & 8 \\ \text { Terbium } & 3 & 3 & 2 & 2 & 2 & 2 \\ \text { Yttrium } & 35 & 35 & 29 & 25 & 22 & 19\end{array}$

Figures 6-13 present the discarded quantities of each CRM in Denmark, Finland, Norway and Sweden. 
Figure 6: Total available quantities (tonnes) of cerium in the discarded lighting products in Denmark, Finland, Norway and Sweden

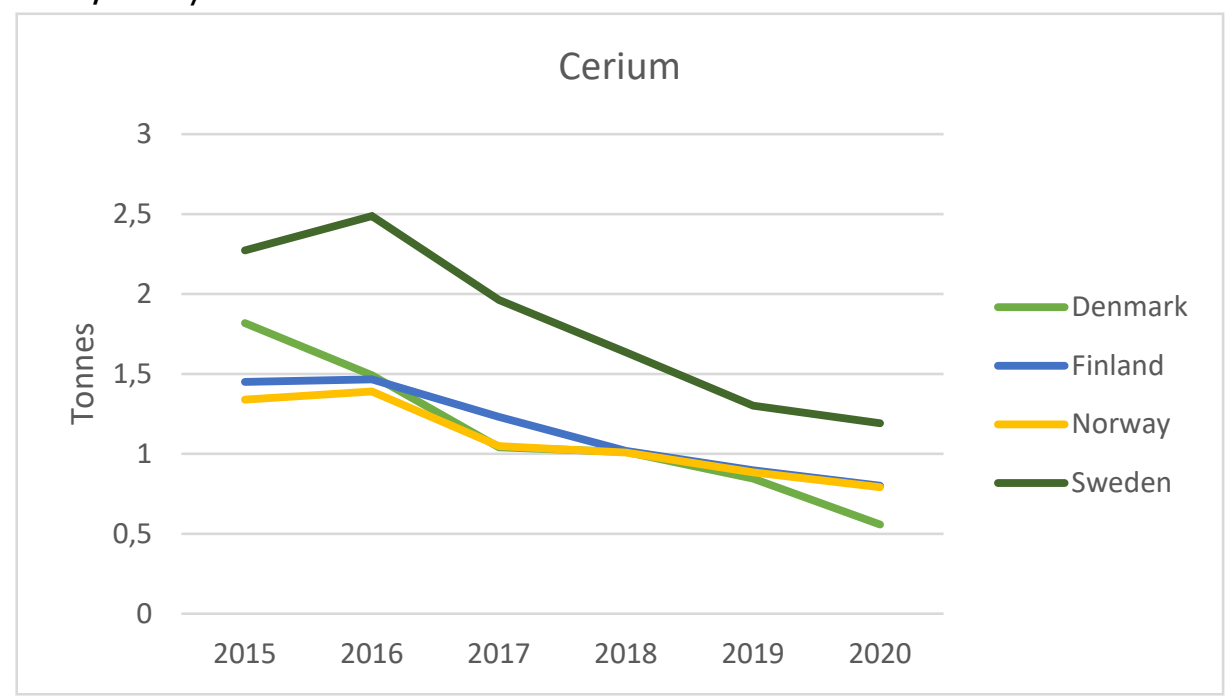

Figure 7: Total available quantities (tonnes) of europium in the discarded lighting products in Denmark, Finland, Norway and Sweden

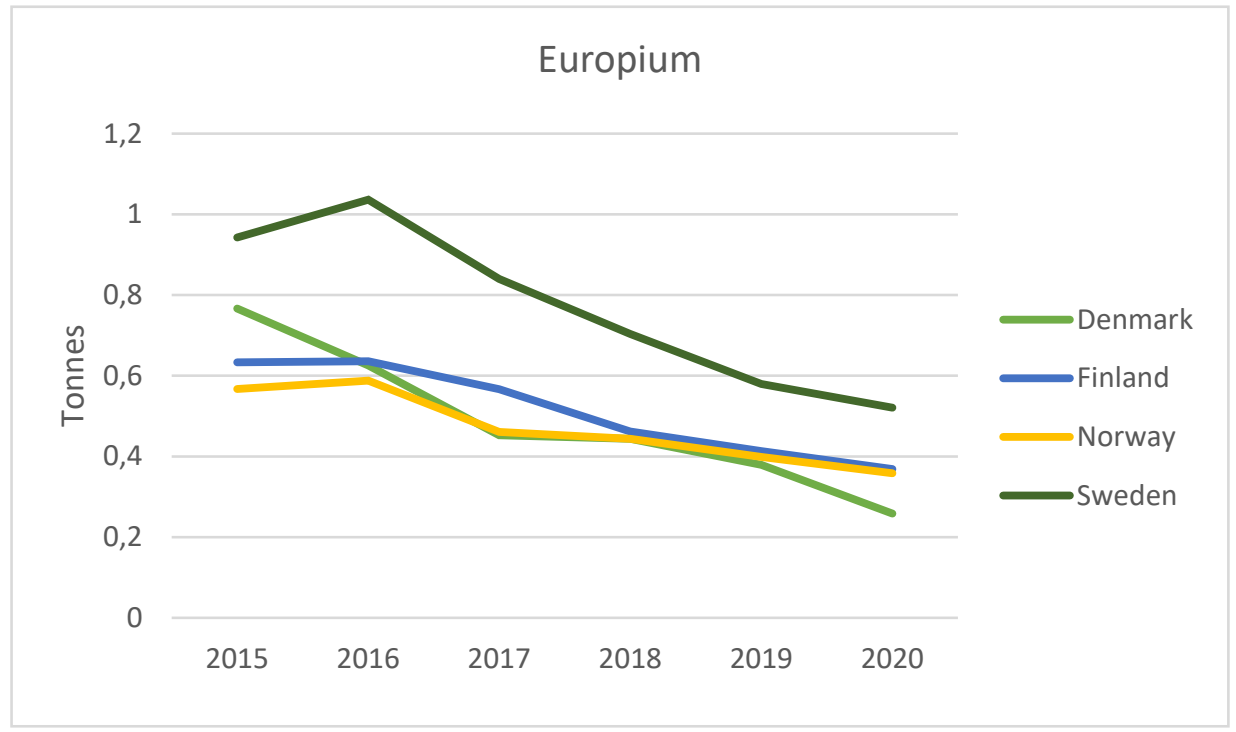


Figure 8: Total available quantities (tonnes) of gadolinium in the discarded lighting products in Denmark, Finland, Norway and Sweden

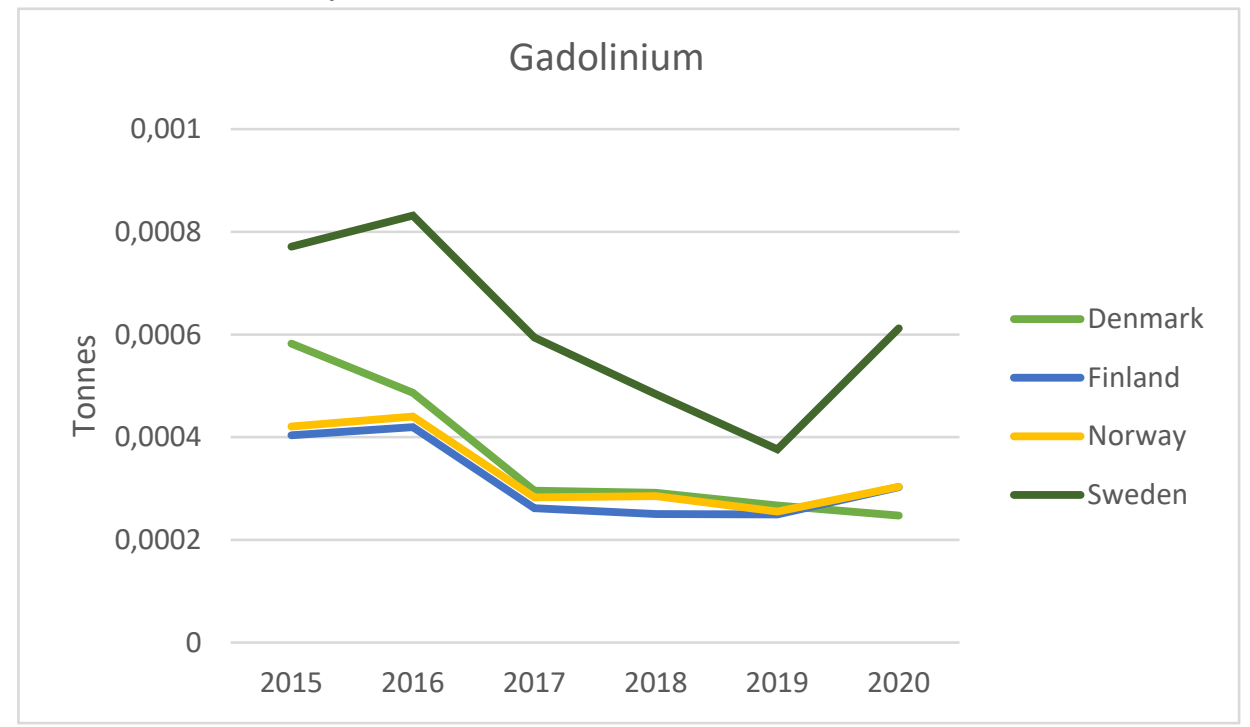

Figure 9: Total available quantities (tonnes) of gallium in the discarded lighting products in Denmark, Finland, Norway and Sweden

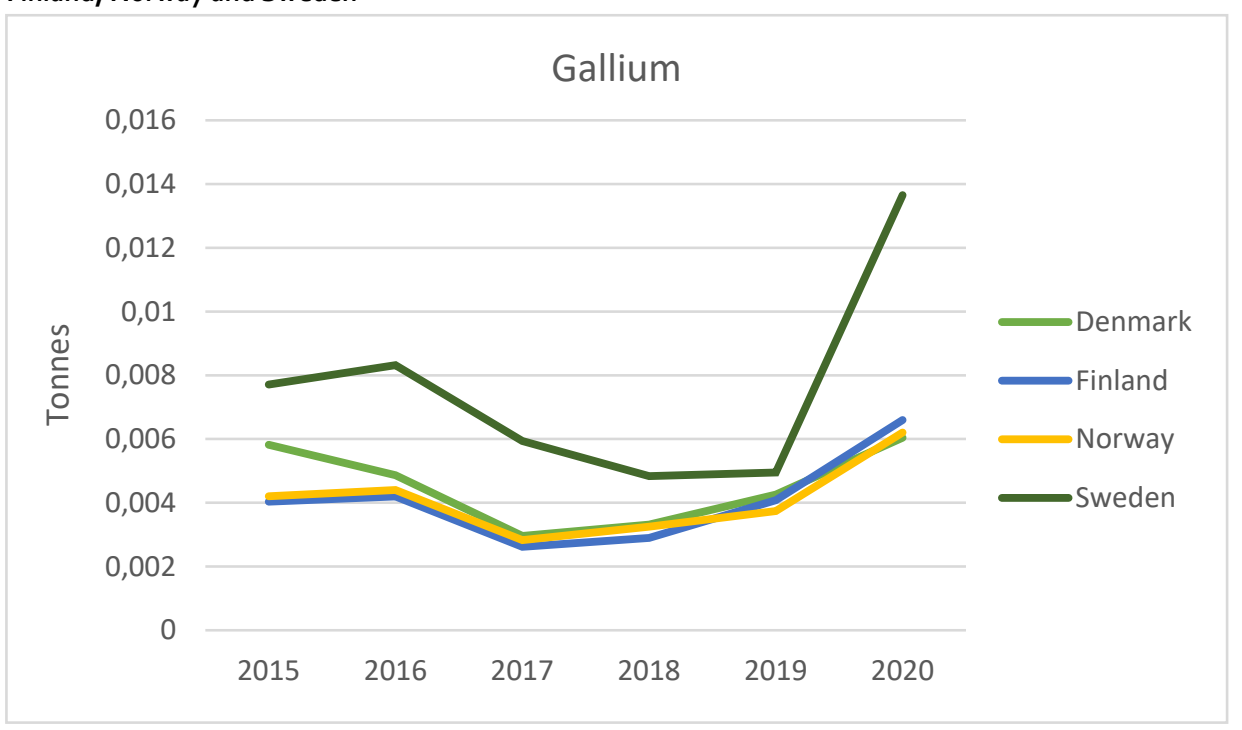


Figure 10: Total available quantities (tonnes) of indium in the discarded lighting products in Denmark, Finland, Norway and Sweden

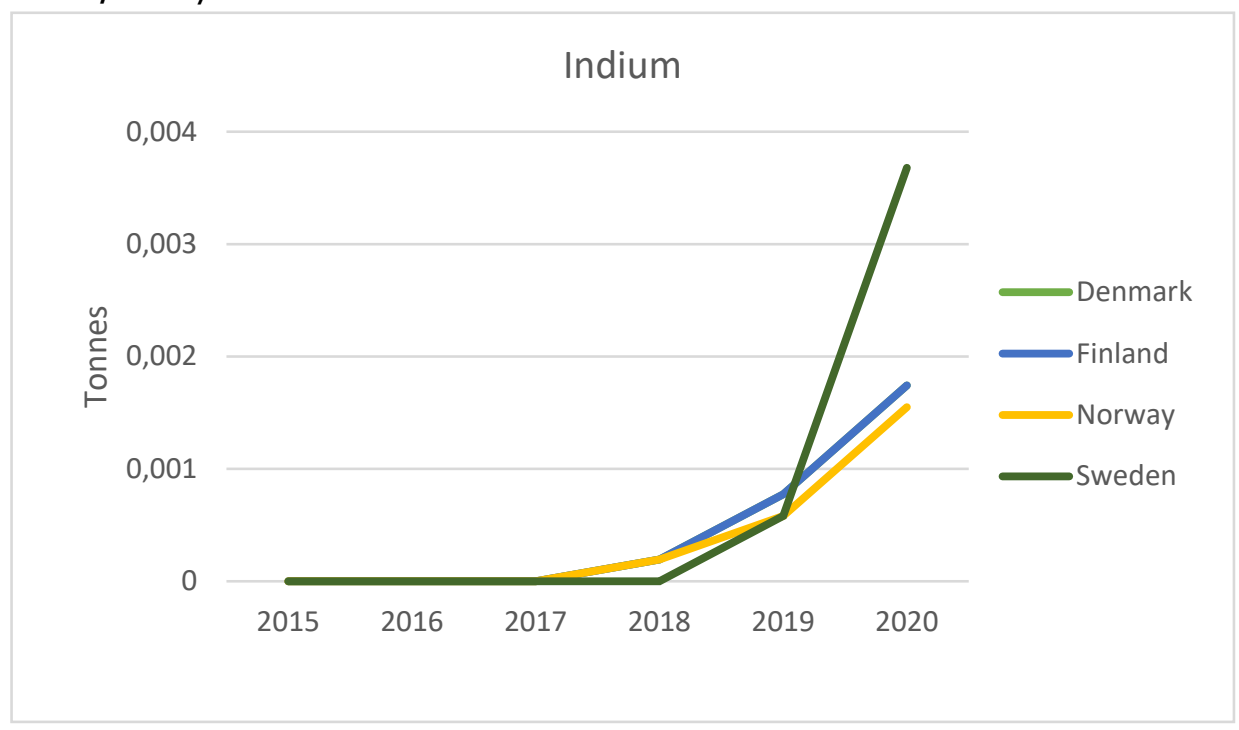

Figure 11: Total available quantities (tonnes) lanthanum in the discarded lighting products in Denmark, Finland, Norway and Sweden

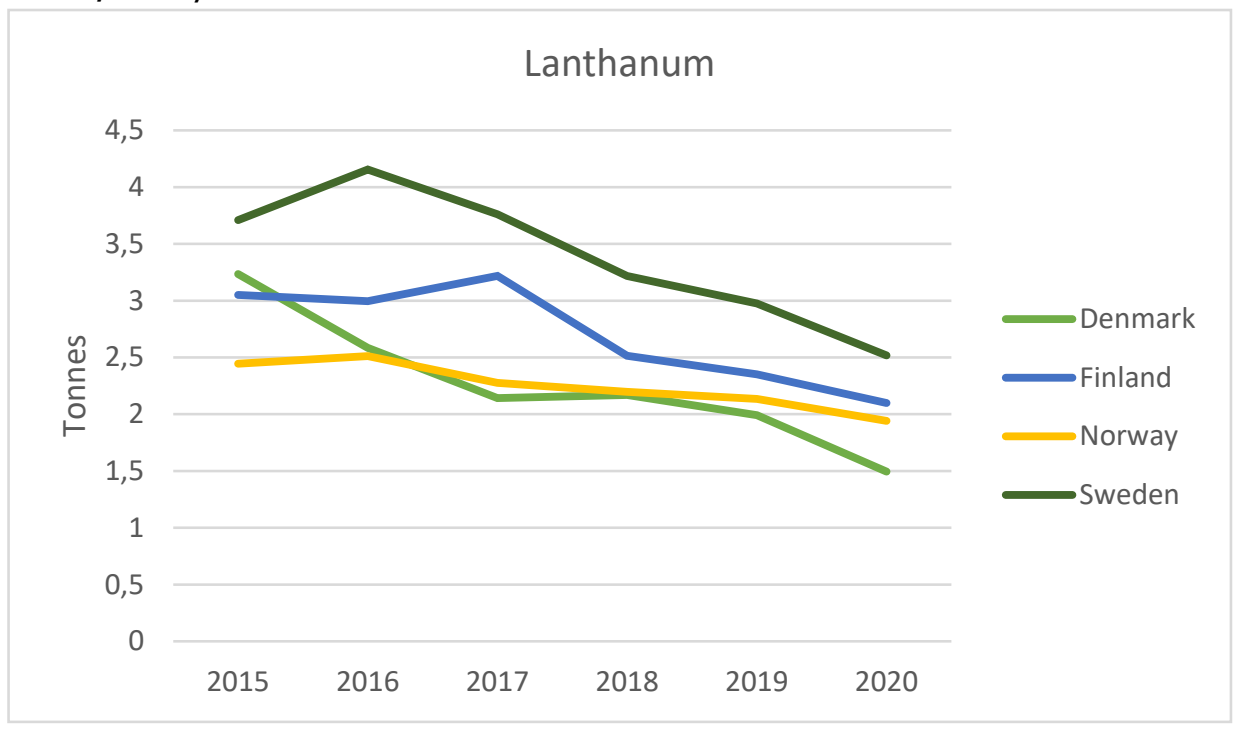


Figure 12: Total available quantities (tonnes) of terbium in the discarded lighting products in Denmark, Finland, Norway and Sweden

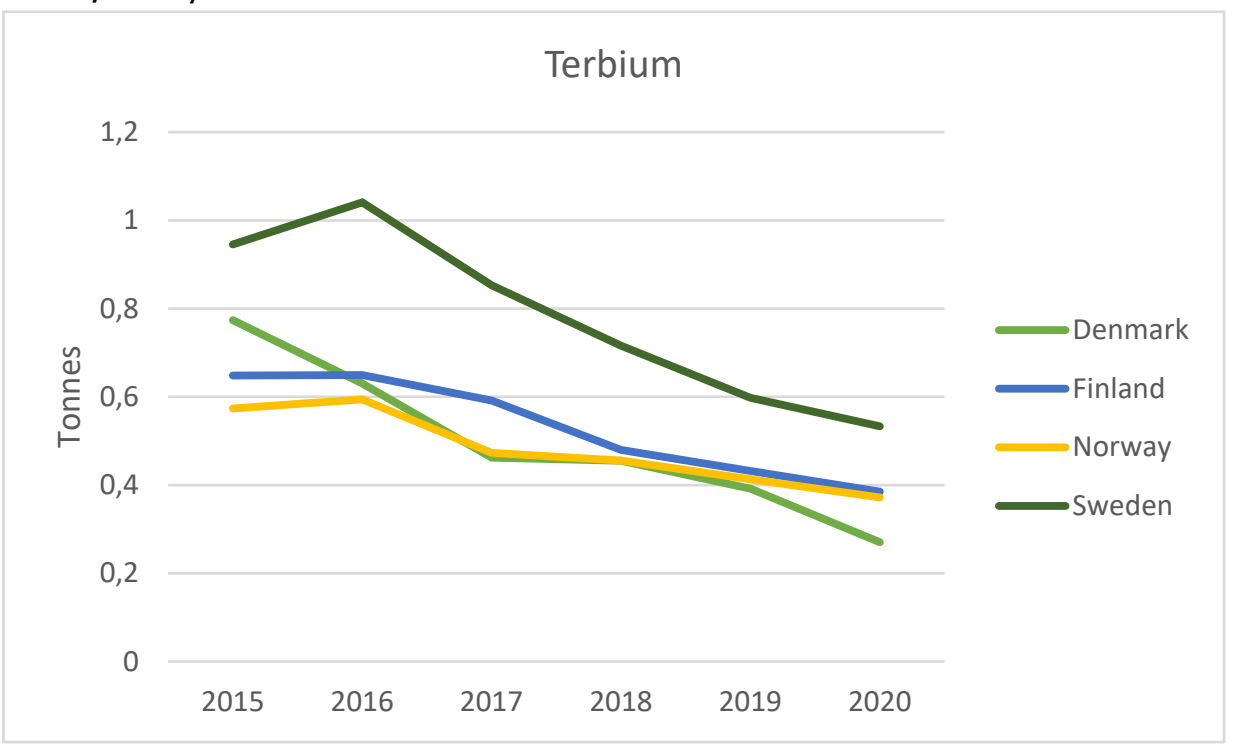

Figure 13: Total available quantities (tonnes) of yttrium in the discarded lighting products in Denmark, Finland, Norway and Sweden

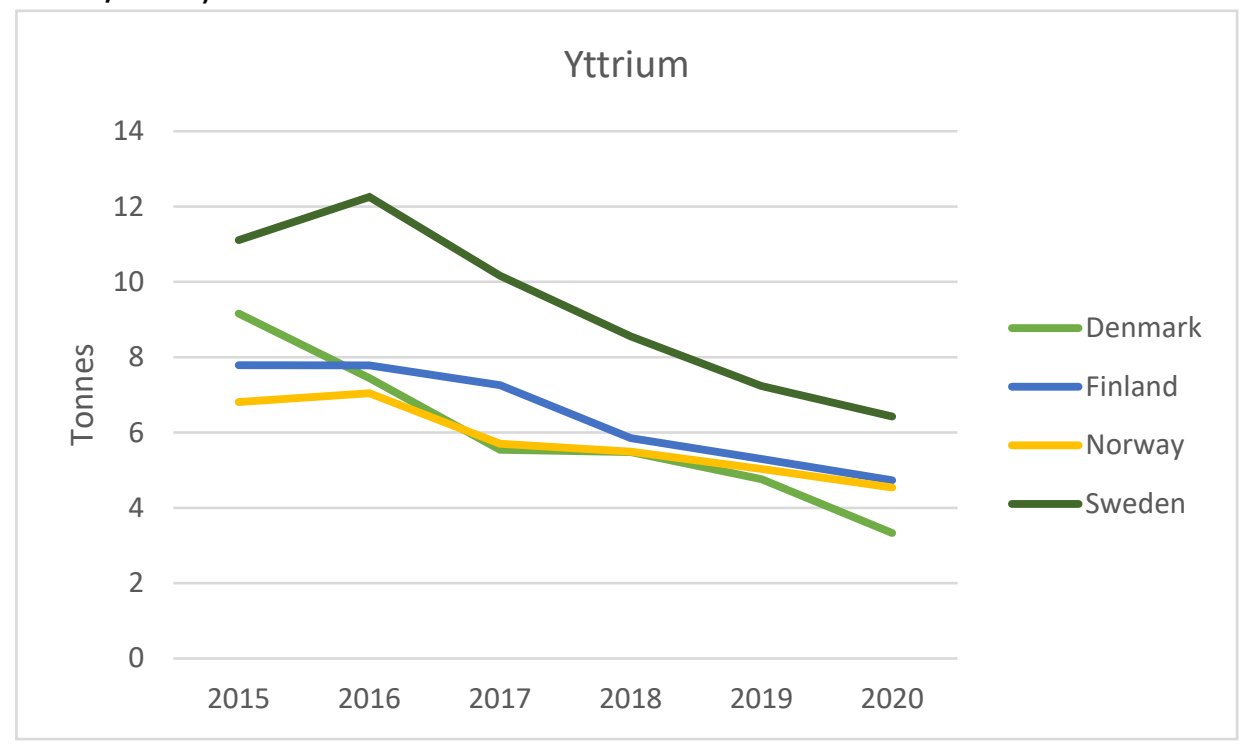




\subsection{Consumer electronics and rechargeable batteries}

The TemaNord report by Bakas et al. (2016) presents the total CRM quantities in EoL consumer electronics (including mobile phones, PCs, flat screen TVs, laptops and notebooks) and rechargeable batteries. The metals to be analyzed were selected based on estimated relevance and availability of reliable data. Because of economic significance, also precious metals (gold and silver) which are not on the list of CRMs were selected in the analysis. Table 13 and Figure 14 summarize the estimates presented in their study. However, the total CRM quantities for gold and silver in PCs were recalculated using the data on waste generation presented by Bakas et al. (2016), and the following average contents: silver $0.092 \mathrm{mg} / \mathrm{kg}$ and gold $0.04 \mathrm{mg} / \mathrm{kg}$. The silver and gold contents were estimated based on the following literature sources: Bakas et al. (2016); Oguchi, M. et al. (2011), Yamane et al. (2011); Cuchinella et al. (2015).

Table 13: Total available CRM quantities (tonnes) in discarded consumer electronics and rechargeable batteries in Denmark, Finland, Norway and Sweden (Bakas et al., 2016). The quantities of gold and silver were calculated by VTT using revised gold and silver percentages for PCs

\begin{tabular}{|c|c|c|c|c|c|c|}
\hline CRM & 2015 & 2016 & 2017 & 2018 & 2019 & 2020 \\
\hline Beryllium & 0.04 & 0.04 & 0.04 & 0.04 & 0.03 & 0.03 \\
\hline Cobalt & 736 & 755 & 764 & 778 & 792 & 807 \\
\hline Gallium & 8 & 9 & 8 & 8 & 8 & 7 \\
\hline Gold & 4.2 & 3.8 & 3.5 & 3.5 & 3.3 & 3.3 \\
\hline Indium & 1 & 0.94 & 0.87 & 0.85 & 0.76 & 0.81 \\
\hline Lithium & 253 & 258 & 263 & 269 & 275 & 281 \\
\hline Palladium & 0.82 & 0.75 & 0.70 & 0.68 & 0.64 & 0.66 \\
\hline Ruthenium & 0.03 & 0.03 & 0.02 & 0.03 & 0.03 & 0.03 \\
\hline Silver & 8 & 7 & 6 & 6 & 6 & 6 \\
\hline Tantalum & 8 & 9 & 9 & 8 & 8 & 8 \\
\hline Tungsten & 8 & 6 & 5 & 6 & 5 & 5 \\
\hline
\end{tabular}

Figure 14: Total available CRM quantities in discarded consumer electronics and rechargeable batteries in Denmark, Finland, Norway and Sweden (in tonnes)

\section{Total available CRM quantities in discarded consumer electronics and rechargeable batteries}

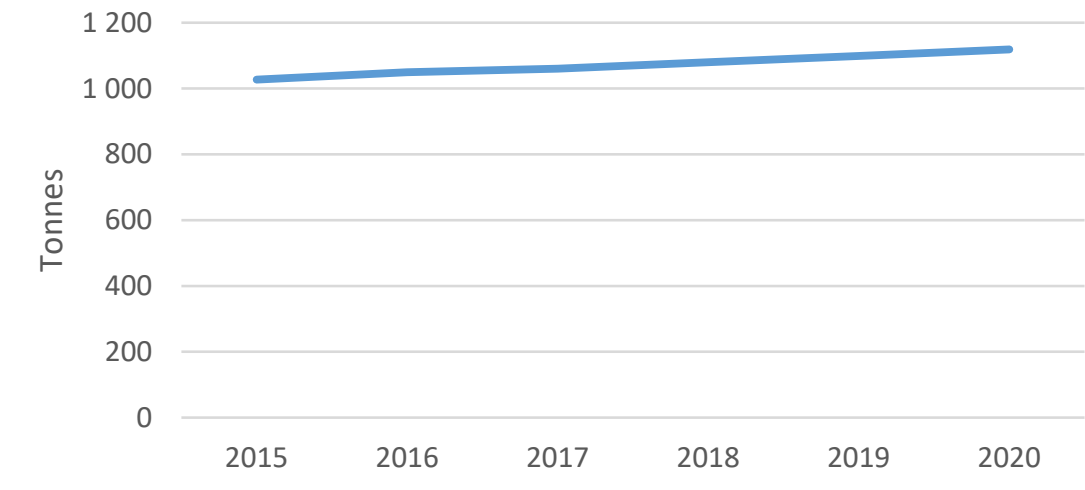




\subsection{Data creditability issues}

In their report, Bakas et al. (2016) present the issues concerning the creditability of the data on critical metal contents. These aspects can be generalized to concern also the product groups discussed in this report. For example, also here the CRM values found in the literature varied, sometimes even significantly. This kind of difference indicates that information collected should only be used to estimate the magnitude of the CRM content, and thus the contents of CRMs in each product group presented in this report should be considered indicative only (Bakas et al., 2016). The differences in CRM values reported in the literature are caused either by the diversity of products, or/and the differences in measuring methods used to measure CRM contents (either experimental or theoretical methods may be used) (Chancerel et al., 2013). In addition, for some CRMs the data on their content was scarcer for some products than for others. This may either be caused by the fact that the product in question does not contain certain CRMs, or there is a lack of documented data (Bakas et al., 2016).

In the following sections, data creditability issues specific to ELVs and lighting products are discussed.

\subsubsection{End-of-life vehicles}

Data on generated ELV was as previously mentioned collected from statistical bureaus and branch organizations. Some uncertainty is linked to the definition of a personal vehicle, e.g. in Sweden campers weighing less than 3.5 tonnes are included in the statistics of category $\mathrm{M}_{1}$ (category $\mathrm{M}_{1}$ is used to collect data), where they are not in the data for the other countries.

The generated ELV waste from 2016 to 2020 is estimated by linear extrapolation based on data provided for the years 2010 to 2015 . The estimation is thus rough and should only be interpreted as an indication. The ELV waste amounts are most likely overestimated (and thus also the total available CRMs in ELVs) as new cars are heavier than older ones being scrapped today, and the average weight per car in the calculations is based on cars in use today and not based on the car fleet 16 to 20 years ago (average life of a personal car). On the other hand, older cars do not contain as much CRM as cars produced today, which could counter the uncertainty to a certain degree.

The CRM content in EVLs is based on three car models from the same brand, commonly used in Sweden based on condition in 2012. Uncertainties are here connected to the fact that the average CRM content would differ if the entire car fleet was taken into consideration rather than only three models from the same brand. These models are also only common in Sweden, and other models/brands may be more common in the other Nordic countries. Other factors also have a significant effect on the average CRM content in ELV: the electrification of car fleets, the need for lighter construction material in order to produce light-weight cars and technology for decreasing emissions, e.g. catalysts and particle filters. 


\subsubsection{Lighting products}

Obtaining accurate data for measuring the amount of waste generation is a significant challenge. As statistics on waste generation in different lighting product groups are not compiled, it was decided to combine the trade data (the net of import and export) with the estimated product lifespans to be able to estimate waste generation. However, as Bakas et al. (2016) mentioned, the uncertainty level of this method is relatively high. Some examples of the potential factors affecting data creditability of the waste generation data for lighting products are gathered below:

- Combined nomenclature (CN) codes for lamps are rather general (Wang et al., 2012) and a risk of error occurs in their use. For fluorescent lamps, the two $C N$ categories (85393110 and 85393190 ) seem rather unambiguous, but for LEDs the situation is much more complicated. According to Lighting Europe (2014), LED products (consisting of three different subclasses: LEDs, LED Light Sources, and LED Luminaires) are currently being categorized inconsistently under many different $\mathrm{CN}$ subheadings with no clear distinction between, LED dies/packages, lamps and luminaires. Thus, it was decided not to use trade statistics to analyze waste generation of LED lamps.

- A risk of multiplying occurs when using the trade data, as $\mathrm{CN}$ codes may be used erroneously or double counting arises (Richter \& Koppejan, 2015).

- According to Eurostat (2016), there has also been some (but quite low level) domestic production of fluorescent lamps in Denmark, causing inconsistency in the data.

- To be able to generate approximation on waste generation of LED lamps, confidential sales data had to be used. This is not a transparent means to generate data, because, e.g. the presumptions used could not be described due to confidentiality of the source information. In addition, the Finnish data was also used to estimate waste quantities in Norway and Denmark, as corresponding data from these countries was not available. This approach is, of course, very rough and contains several uncertainty factors and should be considered indicative only.

- Lifespan estimates were used to estimate the amount of waste generated. However, the prolonged lifespans of fluorescent and LED lamps, the varying lifespan estimates between different sources (Table 6), as well as the "true" lifespans often being something other than expected, all cause uncertainty to the waste generation data. For example, according to the estimate presented in Section 2.1.2, there should not be any LED lamp waste generation before 2018, although it is known that some waste generation already exists. One explanation for this is that the true lifespans are actually very different from the expected ones. Lifespans can correspond to a few years or even decades depending on, e.g. the year of manufacture, number of turn on/off cycles, operating conditions, and quality variations in manufacturing. 
Some additional factors that especially affect the creditability of lighting product CRM content estimates were also identified:

- Due to the lack of data on automotive lighting and backlighting waste generation, their CRM content potential was not estimated although CRMs are present in these applications as well.

- To be able to estimate CRM contents in different product groups, CRM amounts were converted to kilograms and tonnes using estimated average lamp weights. However, all three product groups contain a countless number of different lamp models with considerably varying weights, so the use of just one average value inevitably affects the data creditability.

- The fast technical development and rapidly changing characteristics of lighting products may affect the content of the critical metals as well as the weights of the lamps. The effect of these factors was not considered.

- In the calculations, all LED lamps were assumed to be light bulbs, although there are lot of other types of LED products (e.g. LED strips) that are used in general lighting and contain CRMs as well.

- In some of the references, CRM contents were expressed in the unit mg/diode. In these cases, to be able to generate estimates of CRM content for the study, it was assumed that one lamp contained 72 diodes, although in reality the number of diodes varies widely between different lamp types. 


\section{Current status and bottlenecks of recycling}

This chapter presents the current status of recycling of CRMs in the target end-of life products, identifies the key bottlenecks of recycling (and reuse) of the selected products, and briefly describes their reasons and impacts. Bottlenecks are defined as factors that limit the performance and efficiency of recycling or reuse of the products and thus prevent or limit the move towards a near zero-waste value chain and circular economy. The bottleneck analysis of ELV and WEEE sectors carried out as a part of the European project NEW_InnoNet (http://www.newinnonet.eu/) (NEW_InnoNet D2.5 by Bachér et al. 2016) has been utilized as a basis. In addition, literature describing the bottlenecks of recycling of lighting products and batteries has been reviewed. The bottlenecks identified by experts in the project workshop have also been considered, especially in Sections 4.1.2 and 4.3.2

This chapter especially focuses on the bottlenecks of recycling of CRMs in the targeted product groups. However, more general challenges of recycling usually hamper the recovery of CRMs, and therefore they are discussed as well. The bottlenecks leading to material losses in collection and different processing stages can be mentioned as an example.

In the NEW_InnoNet report, the identified bottlenecks were prioritized using multiple criteria decision-making (MCDM). In the process of prioritizing the bottlenecks, their significance was analyzed regarding the following potential impacts and the benefits potentially attained when reducing or removing the specific bottleneck (Bachér et al. 2016):

1. Economic value.

2. Improvement of resource efficiency.

3. Greenhouse gas emissions.

4. Strategic value/benefit. (Bachér et al. 2016).

\subsection{End-of-life vehicles}

Within the NEW_InnoNet project, 15 bottlenecks for increased reuse and recycling were identified and prioritized regarding ELVs, many of them being inter-related. These are briefly described in the following sections together with bottlenecks identified in other sources and the current status of recycling ELVs. 


\subsubsection{Current status of recycling ELVs}

The ELV Directive 2000/53/EC sets out targets for ELV reuse, recycling and recovery. According to the Directive, all countries must introduce systems that allow for the following targets to be met by the 1st of January 2015:

- Reuse and recovery rate at 95 per cent.

- Reuse and recycling rate at 85 per cent.

The directive also has targets that were to be met by 1st of January 2006:

- Reuse and recovery rate at 85 per cent.

- Reuse and recycling rate at 80 per cent.

The total reuse and recycling of ELVs in the studied countries is presented in Figure 15. The figure shows that practically all countries reached the 2006 target, and in 2014 Denmark had already reached the 2015 target. Note that the vertical axis starts at 70 per cent.

Figure 15: Total recycling and reuse of ELVs in Denmark, Sweden, Finland and Norway between the years 2006-2014. The same data for EU27 is also included for comparison as well as the ELV Directive targets for 2006 and 2015. Note that the vertical axis starts at 70 per cent (Eurostat, 2016)

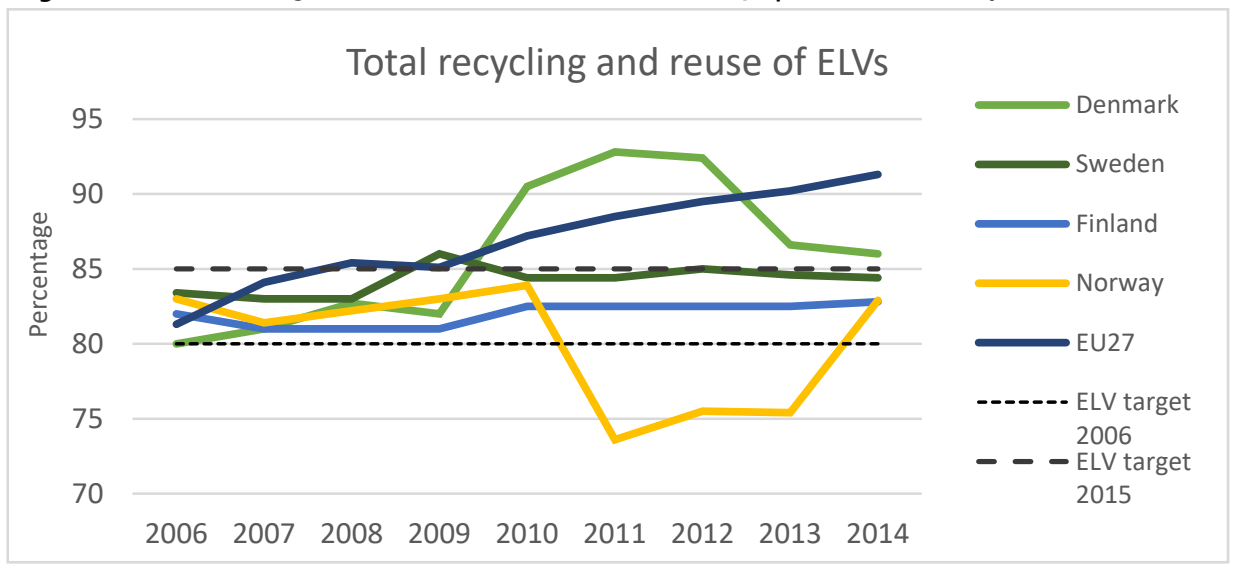

In this data, vehicles used for the carriage of goods (category $\mathrm{N} 1$ as defined in Directive $70 / 156 / E E C)$ is also included and is not directly comparable with the ELV amounts previously mentioned in this report as only category $\mathrm{M}_{1}$ is included.

An important conclusion drawn by Andersson et al. (2016), who studied the CRM recycling from ELVs in Sweden, is that even if recycling rates for ELVs are rather high in general, the risk of losing scarce metals from ELVs is high as they are often lost to carrier metals, construction materials, backfilling materials and landfills. The metals found to be functionally recycled, i.e. recycled with regard to the metals' properties, are presented in Table 14, together with the car part from which the metal can be extracted. 
However, platinum was the only metal that could be recycled in its main application, whereas the other metals presented in the table can be functionally recycled depending on the application and pathways taken. For the other 17 metals studied in the article, no functional recycling takes place (Andersson et al., 2016).

Table 14: Functionally recycled metals from personal cars today according to Andersson et al. (2016)

Metals that are functionally recycled Car parts where the metal is available

Palladium, platinum Catalytic components

Cobalt, molybdenum Steel alloys, nickel alloys, lubricants, electric, electronic and magnetic

components

Manganese Aluminium, magnesium and nickel alloys, lubricants, electric, electronic and magnetic components

Silver, gold, palladium, rhodium Electric, electronic and magnetic components

\subsubsection{Bottlenecks}

The identified bottlenecks of ELV recycling are based on the analysis in the $\mathrm{H}_{2020}$ project NEW_InnoNet, other literature sources and discussions in the project workshop. The bottlenecks identified in the NEW_InnoNet project do not address the recycling of CRMs in particular but rather bottlenecks in the recycling of ELVs in general. However, most bottlenecks related to ELV recycling are also relevant concerning CRMs. A more detailed list of identified bottlenecks from NEW_InnoNet and other literature sources is available in Appendix 3. This section attempts to summarise the most relevant bottlenecks from the list in the Appendix 3 and should be read together with the appendix for a complete list.

The authors of NEW_InnoNet consider the general bottlenecks that most hinder development in terms of quality and quantity in overall recycling to be:

- inadequate performance of the separation, sorting and refining technology

- inadequate performance of vehicle dismantling and reuse application

- limited and low-quality application outlets of non-metallic ELV materials

- inadequate performance of ELV collection and monitoring

- low-cost of energy recovery and landfilling alternatives compared to material recovery.

The following bottlenecks have been identified regarding the recycling of CRMs in particular:

\section{Composition and design of vehicles}

CRMs are used in small amounts and in many components making them difficult to recover due to high related costs (Andersson, 2016). Ciacci et al. (2015) points out the lack of designing vehicles for scarce metal recycling. There is also a lack of recycling 
systems that regards the complexity of ELVs and strategies for the recycling of specific metals (Andersson, 2016). The materials used in ELVs are not only many and complex, but the composition also changes rapidly over time contributing to unstable recycling markets (van der Have, 2016; 2017; Andersson, 2016). It is therefore necessary that long-term policies take this into consideration.

Since the composition is complex, material use need to be communicated between manufacturers and end-of-life operators. This is not conducted today; thus, the end-oflife operators have to investigate this by themselves (NEW_Innonet, 2016).

\section{Recycling technologies}

As previously mentioned, not many CRMs are today being functionally recycled and an important bottleneck is the lack of industrial scale technologies for functional recycling in particular (Söderman \& Ingemarsdottir, 2014; Geological Survey of Sweden, 2014). Additional bottlenecks identified related to recycling technologies are (van der Have, 2016; 2017):

- Propulsion engines including electric ones are not dismantled prior to shredding and processed by specialist motor recyclers.

- The remaining volumes from the shredding process such as mixed ELV/WEEE make CRMs too marginal to detect.

- The machinery for sorting is not accurate enough to detect most of the CRMs.

- Technical measurement and analyses for detecting CRMs are not tailored towards CRMs in mixed form, which leads to inadequate data generation on CRM contents and availability.

- Supply chain / owners of various brands do not know or do not communicate CRM availability in components, which leads to a knowledge gap along the recycling chain. (van der Have, 2016; 2017).

\section{Market and economy}

There must be a functioning market for secondary material for recycling and investment in recycling to be feasible. Thus, many bottlenecks are connected to the market of secondary material. For example, inadequate performance of separation, sorting and refining technology may lead to higher contamination levels in the secondary material causing a decrease in value (NEW_InnoNet, 2016). In addition, CRMs are mostly not supply risk sensitive (van der Have, 2016) making it difficult to compete with virgin material. At the same time, the environmental value of secondary material is not reflected in the financial pricing compared to primary materials. Another example is that dismantling parts for reuse and recycling requires more time, which means reduced feasibility for reuse and recycling of potentially high-value components (NEW_InnoNet, 2016; van der Have, 2016). Except for catalytic converters, car dismantlers in North Western Europe do not take ELVs apart for materials as labour costs exceed the economic benefit of sorting certain parts and materials. Whether 
certain parts are removed from the ELVs (e.g. copper cable or engine) is dependent on their market value at that moment (van der Have, 2016).

Further, overcapacities and competition in incineration and landfill facilities as well as low taxation rates lead to low gate fees in some EU Member States making it difficult for material recycling to compete with alternative treatments. This reduces feasibility for recycling and investing in recycling of non-metallic materials and minor metals. (NEW_InnoNet, 2016)

\section{Policies and legislation}

According to Geographical Survey of Sweden (2014), there is a need for enhanced coordination of research, which today is fragmented. Industry, academia and authorities need to cooperate and exchange knowledge and experience in order to further stimulate economically viable recycling solutions and methods for recycling.

In collection, many factors have an impact on the interpretation of what an ELV is, how it should be recycled, and how the recycling sub-quota should be judged and monitored. The vagueness this causes may lead to substandard treatment. It also leads to a lack of reliable data availability on vehicle registration and composition, ELV collection and trade of vehicles/ELVs. (NEW_InnoNet, 2016) According to van der Have (2016; 2017), ELV recycling regulations are based on vehicle weight, not promoting CRM recycling since the CRM amounts are small and scattered in various components.

Another bottleneck is that ELVs with high CRM potential are often exported and mostly end up in foreign unregulated sectors (van der Have, 2016).

\subsection{Lighting products}

\subsubsection{Current status of recycling}

The reuse, recycling and recovery of lighting products is regulated under the WEEE Directive 2012/19/EU. The directive sets the following minimum targets:

- From 15th of August 2015 until 14th of August 2018:

- for fluorescent lamps: 80 per cent recycling rate

- for other lighting equipment: 75 per cent recovery rate, and 55 per cent prepared for reuse and recycled.

- From 15th of August 2018:

- all: 80 per cent recycling rate.

In addition, mercury should be removed from fluorescent lamps.

The legislation also obliges the implementation of producer responsibility. The execution of this obligation varies between countries (Table 16). For example, in Finland and Denmark lamp-specific producer responsibility organizations exist (Richter \& Koppejan, 2015), whereas in Norway there have been five different producer 
responsibility organizations for WEEE until 2017, which all included lamps in their collection system (Frantzen, 2017).

Table 15: A comparison of EPR system architectures in the Nordic countries, situation in 2013 (Richter \& Koppejan 2015, modified)

\begin{tabular}{|c|c|c|c|c|}
\hline & Denmark & Finland & Norway & Sweden \\
\hline $\begin{array}{l}\text { Lamp scope } \\
\text { legislation }\end{array}$ & Filament bulbs excl. & Filament bulbs excl. & All lamps covered & All lamps covered \\
\hline $\begin{array}{l}\text { Main producer } \\
\text { responsibility } \\
\text { organizations } \\
\text { dealing with lamps }\end{array}$ & LWF (lamp specific) & FLIP (lamp specific) & $\begin{array}{l}\text { RENAS, Elretur } \\
\text { (currently Norsirk), } \\
\text { EPR Norway, Elsirk } \\
\text { and Eurovironment* }\end{array}$ & El Kretsen \\
\hline Retailer take-back & Voluntary & $\begin{array}{l}1: 1,0: 1\left(\geq 1,000 \mathrm{~m}^{2}\right. \\
\text { grocery stores/200 } \\
\left.\mathrm{m}^{2} \mathrm{EEE}\right)\end{array}$ & All selling EEE & $\begin{array}{l}1: 1,0: 1 \text { ( } \geq 400 \mathrm{~m}^{2} \mathrm{EEE} \\
\text { sales space) }\end{array}$ \\
\hline Recycling stations & Yes & Yes & Yes & Yes \\
\hline Kerbside collection & $\begin{array}{l}\text { Limited } \\
\text { (2 municipalities) }\end{array}$ & $\begin{array}{l}\text { Mobile collection a } \\
\text { few times per year }\end{array}$ & $\begin{array}{l}\text { Mobile collection a } \\
\text { few times per year }\end{array}$ & 1.5 M households \\
\hline $\begin{array}{l}\text { Permanent } \\
\text { collection sites } 2013\end{array}$ & 398 & $\begin{array}{l}526 \text { (retailer } \\
\text { collection locations } \\
\text { not included) }\end{array}$ & $\sim 2,700$ & $\sim 2,600$ \\
\hline
\end{tabular}

Note: *From 2017 Norway has three producer responsibility organizations dealing with WEEE: Norsirk, RENAS and EPR Norway.

Basically, all materials used in lamps could be recycled or even reused (Table 17). In practice, however, the situation is not so straightforward, as most of the lamp waste generated does not end up in the recycling processes at all. In 2012, only 37 per cent of fluorescent lamps put on the market were collected for recycling in the EU. The situation in Sweden, Finland and Denmark was better than the average EU collection rate, as they collected 42-68 per cent of fluorescent lamps put on the market, but in Norway only 29 per cent of the lamps were collected. However, all four Nordic countries exceeded the minimum recycling rate of 80 per cent for fluorescent lamps (Richter \& Koppejan, 2015).

In comparison, the recycling rates in 2014 were: Finland 90.0 per cent, Norway 89.0 per cent, Sweden 99.5 per cent, and Denmark 99.7 per cent (Eurostat, 2016). 
Table 16: End use/disposal methods for fluorescent lamp materials (Nordic Recycling, 2014; WEEE Forum, 2011, cited by Richter \& Koppejan 2015, modified)

\begin{tabular}{|c|c|c|}
\hline Material fractions & $\begin{array}{l}\text { Approximate part in \% } \\
\text { (in CFL-LFL) }\end{array}$ & End use / disposal methods \\
\hline Aluminium/other metals & $18-30$ & Reuse or recycling \\
\hline Mix of plastic and metal & 20 & Recycling, energy recovery or landfilling \\
\hline Glass & $45-80$ & $\begin{array}{l}\text { Reused for fluorescent tubes; lamp glass; glazing; glass } \\
\text { wool insulation; fusion agent with black copper foundry; } \\
\text { abrasive sand for cleaning, under layer for asphalt; sand } \\
\text { replacement; silicon substitute, landfill cover }\end{array}$ \\
\hline $\begin{array}{l}\text { REE powder (contains } \\
\text { also mercury and small } \\
\text { glass particles) }\end{array}$ & $2-3$ & $\begin{array}{l}\text { Separated and reused as mercury or phosphors in new } \\
\text { lamps, separated and recycled after REE processing; } \\
\text { powder and mercury landfilled as hazardous waste }\end{array}$ \\
\hline
\end{tabular}

Richter \& Koppejan (2015) describe the recycling practices in the Nordic countries. According to them, LED lamps, although not containing mercury, are currently collected and treated together with fluorescent lamps. There are at least two operators in the Nordic countries that recycle discarded lamps, Ekokem in Finland and Nordic Recycling in Sweden (Richter \& Koppejan, 2015). Nordic Recycling recycles lamps collected from Sweden, Norway and Denmark using a wet oxidation process (Richter, 2014). The centralized treatment in Sweden increases the economic profitability of the process, but at the same time hinders closing of the loop or advanced use of recycled materials, as the long distances present challenges in returning the treated materials back to the lamp manufacturers or recyclers. Consequently, e.g., glass fraction recovered from the treatment process is often used in less valued applications, such as construction material in landfill covers. In Finland, however, there is a glass recycler nearby, and foam glass and glass powder are produced from the glass fraction (Richter \& Koppejan, 2015).

Metal fractions can be sold to local metal recycling companies while plastic materials used in lamps are generally recovered as energy. The lamp phosphors containing REEs (cerium, europium, gadolinium, lanthanum, terbium and yttrium) are not currently recycled in Finland due to their small generation and lower quality (Richter \& Koppejan, 2015). The Swedish process generates a "fluorescent powder mix" containing phosphors and mercury (Nordic Recycling, 2016) that is of higher quality and formed in larger quantities. Previously, the powder mix was sold to the French company Solvay Rhodia (Richter \& Koppejan, 2015) for separation and purification of REEs, which were then formulated to new phosphor powders and used in the lamp production (Solvay, 2016). However, it is reported that Solvay Rhodia was planning to stop the recycling of REEs by the end of 2016 due to decreased prices of primary REE metals, which has caused a significant loss in competitiveness of recycled materials (Sud Ouest, 2016).

In addition to the materials presented in Table 17, semiconductor diodes in LED lamps contain two critical raw materials - gallium and indium. As LED lamps are currently recycled similarly to fluorescent lamps (Richter \& Koppejan, 2015), the 
recycling of gallium and indium from Nordic LED lamp waste probably does not exist, although technically their recycling would be possible.

\subsubsection{Bottlenecks}

Most of the bottlenecks in the recycling of lighting products are common to the recycling of other electronics products, and these are described in the Section 4.3. In addition, the following specific challenges of collection and recycling of lighting products in general were identified by Richter \& Koppejan (2015):

- Cost and limited efficiency of collection:

- Wastes are scattered both geographically and between consumers and businesses. In addition, lamps are lightweight and optimal filling of transportation vehicles may be problematic.

- Presence of unwanted toxic substances:

- As mentioned above, the phosphor powder in fluorescent lamps contains small amounts of mercury, which is hazardous to human health and the environment. Specific treatment methods and work safety measures are therefore needed when the lamps and the powder mix are recycled.

- Fragility of lamps is an occupational risk to the waste handlers, especially in the case of lamps containing mercury.

- Organization of producer responsibility:

- Depending of the country, there are lamp-specific PROs where the decision makers can pay more attention to the lamp-specific needs than larger PROs where lamps are only one group under the WEEE umbrella.

- Data inconsistencies:

- Due to inconsistent categorization of LED lamps, dies, packages etc. between the three trade statistics categories referring to LEDs, the estimation of consumer amounts of LED lamps is difficult. The collection statistics do not distinguish between LEDs and fluorescent lamps. (Richter \& Koppejan 2015).

Whereas the following bottlenecks presented by Richter \& Koppejan (2015) can be seen to address the recycling of CRMs in particular:

- High costs of recycling compared to the value of the lamps:

- The quantities of valuable compounds per lamp are small, which makes the recovery techno-economically challenging.

- Due to the shift to LED lamps with longer expected lifespan and smaller quantities of valuables compared to fluorescent lamps, the available CRM quantities will decrease in the future. 
- Organization, control and verifying of efficiency and safety of multi-stage, multiactor recycling systems:

- Due to the small quantities of valuables, centralized recycling of CRM containing applications or components, such as fluorescent materials in the lamps, could be the most cost-effective solution. However, the organization and control of this kind of system may be challenging and create new challenges, as transports and low-grade use of other materials. (Richter \& Koppejan 2015).

\subsection{Consumer electronics}

\subsubsection{Current status of recycling}

The reuse, recycling and recovery of consumer electronics are regulated under the WEEE Directive 2012/19/EU. From the selected product groups, mobile phones, PCs, and laptops and notebooks belong to the category \#3 (IT and Telecommunications Equipment) in the WEEE Directive, whereas flat screen TVs belong to the category \#4 (Consumer Equipment and Photovoltaic Panels).

The directive sets the following minimum targets for these categories:

- From 15th of August 2015 until 14th of August 2018:

- 80 per cent recovery rate, and 70 per cent prepared for reuse and recycled.

From 15th of August 2018 onwards flat screen TVs, and laptops and notebooks fall within category \#2 (screens, monitors, and equipment containing screens having a surface greater than $100 \mathrm{~cm}^{2}$ ), and mobile phones and PCs within category \#6 (all IT and telecommunication equipment (no external dimension more than $50 \mathrm{~cm}$ )).

The targets for these categories are:

- From 15th of August 2018:

- Category \# 2: 80 per cent recovery rate, and 70 per cent prepared for reuse and recycled.

- Category \#6: 75 per cent recovery rate, and 55 per cent prepared for reuse and recycled.

Similar to the lighting products, the legislation obliges the implementation of producer responsibility. Extended producer responsibility schemes are in place in every Nordic country, although there are some significant differences between the legal, regulatory and practical details (Baxter et al., 2014).

Exact information on selected product groups is not available, but statistics for categories $\#_{3}$ and $\#_{4}$ do exist. As can be seen from Table 18 , all countries are currently 
exceeding the minimum requirements for WEEE recycling and recovery in these two categories. However, it should be noted that the rates are calculated on the amounts collected, not on the amount of waste "generated" or equipment "put on the market". According to Huismann et al. (2007), a large share of WEEE does not end up in the official treatment systems; for example, most of the small WEEE may be discarded along with the household waste. However, from 2016 the collection targets are calculated as a percentage ( 45 per cent from 2016, 65 per cent from 2019) of the average weight of the WEEE placed on the market during the three preceding years, instead of the minimum target of $4 \mathrm{~kg} /$ inhabitant until the end of 2015. This approach better relates the collected amounts to the actual amounts put to the market.

Table 17: Recycling and recovery rates in WEEE categories \#3 and \#4 vs. the amount of WEEE collected in 2014 (Eurostat, 2016)

\begin{tabular}{|c|c|c|c|c|c|}
\hline & Category & $\begin{array}{r}\text { Amount } \\
\text { collected } \\
(\mathrm{t})\end{array}$ & $\begin{array}{r}\text { Share of the } \\
\text { total WEEE } \\
\text { collected (wt-\%) }\end{array}$ & $\begin{array}{r}\text { Recycling } \\
\text { and reuse } \\
(\%)\end{array}$ & $\begin{array}{r}\text { Recovery } \\
(\%)\end{array}$ \\
\hline \multirow[t]{2}{*}{ Finland } & 3. IT and telecommunications equipment & 9,381 & 14.2 & 90.6 & 91.6 \\
\hline & 4. Consumer equipment & 16,073 & $24 \cdot 3$ & 90.8 & 91.3 \\
\hline \multirow[t]{2}{*}{ Norway } & 3. IT and telecommunications equipment & 14,448 & 13.5 & 76.2 & 84.9 \\
\hline & 4. Consumer equipment & 15,182 & 14.2 & 76.3 & 96.6 \\
\hline \multirow[t]{2}{*}{ Sweden } & 3. IT and telecommunications equipment & 24,006 & 16.6 & 84.8 & $93 \cdot 3$ \\
\hline & 4. Consumer equipment & 34,225 & 23.6 & 84.2 & 96.6 \\
\hline \multirow[t]{2}{*}{ Denmark } & 3. IT and telecommunications equipment & 11,625 & 16.2 & 92.9 & $99 \cdot 7$ \\
\hline & 4. Consumer equipment & 17,195 & 24.0 & 92.0 & $97 \cdot 7$ \\
\hline
\end{tabular}

Ylä-Mella et al. (2014) provided a comprehensive overview of the implementation of the WEEE Directive in Finland, Sweden and Norway, but the study does not cover Denmark. According to them, the implementation of the directive as well as the development of the general recovery infrastructure for WEEE have been successful in all three countries. In fact, the recovery systems in Sweden and Norway are amongst the most efficient in in the world (Ylä-Mella et al., 2014). In addition, the collection rates for WEEE are amongst the highest in Europe, except for Finland. However, the Finnish discrepancy may be caused by the different accounting and reporting practices (Baxter et al., 2014).

In Finland, collected WEEE is transported to regional sorting and pre-treatment plants, where it is manually separated, weighed and sorted into two different fractions: reusable and non-reusable WEEE. The components and reusable equipment are manually sorted, stocked, and delivered onwards. Recyclable devices are pre-treated with disassembling to remove hazardous materials and substances. Also, large monomaterial parts are separated manually. After pre-treatment, the waste is crushed and metal, glass, and plastics are mechanically sorted into their own fractions. Metals and glass are delivered to smelters or reprocessing plants for recovery, and plastics mostly utilized as energy. Non-recyclable WEEE is treated for final disposal in special 
treatment plants (e.g. physicochemical treatment plants, high-temperature incinerators) (Ylä-Mella et al., 2014).

In Sweden, collected WEEE which is sorted into seven categories (assorted electrical goods, TVs and monitors, fridges and freezers, large white goods, lighting, fluorescent tubes, and portable batteries) at the recycling centres is transported to the recycling plants for sorting and disassembly. After the disassembly of hazardous substances and components, the waste is mechanically sorted into different fractions (e.g. metals, plastics, and glass), which are then transported to be further utilized in recycling or reprocessing plants. Hazardous wastes requiring selective treatment are directed either to special treatment or for final disposal. The Norwegian recovery process follows the Finnish and Swedish practices (Ylä-Mella et al., 2014).

Recycling of CRMs is not reported, but it is unlikely that Nordic WEEE recyclers recover many of the CRMs present in WEEE. As an exception, the circuit boards in mobile phones and computers can be currently recovered through pyrometallurgical processing followed by hydrometallurgical extraction and purification. Integrated copper smelters are utilized to distribute the contained metals and compounds into various phases such as copper, matter, speiss, slag, flue dust, and offgas, while the recovery of energy is possible. Hydrometallurgical processes can extract various valuable elements, such as bismuth, gold, silver, platinum group metals (PGMs), nickel and cobalt through a variety of processes including leaching, solvent extraction, electro-refining, electro-winning, and precipitation and so forth (van Schaik \& Reuter, 2014). For example, being the world's largest recycler of electronic scrap, Boliden Rönnskär copper smelter (Sweden) recycles PGMs, gold and silver, and also Boliden Harjavalta (Finland) refines a small amount of electronic scrap in its smelter (Boliden, 2016).

\subsubsection{Bottlenecks}

The description of bottlenecks in this section is based on the analysis of bottlenecks of WEEE recycling in the $\mathrm{H}_{2020}$ project NEW_InnoNet (Bacher et al., 2016; VGW, 2016), other literature sources, discussions in the project workshop, and experience from the projects related to WEEE. The focus in NEW_InnoNet was on the bottlenecks in WEEE recycling in general. In the following, the data has been applied to focus particularly on CRM recycling. However, most of the barriers to WEEE recycling are also barriers to CRM recovery.

Most of the bottlenecks discussed in this section also relate to lighting products and rechargeable batteries.

\section{Composition and design of electronics}

Based on the analysis and prioritization of the bottlenecks in WEEE recycling, the design and composition of WEEE were deemed, besides the large share of uncontrolled treatment, to be the most significant challenges in recycling (Bacher et al., 2016). The design-related bottlenecks are closely interlinked to the losses of materials in the recycling processes, because currently there are no economically feasible sorting, recycling and recovery technologies for a large spectrum of different 
materials in complex products. The recovery of CRMs is particularly affected by the current electronics design trends because the CRM concentrations per application are usually small.

It also seems that the development trends will make the recycling even more challenging in the future. The following issues can be mentioned:

- Improved performance and new functionalities are attained by the use of an increased number of smaller components, compact packaging, integrated/joined materials and multi material alloys. The components and materials are difficult to liberate and separate because the methods of joining and integrating materials are not designed for disassembly and separation.

- Miniaturization of the electronic components and decreased use of valuables per application decrease the feasibility of recycling of CRMs and other valuables because there are no economically feasible methods for the recovery of small quantities of materials from complex products.

- Rapid development and short lifecycles of the products lead to continuously changing and heterogeneous input of recycling processes. Development of the processing methods cannot keep pace with these rapid developments.

- Unwanted, toxic or hazardous substances hamper recycling, such as mercury in fluorescent lamps, lead-containing solders, gallium arsenide in LEDs and beryllium, e.g. in mobile phones. However, it should be noted that if end-of-life products are properly dismantled, there should not be any hazardous substances left in them.

Currently there are no, or very few, incentives for manufacturers of electronics to develop recyclable products. The product design is strongly driven by performance requirements, improvement of cost-efficiency, and consumer expectations, which do not emphasize recyclability or reusability.

However, it is expected that the proposal for amendment of the Eco-design Directive and the standardization mandate 543 (eco-design requirements related to material efficiency aspects) will bring new requirements for durability, reparability, reusability, reversible disassembly and recyclability for several product groups, including electric and electronic products.

\section{Collection of electronics}

The losses of WEEE in the collection stage reduce the availability of CRMs for recovery and thus the profitability of the recovery. On the European level, the collection practices as well as monitoring and reporting of the collection rates vary significantly in all the target chains. In general, although there are differences in the practical organization of collection, the reported collection rates in the Nordic countries seem to be at quite good level compared to European averages.

One of the challenges in the collection stage is inadequate control and monitoring of the collection rates, which enables leaking of WEEE to non-compliant treatment and 
illegal export. When analyzing the statistics of the Nordic countries, and also based on Finnish studies, it seems that especially in Finland there may be some leaks in the monitoring and reporting of the collected amounts, particularly related to industrial applications.

The electronics appliances are scattered both geographically and between consumers, public activities and industry. In the Nordic countries, there are also large sparsely populated areas, although a large part of the population currently lives in cities. These factors increase the cost of collection and can make the monitoring of collection complex.

A part of the smaller appliances ends up in mixed waste and further to incineration, because it may be the easiest alternative for consumers. There may also be lacks in the information to waste producers leading to insufficient consumer awareness, for example, which devices should be put to WEEE collection, how to find the collection points, etc.

\section{Recycling technologies}

Development of cost-efficient processing chain for complex products with inhomogeneous material composition and low concentrations of critical and valuable materials per application or component is a challenge in electronics recycling. This has led to optimization of the recycling processes for materials that are technically and economically most feasible to recover, in the case of electronics especially gold and copper. In the Nordic countries, Boliden Rönnskär recovers palladium, platinum, gold and silver from electronics waste. Iron and aluminium are usually recovered, as well. Other valuable materials, such as most of the critical raw materials and plastics end up as fractions, which are disposed of, used in lower grade applications or in some cases exported. Umicore in Belgium is capable of recovering a somewhat larger scale of CRMs. However, for some CRMs their focus is recovery from industrial and manufacturing waste, not from EoL products.

The technological bottlenecks include:

- There are no well performing automatic methods for the dismantling of electronic devices. The main alternative is manual dismantling. Due to the high cost, it is not economically feasible to dismantle and sort, for example, small CRM-containing components from printed circuit boards (PCB) or even to dismantle PCBs before crushing.

- Industrial-scale treatment processes for many CRMs are not available, no investment in recycling plants (Nunweiler, 2017).

- Identification of the material composition of the devices and their components. The material composition of the same kind of appliances and same type of components can be varied due to different performance requirements, age, and producer, etc. Solutions for tracing and tracking of the materials would be needed. 
- The difficulty of separating the critical raw material from the complex construction, alloys, from impurities hampering the processing, etc.

- Losses of materials in different phases of processing is a challenge especially for materials with low concentrations. Critical materials can be lost to shredding waste and dust during shredding, to recovered material fractions, and to pyrometallurgical slags, etc.

- Economy in the processing chain of multiple actors, optimization of processes to economically most feasible materials.

- Need to adapt the processing to the rapidly changing materials and compositions.

These bottlenecks will be even more difficult to solve in the future because of the rapid development and increased complexity and diversity of materials and components, such as composite materials, joined and glued materials and multi-material solutions. Insufficient communication between different actors along the value chain is also a bottleneck, because the recyclers do not get information about product composition and the information about requirements of recycling is not transmitted to the product designers.

\section{Market and economy}

Because of the variation in qualities and quantities of input material supply and dependence of the secondary material prices on those of virgin materials, it is difficult to keep the volumes, qualities and prices of recycled materials stable. This has a negative impact on the motivation of material producers to use recycled materials.

The benchmarking of the prices against primary material prices does not take into account the potential environmental and strategic benefits of recycling. The challenge of material quality is twofold. On the one hand, there is space to improve market trust of the recycled materials by improving the quality control of the recyclates and the control of the whole sorting and processing chain. On the other hand, the standards and guidelines for virgin materials are not always suitable for recycled materials.

In some cases, the costs of landfilling or energy recovery alternatives are quite low due to overcapacities. It can be estimated that the competition is unfair, because gate fees do not take into account all the costs, such as the costs of future care. The same applies to the prices of down-cycling applications of non-metallic materials and processing residues. These easy-to-use solutions reduce the waste quantities available for recycling and thus the economic feasibility of high-quality recycling.

\section{Policies and legislation}

Lack of European-wide harmonization of the enforcement of EU legislation, poor governance and supervision of current regulations as well as lacks in monitoring of collection and recycling system were found to be an obstacle to recycling. Differences in implementation of the legislation between MS lead to inconsistencies in reporting and European statistics. They also ease leaking of materials from the official recycling systems and use of substandard recycling practices. Lacks of statistics and poor availability of representative data hamper evaluation and comparison of the practices 
and performances between different countries and on European level, as well as evaluation of the business potential and key development needs. There are also challenges in reporting of reuse.

The calculation of recycling rates of electronics and other CRM-containing products is currently mass based. This does not encourage recycling of critical and precious materials with low concentrations per product. In addition, there are no formal channels for the collection of the data on the availability of CRMs in electronics products and on the amounts of CRMs imported and exported in the products.

The playing field between PRO approved and non-PRO approved recyclers can be uneven, because the PRO approved recyclers are under tighter control and they have to show that the requirements of PRO are fulfilled. Lack of control does not encourage the development of new solutions, which may be risky, such as recycling of CRMs. Differences in enforcement of the legislation lead to different requirements for recyclers in different countries.

Export of the applications or components can also be a challenge because it reduces the CRM potential available. It can be estimated that in the Nordic countries the share of illegal export is relatively low.

Removal of the legislative barriers and harmonization of the enforcement of legislation can be seen as enablers of the development and introduction of new recycling solutions leading to higher recovery efficiencies.

Table 19: The bottlenecks of WEEE recycling identified by experts in the project NEW_InnoNet (VGW, 2016, modified) and in the CRM_Nord project workshop

\begin{tabular}{|c|c|c|}
\hline Bottleneck & Description of the bottleneck & Impact of bottleneck \\
\hline \multirow[t]{2}{*}{$\begin{array}{l}\text { Unregistered } \\
\text { treatment of WEEE } \\
\text { within EU and/or } \\
\text { Illegal export of } \\
\text { WEEE out of EU }\end{array}$} & $\begin{array}{l}\text { WEEE can easily end in illegal or non-compliant } \\
\text { treatment due to the leaks in official reporting and } \\
\text { monitoring systems because of unofficial } \\
\text { collection, e.g. with metal scrap. Usually reporting } \\
\text { obligations do not cover these actors and this part } \\
\text { is not reported as WEEE. } \\
\text { Reuse is not reported or is poorly reported. }\end{array}$ & $\begin{array}{l}\text { A part of the total volume is not } \\
\text { available for the PRO-approved } \\
\text { recyclers. } \\
\text { Reduces feasibility of recycling in the } \\
\text { EU. } \\
\text { Risk of treatment in uncontrolled } \\
\text { conditions, leading to environmental } \\
\text { and occupational safety risks as well as } \\
\text { low recovery efficiencies of most of the } \\
\text { materials. } \\
\text { Leads to inconsistencies in reporting. }\end{array}$ \\
\hline & The same as above. & $\begin{array}{l}\text { Loopholes in monitoring of efficiency } \\
\text { and environmental safety of processing. } \\
\text { Leads to inconsistencies in reporting. }\end{array}$ \\
\hline Grey market & $\begin{array}{l}\text { WEEE is stolen from legal collection points and } \\
\text { sold back to the shredder. }\end{array}$ & Leads to inconsistencies in reporting. \\
\hline $\begin{array}{l}\text { Different legislation } \\
\text { and enforcement } \\
\text { between countries }\end{array}$ & $\begin{array}{l}\text { Large differences in the collection systems, } \\
\text { reporting and monitoring requirements, } \\
\text { codification, etc., make it complex to understand } \\
\text { what requirements are for legal operator. }\end{array}$ & $\begin{array}{l}\text { Deficiencies in EU statistics, no } \\
\text { certainty about international market } \\
\text { volume, easier to use substandard } \\
\text { practices in the value chain. }\end{array}$ \\
\hline $\begin{array}{l}\text { Uneven playing field } \\
\text { between PRO and } \\
\text { non-PRO approved }\end{array}$ & $\begin{array}{l}\text { Only PRO-approved recyclers are required to show } \\
\text { that they fulfil all the requirements for PRO- } \\
\text { approved WEEE recyclers. }\end{array}$ & $\begin{array}{l}\text { PRO-approved recyclers have to } \\
\text { maintain approval status with higher } \\
\text { cost. }\end{array}$ \\
\hline
\end{tabular}

recyclers 


\begin{tabular}{|c|c|c|}
\hline Bottleneck & Description of the bottleneck & Impact of bottleneck \\
\hline $\begin{array}{l}\text { Rapidly changing } \\
\text { design of WEEE and } \\
\text { use of materials (look } \\
\text { and feel) }\end{array}$ & $\begin{array}{l}\text { The composition of WEEE is continuously } \\
\text { changing. The fact that it is changing gradually, } \\
\text { containing newer and older designs, increases } \\
\text { inconsistency of composition. }\end{array}$ & $\begin{array}{l}\text { No consistent composition of WEEE for } \\
\text { recycling, so sub-optimized processes } \\
\text { are in place. This leads to smaller } \\
\text { volumes or dilution of valuable } \\
\text { materials. }\end{array}$ \\
\hline $\begin{array}{l}\text { Components are } \\
\text { getting increasingly } \\
\text { complex } \\
\text { WEEE is getting } \\
\text { smaller } \\
\text { More functions per } \\
\text { WEEE appliance }\end{array}$ & $\begin{array}{l}\text { In order to improve efficiency of devices and } \\
\text { reduce material costs, electronics producers aim } \\
\text { for miniaturization and multifunctionality of } \\
\text { components. } \\
\text { Smaller amounts of valuables, increasing amounts } \\
\text { of components and integrated materials and } \\
\text { components difficult to separate are used. }\end{array}$ & $\begin{array}{l}\text { Amount of valuables within WEEE is } \\
\text { decreasing and complexity for recovery } \\
\text { is increasing. } \\
\text { Increasing recycling process } \\
\text { development cost, and no certain } \\
\text { volume expectation. }\end{array}$ \\
\hline $\begin{array}{l}\text { No incentive for } \\
\text { producers to develop } \\
\text { recyclable products }\end{array}$ & $\begin{array}{l}\text { Recyclability is not a priority for product } \\
\text { developers because consumers or legislation do } \\
\text { not emphasize it. New designs may require shift } \\
\text { from well-defined and steadily available materials } \\
\text { and components, which requires time and money } \\
\text { for development and probably optimization } \\
\text { between current priorities and recyclability. }\end{array}$ & $\begin{array}{l}\text { Complexity of recovery is further } \\
\text { increasing. } \\
\text { Valuable materials are lost due to } \\
\text { difficult recovery. } \\
\text { Recycling process development costs } \\
\text { are increasing }\end{array}$ \\
\hline $\begin{array}{l}\text { Lack of stability in the } \\
\text { recycled material } \\
\text { supply (volume - } \\
\text { price - quality) }\end{array}$ & $\begin{array}{l}\text { Due to the changing qualities and quantities of } \\
\text { input material supply and dependence of the } \\
\text { prices of recycled materials on those of virgin } \\
\text { materials, it is difficult to keep the volumes, } \\
\text { qualities and prices of the recycled materials } \\
\text { stable. }\end{array}$ & $\begin{array}{l}\text { In development phase of a new product, } \\
\text { it is not easy to align with recycled } \\
\text { material volumes. }\end{array}$ \\
\hline $\begin{array}{l}\text { Market of recycled } \\
\text { CRMs is not clear }\end{array}$ & $\begin{array}{l}\text { It is not obvious where the market for recycled } \\
\text { CRMs is. EEEs are primarily manufactured in Asia, } \\
\text { and also the production of primary CRMs occurs } \\
\text { there (in China). Thus, it may be difficult to } \\
\text { determine the market and how this will be } \\
\text { profitable. China owns a large share of the } \\
\text { material stock, and can set the market price so } \\
\text { that the price of recycled CRMs will be too high. }\end{array}$ & Recycling is not profitable. \\
\hline $\begin{array}{l}\text { Low and volatile } \\
\text { market value of CRMs }\end{array}$ & $\begin{array}{l}\text { Value of the primary material is too low to increase } \\
\text { the interest of recycling. }\end{array}$ & Recycling is not profitable. \\
\hline
\end{tabular}

\subsection{Rechargeable batteries}

\subsubsection{Current status of recycling}

The treatment and recycling of batteries is regulated under the Directive on Batteries and Accumulators (2006/66/EC). The Directive sets the following minimum requirements:

- For collection: 45 per cent collection rate.

- For treatment: All fluids and acids should be removed.

- For recycling:

- Lead-acid batteries and accumulators: 65 per cent recycling rate.

- Nickel-cadmium batteries and accumulators: 75 per cent recycling rate. 
- Other waste batteries and accumulators: 50 per cent recycling rate.

The implementation of producer responsibility is also required for this product group.

According to the Finnish producer responsibility organization for portable batteries of all types, Recser Oy, in Finland 41 per cent of all discarded portable batteries and accumulators were collected for recycling in 2013. The recycling of ordinary nonrechargeable batteries is a common practice in Finland, but the recycling of rechargeable batteries is not yet so familiar. The household battery and accumulator waste collected in Finland is sent to AkkuSer Oy for recycling. First, the company sorts materials into different fractions according to their chemical composition. In the recycling process, sorted batteries and accumulators are crushed, and valuable metals separated using a so-called Dry Technology dry separation process. With this technology, even go per cent of the materials used in rechargeable batteries can be utilized. For example, discarded mobile phone and laptop batteries are treated in such a way that their materials can be utilized in the manufacturing of new rechargeable batteries. Plastics, cardboard, and other organic materials can be utilized as energy. According to Recser, e.g. the critical metals cobalt and manganese can be separated for utilization from rechargeable nickel-metal hydride ( $\mathrm{NiMH}$ ) and lithium-ion (Li-lon) batteries with their process (Recser Oy 2012, 2014).

According to the Swedish producer responsibility organization El-Kretsen and the Norwegian Batteriretur, the batteries and accumulators collected through their collection systems are first sorted and disassembled and then sent to different locations in Europe for recycling according to their type. The chemical content of the battery determines the recycling method used (Batteriretur, 2016; El-Kretsen, 2016), According to the Finnish battery recycler IsoLogistics, the company is in co-operation with ElKretsen and recycles around 65 per cent of batteries collected from Swedish households. IsoLogistics uses a pyrometallurgical process for the treatment of nickelcadmium ( $\mathrm{NiCd}$ ), NiMH, and Li-Ion batteries (IsoLogistics, 2014). Batteriretur sends the batteries for recycling to the companies presented below (similar to the report of Bakas et al. (2016) only $\mathrm{NiCd}, \mathrm{NiMH}$, and Li-lon batteries are reported here) (Scoullos et al., 2001; SAFT, 2013; Accurec, 2016; Batteriretur, 2016; SNAM, 2016; Nickelhütte, 2016):

- Accurec, Germany:

- A recycler of used rechargeable $\mathrm{NiCd}, \mathrm{NiMH}$, and Li-lon batteries.

- Uses a vacuum thermal recycling (VTR) technique.

- Extracts at least cadmium, nickel, lithium, and cobalt.

- SAFT, Sweden:

- Recycles used rechargeable $\mathrm{NiCd}$ and $\mathrm{NiMH}$ batteries using pyrometallurgical treatment.

- Recovers at least cadmium and nickel. 
- SNAM, France:

- Recycles used rechargeable $\mathrm{NiCd}, \mathrm{NiMH}$, and Li-lon batteries.

- Pyrometallurgical treatment.

- Produces a cobaltferous mixture "MELCO" from recycling of Li-lon batteries (with varying Co content between 10 per cent and 30 per cent).

- Nickelhütte, Germany:

- Used Li-lon batteries are sent to Nickelhütte for recycling.

Based on the information given on the companies' web pages, it can be assumed that recycling of the critical metals cobalt and lithium exists for the batteries collected in Norway. El-Kretsen (2016) gives similar information, and according to them cobalt and lithium are recycled from batteries collected in Sweden.

Information on the Danish recycling practices was not found.

\subsubsection{Bottlenecks}

Most of the general bottlenecks of recycling of CRMs from consumer electronics described in the Section 4.3 are also valid for rechargeable batteries. In addition, more specific information about bottlenecks related to recycling of rechargeable batteries in general is presented in the following:

- In general, it is difficult to attain high collection rates for small items like rechargeable batteries used in consumer applications. However, it can be mentioned that in Sweden, where the battery collection targets are higher than the common EU targets, the battery collection rate is already over 65 per cent.

- There are several types of rechargeable batteries and no standardized marking of battery chemistry, which may make sorting difficult. Different battery types need also different recycling methods. The share of Li-ion batteries is quite significant and it is expected to grow in the short term. Other types include $\mathrm{NiMH}$, lead-acid (mostly used in cars but also in UPS and wheeled mobility systems) and $\mathrm{NiCd}$ batteries. NiCd has been banned in Europe since 2009 (2016 for power tools) and it can be expected that the amounts will decrease (Battery University, 2016).

- A part of the batteries is sold integrated in the products and not designed for easy disassembly. This may decrease the recycling rate of batteries. The share of integrated smartphones has grown quickly in recent years and is now 50-6o per cent (Oehme et al., 2016). Easy disassembly of batteries would also ease the depollution of the main device and decrease risks to workers.

- Depending on the situation, it can be either a benefit or a problem if the electronics recycler separates the batteries.

- Car batteries are not designed for other applications although they can be rebuilt. However, this requires a lot of resources. 
- Risk of self-ignition and explosion of Li-ion batteries during collection if not isolated to prevent short-circuits, crushing, etc. - special actions needed.

- Economic feasibility of recycling:

- Dismantling/reuse of batteries costs more than producing a new one.

- High logistics costs, organization of efficient logistics needed.

- Complex and energy-intensive processing to battery grade. Recycling of lithium can be even significantly more energy-intensive than mining and processing of virgin lithium.

- Due to the costly processing to battery grade (minimum 99.5 per-cent purity, recycling of lithium from Li-ion batteries is currently not economically feasible. Battery recyclers focus currently on cobalt and iron.

- Uncertainty in battery chemistry developments complicates estimation of the feasibility of battery recycling business.

\subsection{Key bottlenecks}

Although there are differences between different product groups, it is easy to see that most of the key bottlenecks of CRM recycling are quite similar. These common bottlenecks are:

- The products and their components are currently complex, making the disassembly and separation of components and metals complex. Currently there are no incentives for manufacturers and designers to develop recyclable products/CRMs.

- The current recycling systems have been developed for recovery of base metals with significant concentrations. They are not optimal for recycling of CRMs because they do not regard the complexity of CRM-containing structures and strategies for recycling specific metals.

- Lack of economically viable industrial-scale technologies for functional recycling and recovery of CRMs from WEEE and ELV.

- Weight-based recycling regulations provide no incentive for recycling of CRMs in low concentrations.

- Knowledge gaps related to the current and future availability of critical and precious raw materials in end-of-life products. 



\section{Policy instruments}

This chapter presents the results of a review of strategic and policy instruments which support the recycling of critical raw materials from the applications studied. More general, advanced instruments targeting improved recycling are also included. The following countries are included in the review: Japan, USA, Germany and the Nordic countries. These countries have been selected because they have advanced policies and strategies for CRMs.

A literature review was conducted to identify and collect the relevant policy instruments from the countries studied. The focus for the literature review was on strategy reports, national policy documents, and project reports on the relevant research programmes. References were identified using keyword searches on critical raw materials, their recycling, and recycling of ELV and WEEE in general. Based on the review, other results of the study and discussions in the project workshop, recommendations on potential policy instruments are presented in Chapter 6 . Workshop discussions on policy instruments are briefly summarized in Appendix 1.

\section{$5.1 \quad$ Sweden}

Although no policy instruments targeting CRMs in particular are in place in the current National Waste Plan, policy instruments on CRMs have been discussed in connection with the upcoming revised National Waste Plan for the period 2018-2023 (Östlund, 2016). Current goals will also be assessed in the new waste plan that will be presented in March 2017 (Swedish Environmental Protection Agency, 2016b).

In the Swedish National Waste Plan of 2012-2017, two milestone targets have been formulated and the focus has been on increasing the reuse and recycling of construction and demolition waste and decreasing food waste (Swedish Environmental Protection Agency, 2016a). The plan addresses issues regarding recycling in general, but currently there are no implemented policy instruments for the recycling of CRMs in particular.

Regarding WEEE, the Swedish National Waste Plan 2012-2017, emphasizes the need to increase the collection, sorting and recycling of WEEE and batteries, especially for small electronic and electric devices, and it has set a goal to increase collection and sorting (Swedish Environmental Protection Agency, 2012). The emphasis on small electronic and electric devices concerns products that often end up in the household bin, e.g. lamps, batteries and toys.

Concerning ELVs, the goal is that all ELVs are sent to an authorized vehicle scrapper and that sanitation and the dismantling of ELVs is enhanced. The goal for recycling of ELV is regulated through the EU ELV Directive and the set goal is as previously mentioned, that at least 95 weight-per cent should be reused or recycled of which no 
more than 10 per cent may be incinerated. Following these goals, the Swedish authorities have, among other measures, developed supervision guidance for ELV scrappers (Swedish Environmental Protection Agency, 2012).

\subsubsection{Sweden's Mineral Strategy}

Sweden also has a national mineral strategy with the aim to increase competitiveness in the Swedish mining and mineral sector. The mineral strategy states that the country's mineral resources should be used sustainably. The strategy identifies five strategic areas of importance (Ministry of Enterprise and Innovation, 2013):

1. A mining and mineral industry in keeping with other industries

(e.g. environmental and cultural industries).

2. Enhancing innovation and growth through dialog and collaboration.

3. Implementing framework conditions and infrastructure for enhanced competitiveness and growth.

4. An innovative mining and mineral sector with a rich knowledge base.

5. An internationally known, active and attractive mining and mineral industry.

Within each strategic area, the mineral strategy formulates several areas of action; in total there are 11 areas of action of which one emphasizes increased resource efficiency. Within this area of action, a goal is to map and analyze the extraction and recycling potential of Swedish metal and mineral assets. This was conducted by the Geological Survey of Sweden together with the Swedish EPA in 2014. Part of the area resource efficiency is to increase the recycling of metals and minerals from end-of-life products (Ministry of Enterprise and Innovation, 2013). The strategy emphasizes increased growth without increasing resource extraction and mentions the importance of the recycling of critical metals.

The Swedish Mineral Strategy mentions the importance of recycling rare minerals in one of its action areas; however, the only action connected to the strategy was to analyze the recycling potential. The Geological Survey of Sweden (2014) propose in their study that the potential states of recycling technologies for the recycling of metals from WEEE need to be developed. They also suggest that an authority be assigned to develop the Swedish metal and mineral statistics with regard to the metals' life cycle. Further, they suggest that there is a need for collaboration within research areas, an enhanced knowledge base of environmental impacts and recycling potentials as well as increased collaboration between industry, academia and authorities to stimulate recycling (Geological Survey of Sweden, 2014). 
The Strategic Innovation Programme for the Swedish Mining and Metal Producing Industry (STRIM) is a collaborative investment by VINNOVA, the Swedish Energy Agency and Formas in a strategic innovation area (STRIM, 2016). The aim of the programme is to encourage international competitiveness and sustainable solutions in the industry. One of the areas of the programme is recycling and metallurgy, which addresses the need for enhanced recycling solutions of metals in Sweden in general, but with no elaborate action plan, related to recycling critical metals from WEEE.

\subsubsection{Policy measures suggested by Growth analysis}

A review of policies for increased recycling of critical metals was conducted by Growth Analysis (2015). Similar to the current report, they studied the policy measures of countries that have the most advanced strategies. Based on the best-practices studied, they listed possible policy measures that could be implemented in order to increase the recycling of critical metals (Growth Analysis, 2015):

- Increased support for demonstration facilities.

- Continued and increased cooperation with EEE companies and their networks (e.g. WEEE 2020 within the European Innovation Partnership).

- Legal demands on mandatory sorting and dismantling of components (e.g. electric engines and printed circuit boards (PCBs)).

- Facilitating recycling by altering regulation within, e.g. the Eco-design Directive.

- Increased support for the development of standards regarding information on critical metals in products. Also, considering demands that such information should be available on certain products of interest.

- Development of existing producer responsibility systems for WEEE and ELVs to promote the recycling of certain critical metals. Also, to examine how certain economic instruments might shift the development further in this direction.

- Increased international cooperation both voluntarily and in the form of developed conventions on products and waste.

- A more elaborate view on governance of global metal-flows is necessary in order to facilitate sustainable supply chains and innovation in terms of resource efficiency.

\subsection{Finland}

The Finnish economy is characterized by its export-oriented high-tech industry that is dependent on CRMs. In contrast to other European countries, Finland is a resource-rich country, its bedrock containing significant known deposits of many critical metals and 
minerals (Finnish Ministry of Employment and the Economy, 2010). Finland has several operational metal mines, and therefore the Finnish policies focus mostly on raw material resources.

Finland has two main strategies, the Minerals Strategy and the Natural Resource Strategy, related to raw materials. The Minerals Strategy is most focused on inorganic materials, but in the Natural Resource Strategy also bio-based and renewable resources are included.

\subsubsection{Natural Resource Strategy}

The Natural Resource Strategy of Finland released by the Finnish Innovation Fund Sitra was issued in 2009. The strategy aims at drawing up a long-term vision of well-being based on the sustainable use of natural resources. It sets goals that support this vision, defines the measures and means that support the goals, and aims at committing key actors to implement development projects (Sitra, 2009).

According to the strategy, the material cycle is one of the areas in which structural changes are required. Finland needs to reduce its dependency on imported raw materials, secure their supply, and make sure that the CRM markets remain also internationally open. The strategy also sets a vision for 2030: "By using natural resources intelligently, Finland thrives and leads the way" and gives four key strategic goals that should be implemented to realize the strategy. The second of these goals emphasizes the need for effective utilization and recycling of the material flows (Sitra, 2009).

\subsubsection{New National Waste Plan}

Although there are currently no strategic or policy instruments that support the recycling of critical raw materials at a national level, the situation may well change in the near future. The New National Waste Plan (VALTSU), covering the years 20172022, is currently in the drafting phase (situation in January 2017), and the draft contains several targets for WEEE. Regarding CRMs, the waste plan draft aims at more effective recovery and recycling of critical raw materials and other valuable materials in WEEE. Measures to target this goal include increased financing for R\&D projects aiming to recover critical and other valuable raw materials and assess their potential. In the long term, recycling targets should also be tied down to the value, rarity or harmfulness of the material or combinations of these features, instead of just counting the volumes (Draft of the New National Waste Plan, 14.12.2016).

In the draft, the other targets for WEEE include: diminishing the share of WEEE in MSW and increasing its recycling, removal of harmful substances of WEEE from circulation, and intensifying the supervision of WEEE exports from country to country (Draft of the New National Waste Plan, 14.12.2016). 


\subsection{Norway}

\subsubsection{Strategy for the Mineral Industry}

Norway is one of the most important raw materials producers in Europe, and it has strategic instruments also focused on the mineral industry. The most important strategy in this field is the Strategy for the Mineral Industry that was issued in 2013 by the Ministry of Trade and Industry. The main objectives of the strategy are:

1. The mineral industry of Norway should be profitable, value-generative, and have good growth.

2. The mineral industry should be amongst the most environmentally friendly ones globally, and it should also actively seek future-oriented solutions.

3. Predictable and efficient procedures and administration should guide regulating activities at national, regional and municipal levels.

4. Industrial growth should be heightened through prioritizing the mapping of mineral deposits, access to information about national mineral resources, better planning of resources, continued development of the mineral agencies and investment into knowledge and proficient labour. (Ministry of Trade and Industry, 2013).

A number of policies to reach these goals are proposed in the strategy. In addition, the importance of recycling of metals from WEEE and the supply risk associated with special metals used in electronics are mentioned in the strategy, but only at quite a general level (Ministry of Trade and Industry, 2013).

\subsubsection{A National Waste Strategy}

In 2013 the Norwegian Ministry of the Environment published the National Waste Strategy. Among many other topics, also the collection and recycling of WEEE are discussed, and the strategy suggests, e.g. increased collection targets for WEEE. Although the collection rates of WEEE in Norway are among the highest in Europe, there is still potential to enhance especially the collection of certain types of discarded small electronics, such as mobile phones and compact fluorescent lamps containing rare earth and other valuable elements, whose recycling would be particularly useful. There is potential to increase the utilization of rare earth resources, but at first this will require more knowledge about the contents of metals in different sources and the barriers of increased recycling (Ministry of the Environment, 2013).

The collection of small electronics is challenging as their small size allows them to be discarded along with the household waste, or to be stored in homes. It is expected that currently only about third of all small electronics waste is collected and recycled. If the collection rates do not significantly improve, it is possible to contribute remedies such as a possible deposit scheme for small electronics to contribute to the situation. 
The industry has a responsibility to take actions, which improve the collection level, and they have started measures to achieve this goal. For example, the four major supermarket chains have reported their measures to increase the collection of used light bulbs (Ministry of the Environment, 2013).

The strategy also highlights some instruments targeting better collection and recycling of WEEE in general:

- There is a need to ensure that all WEEE ends up being properly treated, as in recent years' some serious discrepancies in the treatment of discarded electronics have been reported both nationally and internationally.

- In addition, it should be ensured that WEEE exported from Norway for reuse or recycling receives proper treatment. Thus, it should be considered whether to set clearer documentation requirements for operators exporting WEEE. The EU regulations state that used EEE should be tested before it is exported, and there is a need to establish testing criteria.

- To be able to follow up the recycling scheme better, improved statistics on WEEE generation (especially concerning small electronics) is needed to be able to generate information on the collection rates and to gain more knowledge on composition of WEEE.

- In connection with the implementation of the changes of the WEEE Directive in Norwegian regulations, also changes resulting from Norway's own experiences with regulations will be considered.

- According to the Norwegian certification scheme, a neutral third party considers that the recycling companies comply with the regulatory requirements.

Experience has shown that this arrangement does not work optimally, and therefore there is a need to consider improvement of this scheme and the requirements of certification.

- It is of high priority that companies fulfil the requirements concerning waste reporting, collection and treatment, and these activities are being increasingly supervised. (Ministry of the Environment, 2013).

\subsection{Denmark}

\subsubsection{Strategy for the Arctic 2011-2020}

Greenland is known to have potential deposits containing rare earth elements, and it is anticipated that Greenland could become a medium-sized REE supplier in the future. In 2011, the Danish Ministry of Foreign Affairs launched its Strategy for the Arctic 2011-2020, which aims to contribute to sustainable growth and social sustainability by developing the Arctic region. The strategy also has a link to critical raw materials, as it gives an overview of the current critical minerals, presents minerals that may become 
critical in the long run, and describes opportunities to mine them in Greenland (Ministry of Foreign Affairs, 2011; Eckartz et al., 2015). However, the recovery or recycling of CRMs is not discussed in the strategy (Ministry of Foreign Affairs, 2011).

\subsubsection{Resource Strategy for Waste Management}

Generally speaking, Denmark has a strategy related to recycling, as in 2013 the Danish Ministry of the Environment released a strategy called "Denmark without waste. Recycle more-incinerate less". The strategy is focused on household wastes and stems from the vision of the Danish government to protect its resources and materials by reducing the role of waste incineration and enhancing recycling. As a result of these actions, more materials will be sent back into the economic cycle, being also environmentally beneficial (The Danish Government, 2013).

In the strategy, six measures are given of which one is entitled "More recycling of materials from waste electronic equipment and shredder waste" and has links to critical raw materials. According to the strategy, the recycling rate for rare earth elements is only 1 per cent in Denmark. The main reasons for the low recycling are the current collection and processing practices, and the high costs of recovering these metals. However, if the global market prices for REEs continue to rise, the recovery of even small amounts of these metals from electronics may become profitable in the long term. In addition, technological development of the pre-treatment and the separation processes could increase the recycling of rare earth elements and other valuable metals. The enhanced separate collection and recycling of mobile phones, fluorescent lamps and digital cameras are especially emphasized due to their greatest recycling potentials and high content of hazardous substances (The Danish Government, 2013).

The following initiatives are suggested in the strategy:

- Regarding the increased collection of WEEE, a partnership between relevant players, e.g. manufacturers, municipalities and registered collectors should be established, which focuses on identifying suitable fractions and product categories, and proposes initiatives, among other things.

- A partnership should be established also to increase the recycling and reuse of end-of-life electric and hybrid vehicles to the same extent as other vehicle types.

- A possibility for a voluntary collection scheme of mobile phones should be investigated.

- Strategic (preferably international) collaboration in WEEE recycling, which includes funding for the development and demonstration of new pre-treatment technologies.

- Participation in EU-level work on the technical foundation for setting WEEE treatment standards aimed at ensuring resource exploitation.

- For shredder residue, preparation of life-cycle and socio-economic analyses. (The Danish Government, 2013). 
The following effects are expected in 2018:

- for WEEE: total collection rate of 65 per cent, for households 75 per cent.

- for portable batteries: total collection rate of 55 per cent.

- for shredder residue: 70 per cent recovery rate, 10 per cent recycled at a minimum, 30 per cent landfilled at most. (The Danish Government, 2013).

\subsubsection{Action Plan to Promote Eco-Efficient Technology 2010-2011}

Prior to the resource strategy for waste management in 2010, the Danish Ministry of the Environment released the "Action plan for promoting eco-efficient technology 2010-2011" focusing on the development of environmental technologies that lead to economic growth and social development which do not conflict with the environment. No direct link to raw materials exists, but the importance of recycling in general is highlighted. The action plan also observes that there are many raw materials with limited supply, and emphasizes the importance of reducing the use of these resources, their recycling, and not diminishing the quality of these resources when put back into circulation (The Danish Government, 2010).

\subsection{Germany}

\subsubsection{German Resource Efficiency Programme}

In Germany, improved recovery of precious and critical materials from end-of-life vehicles, WEEE and other waste streams are included in the objectives and action areas of the German Resource Efficiency Programme (BMUB, 2016). It defines the principles, strategies and actions for sustainable use and conservation of natural resources. The aims include securing the sustainable supply of raw materials, enhanced resource-efficiency of production, less resource-intensive production and consumption, and building resource efficient circular economy. The programme was adopted in 2012 and updated in 2016. It will be updated every fourth year. The key objectives, targets and action areas related to critical and precious raw materials are presented in the following.

The CRM-related objectives of the programme include:

- Improvement of ELV recycling - separation of automotive electronic components (primarily circuit boards and rare earth magnets) from ELVs before shredding.

- Target: Largest possible proportion of automotive electronics removed from each ELV by 2020.

- Increase of WEEE collection and recycling. 
- Target: Permanent increase of WEEE collection rate to 65 per cent by 2019 (in conformity with the WEEE Directive).

- Development of the strategy for and intensification of research on substitution critical raw materials. (BMUB, 2016).

The following action areas of the programme refer to critical raw materials (BMUB, 2016; Kohlmayer, 2016):

- Reducing dependence on critical resources by substitution by investing in research on substitution and developing a strategy for substitution of critical materials in environmental and other technologies. Due consideration of remanufacturing is also mentioned.

- Strengthening producer responsibility:

- Assessment of whether EPR can be extended to additional product groups. Wind turbines are mentioned as an example in need of a high-quality recycling system in near future. EPR systems developed on a voluntary basis are mentioned as one potential alternative.

- Improving WEEE collection.

- Improving WEEE treatment and recycling by new secondary legislation under the German transposition of the WEEE directive on requirements for highquality recycling.

- Increasing the collection and recycling of precious and rare metals:

- The policy approach is to develop innovative collection schemes based on compiling a register of waste streams with similar metal content (waste stream pooling). One crucial issue is to establish new collection networks because many waste streams with critical metals are new waste streams and contain only small quantities of rare and critical metals.

- Another crucial issue is to provide the necessary information for treatment and recycling. It is planned to bring together the relevant actors (manufacturers and recyclers) to resolve information deficits, e.g. on complex products, and about the recyclable content of metals in the products, etc. (BMUB, 2016; Kohlmayer, 2016).

\subsubsection{Actions performed}

Sufficient data bases on CRMs available for recycling, barriers of recycling and realistically applicable recycling potential are essential when identifying the best strategies and measures. Recycling and recovery of precious and critical metals during recent years has been subject to several studies performed by consultants on behalf of the German Federal Environment Agency (UBA). The motivation for the selection of metals was that recycling precious metals is important from the viewpoint of environmental protection, and the recycling of gallium, indium, platinum group metals, 
and rare earth elements are important due to the availability risks. The main aims of the studies have been to analyze the 2020 CRM potential of the specific waste streams, whose proportion is already recycled and which might be recycled in the best-case scenario. The obstacles that hamper efficient recycling have also been identified (Kohlmayer, 2016). The studies included:

- RePro, which aimed to identify which metals used in electronics are relevant from the viewpoint of resource saving and to analyze the mass flows, potentials and losses of CRMs in the selected applications. Measures and instruments for governance and management of the WEEE were also identified and evaluated. The project focused on 30 electronics applications relevant for resource consumption and the following metals: gold, silver, palladium, cobalt, gallium, indium, tin, zinc, manganese and rare earth elements.

- Restra, which studied the recycling potential of strategic metals aimed at analysis of waste material flows and waste removal chain in order to identify relevant wastes and develop suggestions on potential actions for development of the recycling chain. The studied applications included wind energy plants, electric bicycles, photovoltaics, LEDs, catalysts, medical devices, optical applications and metal polishers, among others.

- ORKAM, which focused on the role of CRMs in components - dismantling components determined by profitability, and the dismantling of vehicle electronics, such as electric motors, sensors, and steering apparatus.

Based on the studies, approaches and recommendations have been developed to better reclaim the metals from end-of-life vehicles, WEEE and other waste streams. Specific focus areas have been vehicle electronics and rare earth magnets. It was also found that the main justification for the recycling of precious and critical metals can be different: for precious metals (gold, palladium) the key motivation is reduction of environmental impacts, and for CRMs a dual approach for improving the recovery of precious and critical materials is proposed (Kohlmayer, 2016):

1. Development and implementation of large-scale recycling facilities for critical metals, also requiring support for technology development.

2. At the same time provide sufficient input into these facilities by better collection and separation of the metals (metal components) from the waste streams.

(Kohlmayer, 2016).

The opinion of the German Federal Environment Agency (UBA) is that it is essential to combine treatment requirements (e.g. dismantling/separation obligations) with complementing design requirements (e.g. easy disassembly) under the Eco-design Directive. 


\subsubsection{Current and planned actions of Umweltbundesamt}

In February 2016, UBA started a process to develop "WEEE treatment ordinance". All relevant stakeholders were involved in six working groups (printed circuit boards and other resource-relevant components, TV sets and monitors, photovoltaic panels, plastics, depollution, refrigerators) (Kohlmayer, 2016). The objective is to develop technical requirements concerning the depollution of hazardous materials and the separation and recycling of valuable and critical raw materials.

Also discussed is the development of a similar ordinance with collection, separation, treatment and/or information requirements for applications of critical metals, which are not in the scope of the WEEE or ELV Directives (e.g. for magnet applications, environmental catalysts).

In the field of ELV recycling, the following potential measures are discussed (Kohlmayer 2016):

- To improve the collection and logistics of separated vehicle electronics.

- Better information flows.

- Potential for establishing a dismantling requirement in Annex I of the ELV Directive (Kohlmayer 2016).

Some topics that require further study have been identified as well (Kohlmayer 2016), and these include:

- Pooling of waste streams from different sources for more efficient collection, logistics and recycling.

- Question of interim storage until large-scale recycling facilities are available.

- How to improve the information flows on the content of precious and critical metals in products/waste streams (Kohlmayer, 2016).

\subsection{USA}

The secure supply of raw materials has been an important topic in US policymaking for a long time, and also the term critical materials was coined in legislation as early as in the late 1930 (Barteková \& Kemp, 2016). The key strategic reports available are the Critical Materials Strategy published by the US Department of Energy (DOE) in 2010 and an updated version of the report published in 2011. An update of the strategy will be released in 2017 (DOE, 2016), which takes into account the results of the analyses made after 2011 and changes in the raw material supply and demand. 


\subsubsection{Critical Raw Material Strategy}

The Critical Raw Materials Strategy (2010) and its updated version (2011) were compiled by the US Department of Energy. The strategy focuses on energy applications (wind turbines, electric vehicles, photovoltaic cells and lighting) and especially, but not only on rare earth elements as several other metals are also included. As such, the strategy is not all-inclusive, but because the approach on criticality is holistic and there are no wider national strategies so far, it is usually referred to when discussing US strategic approaches related to CRMs.

The three main pillars of the DOE's strategy are:

1. Diversifying the supply of critical materials for US industry to mitigate supply risks.

2. Developing material and technology substitutes for critical materials.

3. Promoting recycling, reuse and more efficient use of these materials in order to significantly lower global demand for critical materials (US Department of Energy, 2016).

The three pillars are further expanded to eight action points. Regarding recycling and reuse, the most important are research and development, and promoting policies towards end-of-life recycling. In addition, information gathering and cooperation with international partners present the same challenges related to all three pillars.

R\&D for recycling, reuse, design for recycling and more efficient use of CRMs have been highlighted in the strategy as a means of increasing the supply. This relates to all three pillars, but especially to recycling and substitution. In 2013, the DOE established the Critical Materials Institute (CMI) to lead and coordinate research activities, which is led by the state-owned Ames Laboratory working with several partner organizations, including national laboratories, academia and industry. The CMI aims for:

- Development of economically viable technologies for efficient material use in manufacturing, recycling, and reuse.

- Enabling new sources of CRMs, including both primary materials and by-products and improvement of the economics of processing existing sources.

- Development of substitutes.

- Development of tools supporting the basic science needs of the other focus areas.

- Development of strategies to assess and address environmental sustainability and social and economic viability of the solutions CMI develops.

Although many of the CMI's research efforts have focused on developing substitutes, also the recovery of CRMs from waste has been an important topic. The focus areas are REEE recovery from permanent magnets and lighting, but there are also research activities on recycling electronics components (such as permanent magnets) and materials. The approach in the projects is mainly technical and strongly aims for 
industrial applications. For example, different kinds of extraction and separation solutions (supercritical and solvent extraction, electro- and pyrometallurgical and biological) are developed (Peterson \& Jones, 2014). One example is technology for identification and robotic disassembly of permanent magnets in hard drives, which is currently tested on industrial scale (Oak Ridge National Laboratory, 2016). The targets include also understanding the collection mechanisms and techno-economics of recycling. Here the aim is to develop a set of models to provide insight into increasing the efficiency and economic viability of materials collection and processing.

Research cooperation with other countries in the same situation as the USA, especially Japan and the EU, is considered important because it helps to optimize resources and accelerate R\&D. One way of cooperation is organizing workshops, conferences, and committee meetings, etc. Some examples are the Annual Trilateral US-EU-Japan Conference on Critical Materials and the US-Japan Roundtable on Rare Earth Elements Research and Development. Recycling of CRMs is also one of the research topics of the Center for Resource Recovery and Recycling, which is an alliance of US, EU and Japanese universities (Colorado School of Mines, KU Leuven, University of Tokyo and Worcester Polytechnic Institute).

\subsubsection{Recycling of e-waste}

The total amount of e-waste in the USA in 2010 was about 3.4 million tonnes (Johnson, 2014). The amounts are smaller than in Europe, because in the USA the definition of ewaste contains usually only IT and consumer electronics, including batteries. There may be differences in the numbers presented by different sources due to the lack of common national definition (Johnson, 2014). A lack of data on domestic and transboundary material flows has been identified as a factor hindering recycling. According to the EPA, the recycling rate was 20 per cent in 2010 and 29 per cent in 2012 (Johnson, 2014). Another study on national and transboundary flows of computers and monitors proposes that 3-47 per cent of the total quantity in 2010 was exported (Miller et al., 2016). According to Namias (2013), e-waste is pre-processed domestically, and metals, plastics, printed circuit boards, etc. are sent overseas for end-processing, including the recovery of precious and special metals. It was estimated that over 50 per cent of e-waste collected is sent to Europe, Canada and developing countries for processing. The export of pre-processed materials and components was not included in the survey on transboundary flows. There is no representative data on the recovery of CRMs from WEEE in the USA, but it seems that recovery rates are low.

One of the key challenges of recycling of CRMs is that the USA lacks national regulation, which would encourage the private sector to collect and recycle end-of-life products and enforce collection and recycling targets (Namias, 2013; Barteková \& Kemp, 2016). There have been some national legislative initiatives, but they have not been passed so far. In addition to legislation, voluntary agreements are seen as an important means to improve recycling.

On the state level, 25 states have legislation establishing an electronic waste recycling programme. These states cover about 34 per cent of the US population. 
Twenty-four states use extended producer responsibility systems to finance the recycling activities. Administrative costs are paid by state agencies and manufacturers (Linnel, 2014). In California, consumers pay retailers a USD 2-5 (originally USD 5-8) fee which is deposited in the state-wide recycling fund. There are differences between states in device types and waste producers (only household, governmental organizations, small businesses) covered by the legislation.

In the 25 states without WEEE legislation, there are also recycling activities organized by manufacturers or retailers offering recycling programs or events, by local authorities (Linnel, 2014).

The United States Environmental Protection Agency has also compiled the National Strategy for Electronics Stewardship. In general, the approach is to focus especially on federal electronics and to foster electronics stewardship through a combination of legal requirements and consensus-driven initiatives. The key targets and actions proposed by the EPA are (Feldt, 2013; Gallo, 2013):

- Build incentives for greener electronics design and innovation:

- Convene multi-stakeholder groups to design greener electronics products that have reduced environmental impacts across the lifecycle and are easier to recycle.

- Launch a series of prize competitions to spur innovations in technology and design across the lifecycle of electronics.

- Develop new standards for Electronics Procurement Environmental Assessment Tool (EPEAT).

- Support research into the toxicology, exposure pathways, and recovery methodologies of the rare earth elements used in electronics and during their recycling, remanufacturing and disposal.

- Optimize the systems for priority devices.

- Ensure that the federal government leads by example:

- Regulation for Government-wide Electronics Management, which requires federal government to use certified electronics recyclers and bans landfill disposal of Federal electronics (Johnson, 2014).

- Improve tracking of used federal equipment throughout the lifecycle.

- Encourage electronics manufacturers to expand their product take-back programmes in federal electronics purchase, rental and service contracts.

- More effectively direct federal government spending on electronics toward green products through procurement.

- Increase safe and effective management and handling of used electronics in the United States:

- The EPA encourages all electronics recyclers to be certified by an accredited, independent third-party auditor. There are two certification standards. 
- Voluntary partnerships (Sustainable Materials Management Electronics Challenge) with the electronics industry and retailers to increase the collection of used electronics that are safely managed by certified recyclers.

- Provide guidance to electronics recycling employers on providing facilities that offer safe and healthy working environments.

- Establish approaches to gather, track, and provide public access to information on the quantities and movement of used electronics within the US.

- Reduce harm from US exports of e-waste and improve safe handling of used electronics in developing countries:

- Improve information on trade flows and handling of used electronics, and share data with federal and international agencies (Miller et al., 2016).

- Provide technical assistance and establish partnerships with developing countries to better manage used electronics.

- Work with exporters to explore how to incentivize and promote the safe handling of remanufactured, recycled, and used electronics at home and abroad.

- Support ratification of the Basel Convention on the Control of Transboundary Movements of Hazardous Wastes and their Disposal (Feldt, 2013; Gallo, 2013).

On a national level, the National Center for Electronics Recycling is dedicated to the development and enhancement of a national infrastructure for the recycling of used electronics in the US. It conducts research and runs collection programs.

\subsubsection{End-of-life vehicles}

End-of-life vehicle recycling in the USA is totally market driven. According to the EPA and the Automotive Recyclers Association, the ELV recycling rates in the USA are high (ARA, 2016). The focus of the ARA members is the disassembly and reuse of car parts. Non-reusable parts are either recycled by the member companies themselves or sent to specific shredder companies. The car recycling companies are mainly small. The authorities focus mostly on the improvement of environmental compliance of companies, such as safe disassembly and treatment of toxic and hazardous compounds (United States Environmental Protection Agency, 2016). There are companies that recycle used catalysts, but it was not possible to find more information about CRM recycling from cars. 


\subsection{Japan}

Due to its wide-ranging electronics and automotive industries, the economy of Japan is outstandingly dependent on rare earth metals. Traditionally, Japan has been especially dependent on import of REEs from China. To reduce this dependency, the Government of Japan has e.g. allocated an extra 730 million EUR (as per 2015 exchange rates) from 2010's supplementary budget for securing REEs and other natural resources (Barteková \& Kemp, 2016).

\subsubsection{Strategy for Ensuring Stable Supplies of Rare Metals}

In 2009, Japan's Ministry of Economy, Trade and Industry (METI) released the Strategy for Ensuring Stable Supplies of Rare Metals. The main objective of the strategy is to sustain Japan's economic security by ensuring stable CRM supplies to Japan and to strengthen the manufacturing industry's competitiveness (METI, 2009; cited by DEFRA, 2012; Barteková \& Kemp, 2016).

The strategy is built on four pillars:

1. Securing overseas resources: Japan should continue and strengthen the effort to invest in mining developments overseas (DEFRA, 2012). Strategic resource diplomacy is the foundation of the supply diversification strategy. Bilateral and multilateral trade agreements should be concluded to simplify technology transfer, infrastructure development as well as energy cooperation. These agreements would secure Japan's access to raw materials and also benefit the development objectives of resource-rich countries. In addition, common exploration instigations with resource-rich countries are close to the strategy. Besides resource-rich countries, Japan also collaborates with the EU and the United States through the regular Trilateral Conference on Critical Materials (Barteková \& Kemp, 2016).

2. Recycling of scrap and end-of-life products: Better recycling is achieved by enhanced utilization of existing recycling systems and developing new technologies if necessary. Recognizing the challenges concerning recycling the CRMs in certain products, the strategy calls for promoting R\&D in recycling technology (DEFRA, 2012; Barteková \& Kemp, 2016). As an example of the recycling of CRMs, e.g. recycling processes to recover REEs from NiMH batteries, and magnets used in air conditioners, hard disk drive motors, and other compressors, are being developed by Japanese companies (Barteková \& Kemp, 2016).

3. Development and promoting the use of alternative materials: The strategy aims at promoting government-industry-university partnerships and investing in R\&D activities that are especially focused on nanotechnology and lowering REE usage in permanent magnets. (DEFRA, 2012; Barteková \& Kemp, 2016).

4. Stockpiling of strategic materials: Japan stockpiles some important rare metals in order to protect itself against short-term supply risks (DEFRA, 2012; Barteková \& 
Kemp, 2016). According to APS/MRS (2011, cited by DEFRA, 2012), seven CRMs are stockpiled by Japan to cover 42 days of consumption. In addition, it has private stocks to cover 18 days of consumption.

According to Eckartz et al. (2015) there are at least two national programmes that implement the strategy.

\subsubsection{Other instruments}

In addition, guidelines for the government to follow when securing natural resources (also including CRMs) are being published (DEFRA, 2012; Eckartz et al. 2015). In these guidelines, substitution is emphasized parallel to the four pillars of the Strategy for Ensuring Stable Supplies of Rare Metals. Guidelines also presume the participation of the Japanese government in negotiations between domestic companies that are planning to acquire exploration / development interests abroad, and the government or state-run companies of the target country, to make sure that the opposing side acts according to international contract rules. Japanese government should also support domestic companies investing in international projects in a suitable manner according to the project type (DEFRA, 2012; Eckartz et al., 2015).

In the Strategic Energy Plan that was released in 2007 and revised in 2010 and 2014, a development of new recycling technologies for rare metals was presented as one way to secure their stable supply. In addition to this, the substitution of rare metals, reducing their use of in products, and stockpiling certain rare metals were emphasized (METI, 2014).

The Japanese government is said to be "the global leader in awareness of raw material dependency" and the hierarchy of $3 \mathrm{R}^{\prime} \mathrm{s}$ (reduce, reuse and recycle) is implemented via many Japanese policy documents. Japan has also implemented several national research programmes focusing on, e.g. substitution / reducing the usage of CRMs (Eckartz et al., 2015). 



\section{Conclusions}

This study aims to identify the of opportunities and potential administrative instruments to enhance the recycling of CRMs in the Nordic countries, and thus to support development of Nordic strategies on CRM recycling. Information about the quantities of critical and precious raw materials in selected end-of-life product groups was collected in order to obtain indications about the recycling potential in the Nordic countries. Together with the analysis of the bottlenecks of recycling and identification of potential policy instruments, the data was used as a basis of recommendations on key measures to enhance sustainable recycling of CRMs.

\subsection{The availability and value of CRMs in selected product groups}

From the viewpoint of development of Nordic recycling strategies and systems, the availability and estimated value of the minor raw materials in different end-of-life products is an important factor. However, the feasibility is dependent on many other factors, such as the availability, efficiency and cost of recycling solutions, current and future market of the raw material, and product development, etc. Within the limits of this project, it has not been possible to make a comprehensive analysis of the economy and sustainability of processing or future development of products.

The estimated total quantities of the most significant CRMs in the following product groups: ELVs, lighting products, mobile phones, PCs, laptops and notebooks, flat screen TVs and rechargeable batteries are summarized in Table 20. The metals in the table were selected based on their relatively high quantities and economic value. The economic values have been calculated based on the prices of primary metals at the end of the year 2016 (www.infomine.com). The table gives only indications about the potential because CRMs can be found in many other product groups. 
Table 20: Available quantities of critical and precious metals in the target product groups in the Nordic countries, and their estimated total value based on prices of primary metals at the end of 2016

\begin{tabular}{|c|c|c|c|c|c|c|}
\hline \multirow[t]{2}{*}{ Metal } & \multicolumn{4}{|c|}{ Quantity in 2015 (in tonnes) } & \multirow{2}{*}{$\begin{array}{r}\text { Price, } \\
\text { (EUR/kg) }\end{array}$} & \multirow{2}{*}{$\begin{array}{r}\text { Total value, } \\
\text { (M EUR) }\end{array}$} \\
\hline & ELV & Lighting & $\begin{array}{r}\text { Electronics and } \\
\text { batteries }\end{array}$ & Total & & \\
\hline Cobalt & 15.5 & & 736 & 751.5 & 33 & 25 \\
\hline Dysprosium & 6.4 & & n.a & 6.4 & 326 & 2.1 \\
\hline Gallium & & 0.02 & 8 & 8 & 144 & 1.2 \\
\hline Gold & 2.8 & & 4.2 & 7.0 & 35,700 & 250 \\
\hline Lithium & 2.6 & & 253 & 256 & 6.9 & 1.8 \\
\hline Magnesium & 2,800 & & & 2,800 & 2.1 & 5.9 \\
\hline Manganese & 3,000 & & & 3,000 & 1.7 & 4.9 \\
\hline Molybdenum & 260 & & & 260 & 14.3 & 3.7 \\
\hline Neodymium & $55 \cdot 5$ & & n.a & $55 \cdot 5$ & 56 & 3.1 \\
\hline Niobium & $35 \cdot 4$ & & & $35 \cdot 4$ & 36 & 1.3 \\
\hline Palladium & 0.62 & & 0.8 & 1.4 & 21,800 & 31 \\
\hline Platinum & 3.1 & & n.a & 3.1 & 29,200 & 91 \\
\hline Rhodium & 4.6 & & n.a & 4.6 & 25,600 & 118 \\
\hline Silver & 8.1 & & 8 & 16.1 & 505 & 8.1 \\
\hline Tantalum & 3.9 & & 8 & 11.9 & 230 & 2.7 \\
\hline Terbium & 2.3 & 3 & n.a & 5.3 & 512 & 2.6 \\
\hline Yttrium & 0.06 & 35 & n.a & 35.0 & 33 & 1.1 \\
\hline
\end{tabular}

Relatively significant amounts of CRMs and precious metals are available, for example, in the following product groups:

- Other electric and electronics products.

- Transport vehicles: trucks, buses, electric bikes, airplanes, boats, etc.

- Low carbon energy technologies and energy systems: wind turbines, solar panels.

- Industrial application: industrial motors, electric tools, control systems, alloys.

- Medical applications.

The table presents estimates of rare earth element amounts in ELVs and lighting waste. For example, $\mathrm{Nd}$ and Dy containing permanent magnets can be found also in consumer electronics as well as in several other product groups. Based on the literature sources, their total quantities in EoL products are significantly larger than the quantities presented in Table 20.

CRMs are scattered amongst many different applications and products under different legislation and subject to different collection and treatment systems. Although individual critical materials are used in many different applications, most of them are concentrated in certain components. Assembled printed circuit boards and their components, permanent magnets, screens and LEDs can be mentioned as 
examples. However, one should remember that, for example, PCBs contain different components and CRMs depending on the requirements of the application.

\subsection{Key challenges}

The current recycling systems are planned and optimized for recycling base metals in large amounts. Therefore, they are not optimal for the recovery of CRMs, which are typically present in low concentrations in complex structures. Although a part of the most valuable precious or critical metals is recovered, the losses in different collection and processing stages are quite high. The same applies to legislation, which is based on quantitative recycling targets and does not give any incentives for recycling of the raw materials in small quantities or design of recyclable and reusable products. There are also other legal provisions, which in broad outlines may be suitable for the prevention of environmental impacts, but hinder efficient recycling of minor materials.

New incentives and new kinds of recycling strategies are needed to enable the economically viable recycling of critical and precious metals. The actions should enhance elimination or reduction of both the above-mentioned and following bottlenecks:

- Product design hampering disassembly and separation of CRM containing components.

- Lack of economically viable industrial-scale recycling solutions for processing of minor metals. There may be relatively advanced technology solutions, which have been tested on laboratory and pilot scale. Due to the uncertainties related to the economy, raw material availability and future market of the products, the technological solutions have not been demonstrated or introduced on a larger scale.

- Data gaps related to current and future availability of CRMs in different end-of-life products. In addition to the total availability, cross-linking data about the same type of components containing the same materials are essential for planning the recycling solutions.

Most of the bottlenecks and their solutions are closely linked to each other. For example, design for recycling and easy disassembly enables more efficient separation of different materials for recycling. Integrated and system-level solutions are essential to achieve economies of scale.

\subsection{Recommendations}

Due to the complexity of the question and diverse barriers, there is no single solution to the challenges of improved recycling. In order to promote recycling of critical and precious raw materials in the Nordic countries, the following actions are proposed: 
1. Improve knowledge and data management

Lack of knowledge about CRM potential and its development in different EoL products, as well as lack of more detailed information about available quantities and separability of the same kind of components in different waste flows complicates evaluation of feasibility of different incentives and technological and system-level solutions. The same applies to state-of-the art and economies of potential solutions. The uncertainties hinder decision making on both the administration and company levels. The existing data is scattered, there are no updatable databases or they are not available for all actors in the value chain. There are also significant differences in reliability of statistics between different countries.

The problems are common to all the Nordic countries and even on a wider European level. The Nordic countries could create common partnership(s) of different actors (actors in product/recycling value chains, researchers and authorities) to resolve information deficits and to discuss how to influence systems for better data availability on a European level. Potential measures include, e.g. labelling of components, registers or databases available for all partners in the value chain and best-practice guidance.

2. Develop and evaluate new recycling strategies enabling more efficient and economic recovery of CRMs

New recycling strategies suitable for efficient recovery of CRMs and precious metals need to be developed to prevent diffusion of these metals to different product and residual flows during the pretreatment and metallurgical recovery stages. Dismantling and pooling of selected components in the pretreatment stage (in mechanical treatment facilities) before shredding and collection of the same type of components in specialized facilities could be one solution to be evaluated. Due to the small amounts, the raw material base of the specialized facilities has to be significantly wider than one country. However, the facilities could be located also in the Nordic countries. Implementation of this kind of strategy requires careful evaluation of the economic, environmental and technical feasibility, legislative barriers and measures to improve preconditions of the potential systemic and technological solutions, for example on the Nordic level.

3. Support $R \& D$ and demonstration

Due to the complexity of the problem, R\&D of systemic and technical solutions is still needed. Adoption of the developed technological solutions by industry is a specific challenge. In this case, this is even more challenging than usual due to the uncertainties linked to the feasibility of the investment. Economic support for demonstration facilities is a potential incentive for enhancing the implementation of technologies. 
4. Strengthen Nordic influence on the development of European legislation and standards

To improve the preconditions of CRM recycling, the Nordic countries could in collaboration evaluate which European-level legislative and standardization measures are, from the Nordic point of view, most important and strengthen their influence on these measures. They could include:

- Development of recycling targets that instead of being weight-based take into account environmental and economic benefits and/or other important European level targets. Material-specific recycling targets are also a potential opportunity to enhance the recycling of minor metals.

- Development of eco-design standards/legislation towards design for disassembly, recyclability and reusability. 



\section{References}

AccuRec (2016). Technologies. Retrieved 7th December 2016, from: http://www.accurec.de/treatment-and-recycling/technologies

Andersson, M. (2016). Innovating recycling of end-of-life cars. Licentiate of engineering. Chalmers University of Technology. Gothenburg, Sweden 2016. Technical report no 2016:7.

Andersson, M., Ljunggren Soderman, M. \& Sanden, B. A. (2016). Are scarce metals in cars functionally recycled? Waste Management, in press. http://dx.doi.org/10.1016/j.wasman.2016.06.031

Angerer, G., Erdmann, L., Marscheider-Weidemann, F., Scharp, M., Lüllmann, A., Handke, V., \& Marwede, M. (2009). Rohstoffe für Zukunftstechnologien. Einfluss des branchenspezifischen Rohstoffbedarfs in rohstoffintensiven Zukunftstechnologien auf die zukünftige Rohstoffnachfrage. Stuttgart: Fraunhofer IRB Verlag. 2. Auflage, ISBN 978-3-8396-0014-6.

ARN (2016). Analysis of the End of Life Vehicle value chain. D2.3 Report summarising the analysis of the End of Life Vehicle value chain. NEW_InnoNet 2016/04/05.

Auto Alliance (2016). Automotive recycling industry. Brochure prepared by Automotive Recycling Industry (ARA), Institute of Scrap Recycling Industries and Auto Alliance, from: www.autoalliance.org

Autoretur (2016). Årsrapport 2015 - Sammenstilling av data fra Autoreturs returordning for kasserte kjøretøy. Oslo.

Bachér, J., Pihkola, H., Kujanpää, L., Mroveh, U-M., Vanderreydt, I. \& Garcia Zambrano, L. (2016). Bottleneck analysis of WEEE, ELV and plastics packaging chains: key findings and commonalities. D 2.5. (V1)_RP_Report on cross linking of the results per value chain, waste streams and raw material stream. NEW_InnoNet 2016/09/05.

Bakas, I., Herczeg, M., Vea, E., Fråne, A., Youhanan, L. \& Baxter, J. (2016). Critical metals in discarded electronics: Mapping recycling potentials from selected waste electronics in the Nordic region. TemaNord 2016:526. https://doi.org/10.6027/TN2016-526

Barteková, E. \& Kemp, R. (2016). Critical raw material strategies in different world regions. UNUMERIT Working Papers, ISSN 1871-9872. Retrieved 19th December 2016, from:

http://www.merit.unu.edu/publications/wppdf/2016/wp2016-005.pdf

Batteriretur (2016). Nedstrømsløsning. Retrieved 7th December 2016, from: http://www.batteriretur.no/om-batteriretur/nedstromslosning/

Battery University (2016). BU-705: How to recycle batteries. Retrieved 7th December 2016, from: http://batteryuniversity.com/learn/article/recycling_batteries

Bil Sweden (2016). Bilismen i Sverige 2016.

BMUB (2016). The German resource efficiency programme II. Programme for the sustainable use and conservation of natural resources. Federal Ministry for the Environment, Nature Conservation, Building and Nuclear Safety. Retrieved 7th December 2016, from: http://www.bmub.bund.de/en/service/publications/downloads/details/artikel/germanresource-efficiency-programme-ii/

Boliden (2016). Company internet page. Retrieved 1st December 2016, from: http://www.boliden.com/

Buchert, M., Manhart, M., Bleher, D. \& Pingel, D. (2012). Recycling critical raw materials from waste electronic equipment. Oeko-Institut. Retrieved 1st December 2016, from: https://www.oeko.de/oekodoc/1375/2012-010-en.pdf

Casamayor, J., Su, D. \& Sarshar, M. (2015). Extending the lifespan of LED-lighting products. Architectural Engineering and Design Management 11, 105-122.

https://doi.org/10.1080/17452007.2013.834813 
Castilloux, R. (2014). Emerging end-uses of REEs that could transform the tarket prior to 2020. Retrieved 3oth October 2016, from:

http://www.techmetalsresearch.com/emerging-new-end-uses-for-rare-

earths/?infcontactkey=6e94bgb9423c24cd24af51cbd577019da719e0326996a76bgd8c1fcc2a8

g8od5

Chancerel, P., Rotter, V R., Ueberschaar, M., Marwede, M., Nissen, N F. \& Lang, K-D. (2013).

Data availability and the need for research to localize, quantify and recycle critical metals in

information technology, telecommunication and consumer equipment. Waste Management \&

Research 31, 3-16. https://doi.org/10.1177/0734242X13499814

Ciacci, L., Reck, B. K., Nassar, N. T. \& Graedel, T. E. (2015). Lost by design. Environmental

Science \& Technology 49, 9443-9451. https://doi.org/10.1021/es505515Z

Clasp (2013). Estimating potential additional energy savings from upcoming revisions to existing regulations under the ecodesign and energy labelling directives - a contribution to the evidence base. 18 February 2013.

Council Directive 70/156/EEC of 6 February 1970 on the approximation of the laws of the Member States relating to the type-approval of motor vehicles and their trailers.

Cuchinella, F., D'Adamo, I., Lenny Koh, S.C, Rosa, P. (2015). Recycling of WEEEs: An economic assessment of present and future waste streams. Renewable and Sustainable Energy Reviews 1(2015)263-272. https://doi.org/10.1016/j.rser.2015.06.010

Cullbrand, K., Fråne, A. \& Jensen, C. (2015). Utökad demontering av personbilar -Utvärdering av demonterings- och fragmenteringsförsök av 220 personbilar. Göteborg: IVL Svenska Miljöinstitutet.

Cullbrand, K. \& Magnusson, O. (2012). The use of potentially critical materials in passenger cars. Master Thesis, Chalmers University of Technology. Report No. 2012:13.

DEFRA (2012). A review of national resource strategies and research. March 2012. Retrieved 19th December 2016, from:

https://www.gov.uk/government/uploads/system/uploads/attachment_data/file/69526/pb137 22-national-resource-strategies-review.pdf

Directive 2000/53/EC of the European Parliament and of the Council of 18 September 2000 on end-of life vehicles. European Commission.

Draft of the New National Waste Plan, 14.12.2016.

Eckartz, K., Sartorius, C., Tercero Espinzola, L., Anta Espada, M., Bachér, J., Bierwirth, A., Bouyer, E., Brunot, A., Etxaniz, J., Fernqvist, N., Garcia, G., Gardner, D., Ganzales, C., Holgersson, P., Karvan, O., Lindahl, E., Lopez, A., Menger, P., Morales Perez, A., Norefjäll, F., Olivieri, N., Rietveld, E., Serrano, B., Thomtén, M. \& van den Eijk, C. (2015). D3.2 Critical raw materials substitution policies - Country profiles. CRM_InnoNet Deliverable Report, April 2015.

ELC (2009). European Lamp Companies Federation. Environmental aspects of lamps. 2nd Edition. Retrieved 3oth October 2016, from:

http://www.lightingeurope.org/uploads/files/ogo811_elc_brochure_environmental_aspects_ amps_updated_final.pdf

El-Kretsen (2016). Årsrapport 2015. 2016-06-09. Retrieved 1st December 2016, from: http://www.el-kretsen.se/\%C3\%A 5 rsrapport-2015

Energy.gov. (2016). Critical materials hub. U.S. Office of Energy Efficiency \& Renewable Energy. Retrieved 31st December 2016, from: https://energy.gov/eere/amo/critical-materials-hub

European Commission (2010). Critical raw materials for the EU. Report of the Ad-hoc Working Group on defining critical raw materials. Retrieved 3oth October 2016, from: http://www.euromines.org/files/what-we-do/sustainable-development-issues/2010-reportcritical-raw-materials-eu.pdf

European Commission (2014). Report on critical materials for the EU. Report of the Ad hoc Working Group on defining critical raw materials May 2014. Retrieved 31st December, from: http://www.catalysiscluster.eu/wp/wp-content/uploads/2015/05/2014_Critical-raw-materialsfor-the-EU-2014.pdf 
European Lighting Companies' Federation (2003). Let There be Light: A blueprint for the sustainable waste management of Lamps in the EU in view of the expected implementation of the Waste Electrical and Electronic Equipment Directive. Retrieved 29th November 2016, from http://www.lightingeurope.org/uploads/files/let_there_be_light_brochure.pdf

Eurostat (2016). Eurostat Prodcom database. Data extracted October 315t 2016, from: http://ec.europa.eu/eurostat/web/prodcom/data/database

Eurostat (2016). End-of-Life Vehicles - reuse, recycling and recovery, totals. Eurostat: European Commission.

Feldt, L. (2013). Electronics Stewardship in the United States of America. Global E-Waste Management (GEM) Network Workshop July 15, 2013. Data extracted October 31st 2016, from: https://www.epa.gov/sites/production/files/2014-05/documents/us-strategy.pdf

Finnish Customs (2017). Statistical database: Foreign Trade Statistics: CN. Data extracted February 2nd 2017, from: http://uljas.tulli.fi/

Finnish Ministry of Employment and the Economy (2010). Finland's Minerals Strategy. Retrieved December 20th 2016, from:

http://projects.gtk.fi/export/sites/projects/minerals_strategy/documents/FinlandsMineralsStra tegy_2.pdf

Frantzen, H. (2017). Miljødirektoratet. Personal communication, January 2nd, 2017.

Geological Survey of Sweden (2014). Uppdrag att utföra en kartläggning och analys av utvinning- och återvinningspotential för svenska metall- och mineraltillgångar. Uppsala.

Gallo, D. (2013). Broad overview of E-waste management policies in the U.S. Global E-Waste Management (GEM) Network Workshop July 15, 2013. Data extracted October 31st 2016, from: https://www.epa.gov/sites/production/files/2014-05/documents/overview.pdf

Globalis (2016). Total befolkning i tusental. UNA Sweden. Retrieved October 1st 2016, from: http://publications.lib.chalmers.se/records/fulltext/235671/235671.pdf

Growth Analysis (2015). Innovativ metallåtervinning för ökad resurseffektivitet. Östersund.

Guyonnet, D., Planchon, M., Rollat, A., Escalon, V., Tuduri, J., Charles, N., Vaxelaire, S., Dubois, D. \& Fargier H. (2015). Material flow analysis applied to rare earth elements in Europe. Journal of Cleaner Production 107, 215-228. Elsevier. https://doi.org/10.1016/j.jclepro.2015.04.123

IsoLogistics (2014). Company web page. Retrieved December 23rd 2016, from: http://www.isologistics.eu/

Johnson, B. (2014). Electronics Stewardship in the United States of America. IEMN meeting, July 14,2014

Kohlmayer, R. (2016). Umweltbundesamt. Written notification. November 2016.

Kohlmayer, R. Kosmol, J. \& Sperlich, K. (2016). Recycling of Edel- und Sondermetallen. Vortragsreihe ITU-UBA.

Ku, A.Y., Setlur, A. A. \& Loudis, J. (2015). Impact of Light Emitting Diode Adoption on Rare Earth Element Use in Lighting. Implications for Yttrium, Europium, and Terbium Demand. The Electrochemical Society Interface, Winter 2015. https://doi.org/10.1149/2.fo4154if

LightingEurope (2014). LightingEurope Position Paper Customs Codes for LED Lighting Products. Retrieved October 17th 2016, from:

http://www.lightingeurope.org/uploads/files/LightingEurope_Position_Paper_on_LED_Custo ms_Codes_February2014.pdf

Lim, S-R., Kang, D., Ogunseitan, O. A. \& Schoenunget, J. M. (2013). Potential Environmental Impacts from the Metals in Incandescent, Compact Fluorescent Lamp (CFL), and LightEmitting Diode (LED) Bulbs. Environ. Sci. Technol. 47, 1040-1047.

https://doi.org/10.1021/es302886m

Linnel, J. (2014). Financing aspects of US. Systems. IEMN meeting, July 14, 2014.

Machacek, E., Richter, J.L., Habib, K. \& Klossek, P. (2015). Recycling of rare earths from fluorescent lamps: Value analysis of closing-the-loop under demand and supply uncertainties. Resources, Conservation and Recycling 104, 76-93.

https://doi.org/10.1016/j.resconrec.2015.09.005 
McKinsey \& Company (2012). Lighting the way: Perspectives on the global lighting market. 2nd edition.

METI (2014). Strategic Energy Plan, April, 2014. Provisional translation. Retreived December 23rd 2016, from:

http://www.enecho.meti.go.jp/en/category/others/basic_plan/pdf/4th_strategic_energy_plan. pdf

Miljöordning for biler (2016). Statistikker Data extracted September gth 2016, from: http://bilordning.dk/Statistikker

Miller, R., Gregory, J., Duan, H. \& Kirchain, R. (2016). Quantitative Characterization of Domestic and Transboundary Flows of Used Electronic Products. Case Study: Used Computers and Monitors in North America. North American Commission for Environmental Cooperation (CEC).

Ministry of Enterprise and Innovation (2013). Sweden's Minerals Strategy. For sustainable use of Sweden's mineral resources that creates growth throughout the country.

Ministry of the Environment (2013). Fra avfall til ressurs: Avfallsstrategi. Retrieved December 22nd 2016, from:

https://www.regjeringen.no/contentassets/27128ced39e74boba1213a09522deo84/t-

1531_web.pdf

Ministry of Foreign Affairs (2011). Kingdom of Denmark Strategy for the Arctic 2011-2020. Retrieved December 20th 2016, from: http://www.uniset.ca/microstates/mss-denmark_en.pdf

Ministry of Trade and Industry (2013). Strategy for the Mineral Industry. Retrieved December 23rd 2016, from:

https://www.regjeringen.no/contentassets/3fe548d142cd496ebb7230a54e71ae1a/strategyfort hemineralindustry_2013.pdf

Motiva (2014). Company web page. Retrieved October 17th 2016, from: http://www.motiva.fi/

Namias, J. (2013). The future of electronic waste recycling in the United States: Obstacles and Domestic Solutions. Thesis, Columbia University. Submitted 08. 2013. Retrieved October 17th 2016, from: http://www.seas.columbia.edu/earth/wtert/sofos/Namias_Thesis_07-08-13.pdf

Nickelhütte (2016). Transformatorenregygling. Retrieved December 8th 2016, from: http://www.nickelhuette-aue.de/index.asp?katid=30\&bodystart=1\&seite=30150100

Nordic Recycling (2016). Company web page. Retrieved November 29th 2016, from: http://www.nordicrecycling.se/nr/

Nunweiler, E. (2017). Policy approaches in Germany for supporting recycling of CRMs in WEEE and ELV. Workshop "Critical Raw Materials in Nordic Countries - Recovery Potential and Opportunities for Removal of Bottlenecks" CRM_NORD. 18-01-2017, Stockholm.

Oak Ridge National Laboratory (2016). Critical Materials Institute, Oddello Industries pursue recovery of rare-earth magnets from used hard drives. Retrieved October 17th 2016, from: https://www.ornl.gov/news/critical-materials-institute-oddello-industries-pursue-recoveryrare-earth-magnets-used-hard

Oehme, I., Sperlich, K., Kohlmeyer, R., Prakash, S., Sander, K. \& Clemma, C. (2016). Strengthening material efficiency of electrical and electronic equipment.

Oguchi, M., Murakami, S., Sakanakura, H., Kida, A. \& Kameya, T. (2011). A preliminary categorization of end-of-life electrical and electronic equipment as secondary metal resources. Waste Management 31, 2150-216o. https://doi.org/10.1016/j.wasman.2011.05.009

Osram (2009). Life Cycle Assessment of Illuminants. A Comparison of Light Bulbs, Compact Fluorescent Lamps and LED Lamps. Executive Summary.

Peterson, E. S. \& Jones, E. (2014). Improving rare earth reuse and recycling. 248th American Chemical Society Meeting San Francisco, CA $10-14$ August, 2014.

Philips (2016). Retrieved October 17th 2016, from: http://www.philips.fi/c-m-li/led-lamput

Premium Light Consortium (2016). Retrieved October 17th 2016, from:

http://www.premiumlight.eu/ 
Recser Oy (2012). Ladattavat akut jäävät usein kotiin lojumaan - Ympäristö ja EU:n raakaaineiden omavaraisuus vaarassa. Retrieved December 2nd 2016, from:

http://www.recser.fi/?Recser_Oy:Ajankohtaista:9.10.2012

Recser Oy (2014). Paristojen ja akkujen palauttaminen kauppaan säästää ympäristöä ja ehkäisee tulipaloriskiä - Läppärinheittokisoissa kierrätettiin akut urheilun lomassa. Retrieved December 2nd 2016, from: http://www.recser.fi/?Recser_Oy:Ajankohtaista:11.7.2014

Richter, J. L. \& Koppejan, R. (2015). Extended producer responsibility for lamps in Nordic countries: best practices and challenges in closing material loops. Journal of Cleaner Production 123, 167-179. https://doi.org/10.1016/j.jclepro.2015.06.131

Richter, J. L. (2014). Where do all the lamps go? November 18, 2014. Retrieved November 29th 2016, from: http://closedloops.blogg.lu.se/

SAFT (2013). SAFT in 2013. Retrived December 8th 2016, from: http://www.saftbatteries.de/sites/default/files/BAT_Essential2013_GB_29052013.pdf

SBR (2016). RE: Personal Communication with Michael Abraham. 2016-11-07.

Scoullos, M., Vonkeman, G.H., Thornton, I. \& Makuch, Z. (2001). Mercury - Cadmium - Lead Handbook for Sustainable Heavy Metals Policy and Regulation. Springer, ISBN 978-94-0100403-9. https://doi.org/10.1007/978-94-010-0403-9

Sitra (2009). A Natural Resource Strategy for Finland: Using natural resources intelligently. Retrieved December 2oth 2016, from:

http://www.sitra.fi/julkaisut/muut/A\%20Natural\%20Resource\%20Strategy\%2ofor\%2oFinland .pdf

SNAM (2016). Marketing Alloys: MELCO. Retrieved December 8th 2016, from: http://www.snam.com/activites/marketting-alloys-next.php

Solvay (2016). Loop Life Project. Retrieved November 29th 2016, from: http://www.solvay.com/en/company/innovation/european-life-projects/loop-life-projectobjectives.html

Statistics Denmark (2017). StatBank Denmark: External economy: KN8Y: Imports and exports CN (EU combined nomenclature) by imports and exports, commodities, country and unit. Data extracted Ferbuary 2nd 2017, from: http://www.statistikbanken.dk/KN8Y

Statistics Norway (2016a). Registered vehicles. Statistisk sentralbyrå. Data extracted September gth 2016, from:

https://www.ssb.no/statistikkbanken/selectvarval/Define.asp?subjectcode=\&Productld $=\&$ MainTable $=$ Bilvrak3\&nvl=\&PLanguage $=1 \&$ nyTmpVar=true $\& C M S S u b j e c t A r e a=$ transport og-reiseliv\&KortNavnWeb=bilreg\&StatVariant=\&checked=true

Statistics Norway (2016b). StatBank Norway. External economy: External trade: External trade in goods, by commodity number, imports/exports, time and contents. Data extracted December 22th 2016, from: https://www.ssb.no/en/statistikkbanken

Statistics Sweden (2016a). Fordonsstatistik - Bestånd, nyregistreringar och avregistreringar. Örebro: Statistiska centralbyrån. Data extracted September gth 2016, from: http://www.scb.se/sv_/Hitta-statistik/Statistik-efter-amne/Transporter-ochkommunikationer/Vagtrafik/Fordonsstatistik/\#c_li_TK1001A

Statistics Sweden (2016b). Fordonsstatistik, juli 2016: Nya bilar minskade med 2,3 procent. Statistiknyhet från SCB och Trafikanalys 2016-08-02 09:30 Nr 2016:178. Data extracted September 9th 2016, from: http://www.scb.se/sv_/Hitta-statistik/Statistik-efteramne/Transporter-och-kommunikationer/Vagtrafik/Fordonsstatistik/10509/10516/Behallarefor-Press/407406/

Statistics Sweden (2017). Statistical database. Trade in goods and services: CN (Combined Nomenclature). Data extracted February 2nd 2017, from:

http://www.statistikdatabasen.scb.se/pxweb/en/ssd/START_HA_HAo201/?rxid=74e779doc2f8-45b1-84fo-e8c2oecb4c5a

STRIM (2016). Strategic Innovation Programme for the Swedish Mining and Metal Producing Industry. Retrieved December 22th 2016, from: http://www.sipstrim.se/ 
Sud Ovest (2016). La Rochelle: fermeture de l'atelier de recyclage des terres rares de Solvay d'ici fin 2016. Article published 5.1.2016. Retrieved January 2oth 2017, from:

http://www.sudouest.fr/2016/01/15/la-rochelle-fermeture-de-l-atelier-de-production-desolvay-d-ici-fin-2016-2243998-1391.php

Swedish Environmental Protection Agency (2012). Från renhållning till resurshushållning Sveriges avfallsplan 2012 - 2017. Stockholm: Swedish Environmental Protection Agency.

Swedish Environmental Protection Agency (2016a). Avfall i Sverige 2014. SMED on behalf of the Swedish Environmental Protection Agency.

Swedish Environmental Protection Agency (2016b). Reviderad nationell avfallsplan. Retrieved December 2oth, from: http://www.naturvardsverket.se/Miljoarbete-i-samhallet/Miljoarbete-iSverige/Regeringsuppdrag/Reviderad-nationell-avfallsplan/

Sähköturvallisuuden Edistämiskeskus Ry (2016). Valonlähteet. Data extracted October 17th 2016, from: http://www.stek.fi/Energiatehokkuutta_sahkolla/Valaistus/fi_FI/Valonlahteet/

Söderman, M. L. \& Ingemarsdotter, E. (2014). Användning och återvinning av potentiellt kritiska material. Gothenburg: Chalmers University of Technology.

The Danish Government (2010). Environmental technology - for improvement of the environment and growth. Action plan to promote eco-efficient technology 2010-2011. Retrieved December 2oth 2016, from:

http://ecoinnovation.dk/media/ecoinnovation/64450/Miljoeteknologi_plan_2010_engelsk.pdf

The Danish Government (2013). Denmark without waste. Recycle more - incinerate less.

Retrieved December 2oth 2016, from:

http://mfvm.dk/fileadmin/user_upload/MFVM/Miljoe/Ressourcestrategi_UK_web.pdf

Trafi (2016). Scrapping and final deregistration of a vehicle. Finnish Transport Safety Agency. Retrieved 22nd September 2016, from: http://www.trafi.fi/en/road/scrapping_and_final_deregistration_of_a_vehicle

Tähkämö, L. (2013). Life cycle assessment of light sources - Case studies and review of the analyses. Aalto University publication series, Doctoral Dissertations 111/201.

UN Comtrade (2017). UN Comtrade Database. Data extracted February 2nd 2017, from https://comtrade.un.org/data/

U.S. Department of Energy (2011). Critical Materials Strategy. December 2011.

U.S. Department of Energy (2012a). Life-Cycle Assessment of Energy and Environmental Impacts of LED Lighting Products. Part I: Review of the Life-Cycle Energy Consumption of Incandescent, Compact Fluorescent, and LED Lamps.

U.S. Department of Energy (2012b). Life-Cycle Assessment of Energy and Environmental Impacts of LED Lighting Products. Part 2: LED Manufacturing and Performance. May 2012.

U.S. Department of Energy (2016). The Department of Energy's Critical Materials Strategy. Retrieved December 2oth 2016, from:

https://energy.gov/epsa/initiatives/department-energy-s-critical-materials-strategy

United States Environmental Protection Agency (2016). Compliance assistance at work at auto salvage yards and recyclers. Retrieved December 20th 2016, from:

https://www3.epa.gov/regiong/enforcement/auto-compliance.html

van der Have, G-J. (2016). Written notification 8.12.2016.

van der Have, G-J. (2017). ELV Recycling: Challenges and opportunities to recover CRM. Workshop "Critical Raw Materials in Nordic Countries - Recovery Potential and Opportunities for Removal of Bottlenecks" CRM_NORD. 18-01-2017, Stockholm.

van Schaik, A. \& Reuter, M.A. (2014). Material-Centric (Aluminum and Copper) and ProductCentric (Cars, WEEE, TV, Lamps, Batteries, Catalysts) Recycling and DfR Rules. In: Worrell, E., Reuter, M.A. (Eds.), Handbook of Recycling: State-of-the- Art for Practitioners, Analysts, and Scientists. Elsevier, ISBN: 978-0-12-396459-5. https://doi.org/10.1016/B978-0-12-3964595.00022-2

VGW (2016). Analysis of WEEE value chain. D2.2 Report summarising the results of the analysis of Electronics valuechain, NEW_InnoNet 2016/08/12. 
Wang, F., Huisman, J., Baldé, K., \& Stevels, A. (2012). A systematic and compatible classification of WEEE. In Electronics Goes Green 2012+(EGG), 2012 IEEE.

Widmer, R., Du, X., Haag, O., Restrepo, E. \& Wäger, P. A. (2015). Scarce Metals in Conventional Passenger Vehicles and End-of-Life Vehicle Shredder Output. Environmental Science and Technology 49, 4591-4599. https://doi.org/10.1021/es505415d

Wu, Y., Yin, X., Zhang, Q., Wang, W. \& Mu, X. (2014). Review: the recycling of rare earths from waste tricolor phosphors in fluorescent lamps: A review of processes and technologies. Resour. Conserv. Recycl. 88, 21-31. http://doi.org/10.1016/j.resconrec.2014.04.007

Yamane, L H., Tavares de Moraes, V., Crocce Romano Espinosa, D. \& Soares Tenório, J.A. (2011). Recycling of WEEE: Characterization of spent printed circuit boards from mobile phones and computers. Waste Management 31, 2553-2558. https://doi.org/10.1016/j.wasman.2011.07.006

Ylä-Mella, J., Poikela, K., Lehtinen, U., Tanskanen, T., Román, E., Keiski, R.L. \& Pongrácz, E. (2014). Overview of the WEEE Directive and Its Implementation in the Nordic Countries: National Realisations and Best Practices. Journal of Waste Management 2014, Article ID 457372, 18 p. http://dx.doi.org/10.1155/2014/457372

Östlund, C. (2016). RE: Personal communication with Catarina Östlund at the Swedish EPA, 21.12.2016. 



\section{Sammanfattning}

Kritiska och sällsynta råmaterial används flitigt i olika typer av produkter. Bland applikationerna finns till exempel transportfordon, elektriska och elektroniska produkter, teknikprodukter för energiproduktion med låga fossila utsläpp samt olika industriella applikationer. Vanligtvis finns kritiska råmaterial (CRM) i komponenter med höga krav på prestanda. Därför är de också kritiska med avseende på produktens funktion. Utmaningen i återvinningen av dessa material är att de oftast änvänds i små kvantiteter och i komplexa strukturer.

Projektets syfte är att analysera hinder för återvinning av CRM och att identifiera potentiella policyåtgärder som kan motverka hindren till ökad återvinning eller reducera effekten av dem. Baserat på resultaten presenteras även rekommendationer på nyckelåtgärder för att främja en hållbar återvinning av CRM i de nordiska länderna. Fokusområdet är uttjänta fordon (ELV), belysningsprodukter, konsumentelektronik och laddningsbara batterier. Uppskattningar på årligen förväntade mängder CRM i dessa produkter under perioden 2015-2020 ger indikationer på återvinningspotentialen i de nordiska länderna (Danmark, Finland, Norge och Sverige).

Mängden CRM i uttjänta bilar och belysningsavfall beräknas med hjälp av uppskattningar på uppkommet avfall och data på CRM-innehåll i dessa produkter funnet $\mathrm{i}$ litteratur. För elektronik och laddningsbara batterier används data från publikationen "Critical metals in discarded electronics" (Bakas et al. 2016), med undantag för guld och silver. Resultaten visar att det finns en betydlig potential av kritiska och sällsynta metaller i dessa produkter, dock utspridda i ett stort antal individuella produkter som regleras av olika förordningar samt samlas in och förbehandlas på olika sätt.

En av huvudutmaningarna är att hitta ekonomiskt effektiva lösningar för återvinning av små mängder material som finns integrerade i legeringar, kompositer eller täta strukturer som är sammanfogade med metoder som försvårar nedmontering. Dessutom leder den snabba utvecklingen inom produktdesign till kontinuerlig förändring i flödet och heterogena inflöden till återvinningsprocesserna. De instabila metallpriserna, bristen på data på återvinningsbara volymer och osäkerheter om framtida marknader för återvunna CRM komplicerar uppskattningen av den ekonomiska lönsamheten.

För närvarande finns det nästintill inga incitament för tillverkare och produktdesigners att utveckla återvinningsbara och återbrukbara produkter. Trenden är istället att öka teknisk prestanda och kostnadseffektiviteten hos produkterna genom att tillverka i liten skala och packa komponenter tätt, vilket försvårar återvinningen ytterligare. Dessutom baseras avfallslagstiftningen på kvantitativa återvinningsmål vilket inte skapar incitament för återvinning av material i små mängder. 
Återvinningssystemen är optimerade med basmetallerna som utgångspunkt. En del av de mest värdefulla metallerna som guld, silver, palladium, platina och kobolt återvinns också. Förlusten av kritiska metaller vid insamlings- och behandlingsstegen är dock hög och det finns betydande potential för högre återvinningsgrader. Sällsynta jordartsmetaller, speciellt permanentmagneter som innehåller neodymium och dysprosium, är också väsentliga ur återvinningssynpunkt. Dessa ämnens totala volymer i olike uttjänta produkter är betydande och återvinningsgraderna är för närvarande minimala. Nya återvinningsstrategier och lösningar på systemnivå är nödvändiga för att utveckla effektiviteten och för att uppnå stordriftsfördelar.

Åtgärder för att öka återvinning är välmotiverade eftersom den totala återvinningspotentialen av CRM i de nordiska länderna är hög. På grund av att utmaningarna för ökad återvinning för de olika produktgrupperna är likartade, samt att det finns begränsade tillgängliga mängder i de enskilda länderna, är planering och utveckling av åtgärder ett potentiellt samarbetsområde både på nordisk och på europeisk nivå. Rekommendationer på policyåtgärder är:

- Ökad kunskap och tillgänglighet av uppdaterade data om befintliga mängder CRM i olika uttjänta produkter. Detta kan minska osäkerheter som för närvarande komplicerar uppskattningen av lönsamheten och genomförbarheten av olika tekniska lösningar och systemlösningar.

- Utveckling av nya återvinningsstrategier för att möjliggöra effektivare och mer ekonomisk återvinning av kritiska metaller. Nedmontering och insamling av samma typ av komponenter som till exempel kretskort eller permanentmagneter till specialiserade anläggningar är ett potentiellt exempel.

- Stöd för demonstrationsanläggningar och särskilda åtgärder inom forskning och utveckling.

- Stärka nordiskt inflytande på utvecklingen av europeisk lagstiftning och standarder såsom:

- utveckling av återvinningsmål som skapar incitament för förbättrad återvinning av kritiska metaller samt

- utveckling av ny europeisk eko-designstandard och lagstiftning som tar hänsyn till återvinningsbarhet och återbrukbarhet. 


\section{Appendix 1: Workshop summary}

As part of the project, a workshop "Critical Raw Materials in Nordic Countries Recovery Potential and Opportunities for Removal of Bottlenecks" was organized for Nordic authorities and all stakeholders involved in the value chain (e.g. organizations for producer responsibility, recycling industry, producers, and universities). The workshop was held on January 18, 2017 in Stockholm, Sweden, and the event was by invitation only. All together 24 experts from Sweden, Finland, Iceland, Denmark, Germany and the Netherlands registered in the workshop, representing authorities, consultants, recyclers, producer responsibility organisations, product manufacturers, researchers and MEG (Nordic Council of Ministers' Working Group on Environment and Economy).

The objectives of the workshop were:

- To spread information on CRMs in ELV and WEEE, and to address specific aspects related to recycling of CRMs.

- To discuss the estimates on generation of lighting products and ELV waste and their CRM contents.

- To discuss bottlenecks of recycling of ELV, consumer electronics, batteries and lighting products, focusing especially on bottlenecks of CRM recycling.

- To discuss measures for removal of barriers of recycling and potential instruments.

- To discuss recycling priorities.

- To give opportunity for networking of stakeholders in different parts of the CRM supply chains and thus to support the shift towards circular economy.

The workshop programme included both presentations and roundtable discussions with the project team on bottlenecks and policy instruments. The bottlenecks identified by experts in the discussions are considered in Sections 4.1.2 and 4.3.2, whereas the policy instruments and suggestions to increase recycling of CRMs are listed below:

- Better and more convenient systems to increase collection:

- Consumer education needed.

- A neutral third party to monitor the collection.

- Deposit refund systems (problems with shared economy/lack of ownership?).

- However, increased collection alone will not do anything for CRMs. 
- Labelling, "Design to Detect": Label components on CRM content? Together with requirements on dismantling?

- Information transfer is important along the whole supply chain.

- Possibility for waste pooling and temporary storage.

- Discussion on needs for prehandling/preconcentration (problem with different interpretation of WEEE Directive: Need for same interpretation of hazardous waste classification (links for permits)).

- More innovation, research and demonstration projects in the Nordic countries are needed:

- Support for research in supply chain and funding of demonstration projects (in the Nordic countries/ Europe) - (test bed for demonstration in Sweden).

- In Germany there is financial (30\% of cost) aid for upscaling technology.

- Better statistics (volumes, contents, locations etc.) needed (for planning, policy planning), enables better tracking of the mass flows.

- Initiatives for companies to invest in recycling.

- If you produce something with CRMs you also have to use recycled CRMs in your products.

- Education of product designers.

- Waste treatment hierarchy (EEE: reparability, durability) - In Sweden, reduction of repairing costs of white EEE.

- Legislation should not only be based on weight but more clearly connected to societal goals such as sustainable development goals.

- Annual reporting requirement for producers regarding recyclability.

- Focus should be on a circular economy.

- Treatment and design requirements for WEEE.

- Focus on global recycling schemes.

- Application of the materials from the waste should also be included, how far is the producer responsibility? At some point there is a limit.

- Put more pressure on treatment plants so they have to develop better technologies. Important to target policy issues on some groups that also have the power to implement.

- Policies should not be country-specific, but on European level.

- Scarcity issues versus sovereignty issue.

- Focus should not be too small on one specific thing; policies need to address issues at a higher level so that market forces can deal with the issue.

- The market needs to reflect the criticality - incentives are needed and regard to future cost.

- Critical metals can be relatively critical or absolutely critical. E.g. in many cases not critical for China but critical for other countries. Chinese dominance, they can 
steer the market. China will drop the prices once we start to recycle. But for absolutely critical material not as crucial.

- Policies should focus on soft issues: producers to understand the recyclability of their products.

- Make it profitable through incentives, both carrot and stick.

- Dismantling requirements for ELV to prevent CRMs ending up in to shredder light fraction.

- CRMs in ashes, and slag piles from the mining industry should be also targeted.

- Legislation should not only be based on weight, but be connected to societal goals. E.g. the sustainable development goals.

- Curriculum for students - recyclability performance.

- Design for recycling. The producer should know where the component/product will end up in the waste flow. Increased interest from producers, they want to increase circularity. Incentives needed.

- Waste management cost for producers - 90\% is logistics cost (in Finland). If you have to take out something from the large flow it will cost more.

- Polymers are taking over the cars, materials changing. Change materials used in the cars. Incentives for producers to develop new materials.

- Different pay-in fees for different dismantling degrees (pre-consumer)? Tax for materials but not for producer organizations, that is not possible?

- The need of harmonized taxation between the Nordic countries. Economics of scale might come into a question.

- Make recycling business as profitable as possible for the "good guys". Standards such as the ELV Directive could be used. Many standards are not used due to lack of monitoring.

- Centralized treatment of certain materials in certain countries. 



\section{Appendix 2: CRM contents in generated ELV}

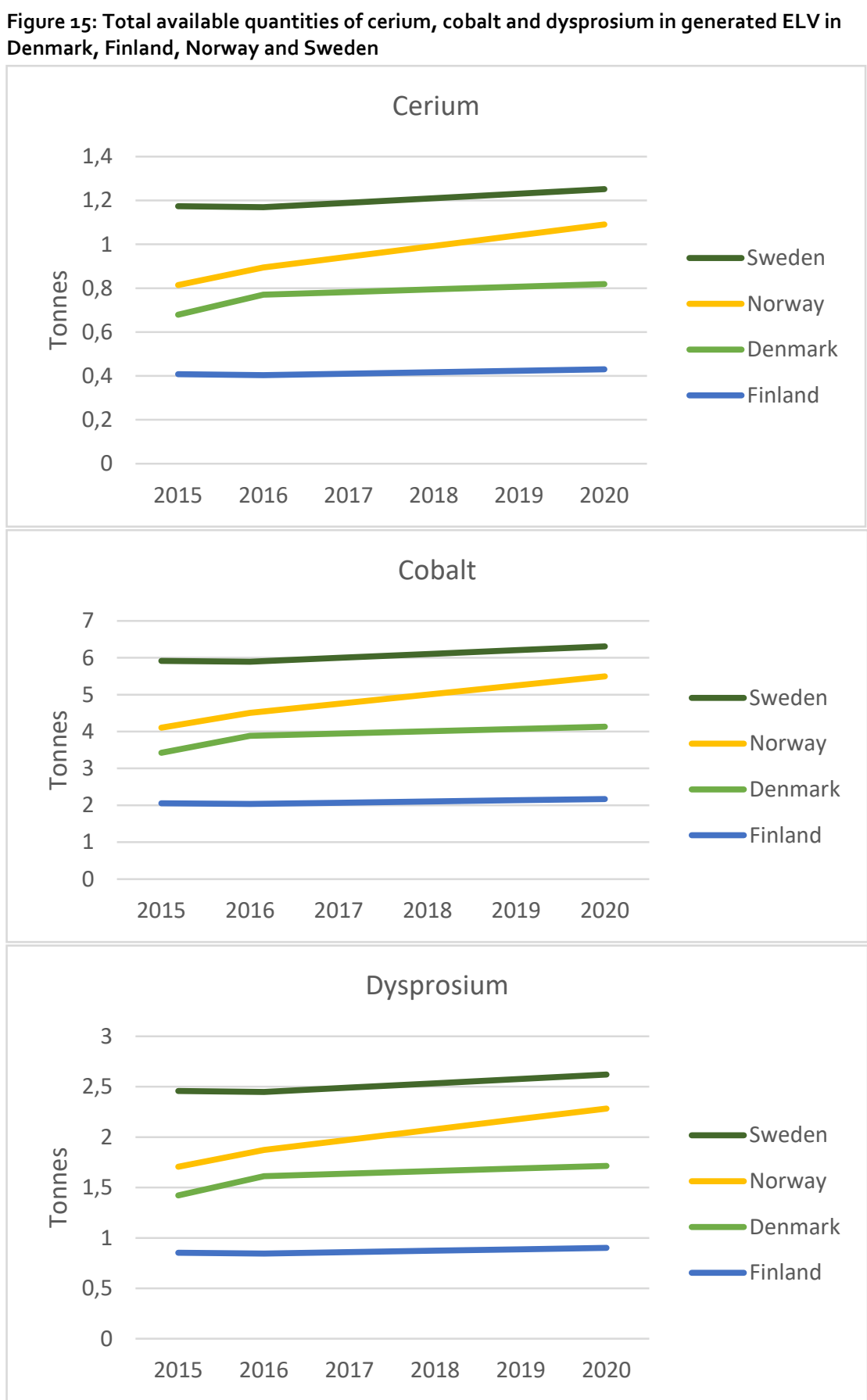


Figure 16: Total available quantities of erbium, gadolinium and gallium in generated ELV in Denmark, Finland, Norway and Sweden

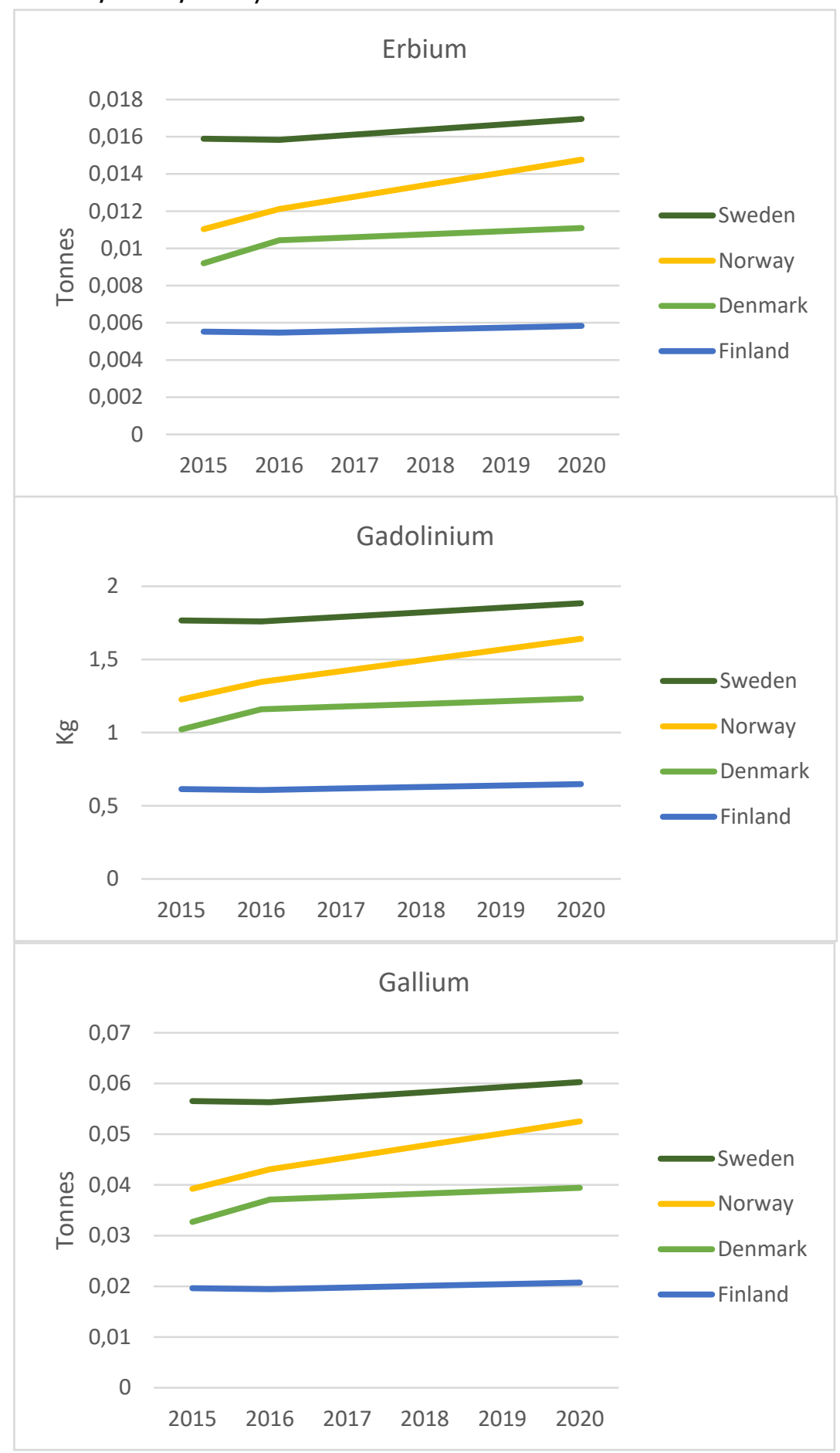


Figure 17: Total available quantities of gold, indium and lanthanum in generated ELV in Denmark, Finland, Norway and Sweden

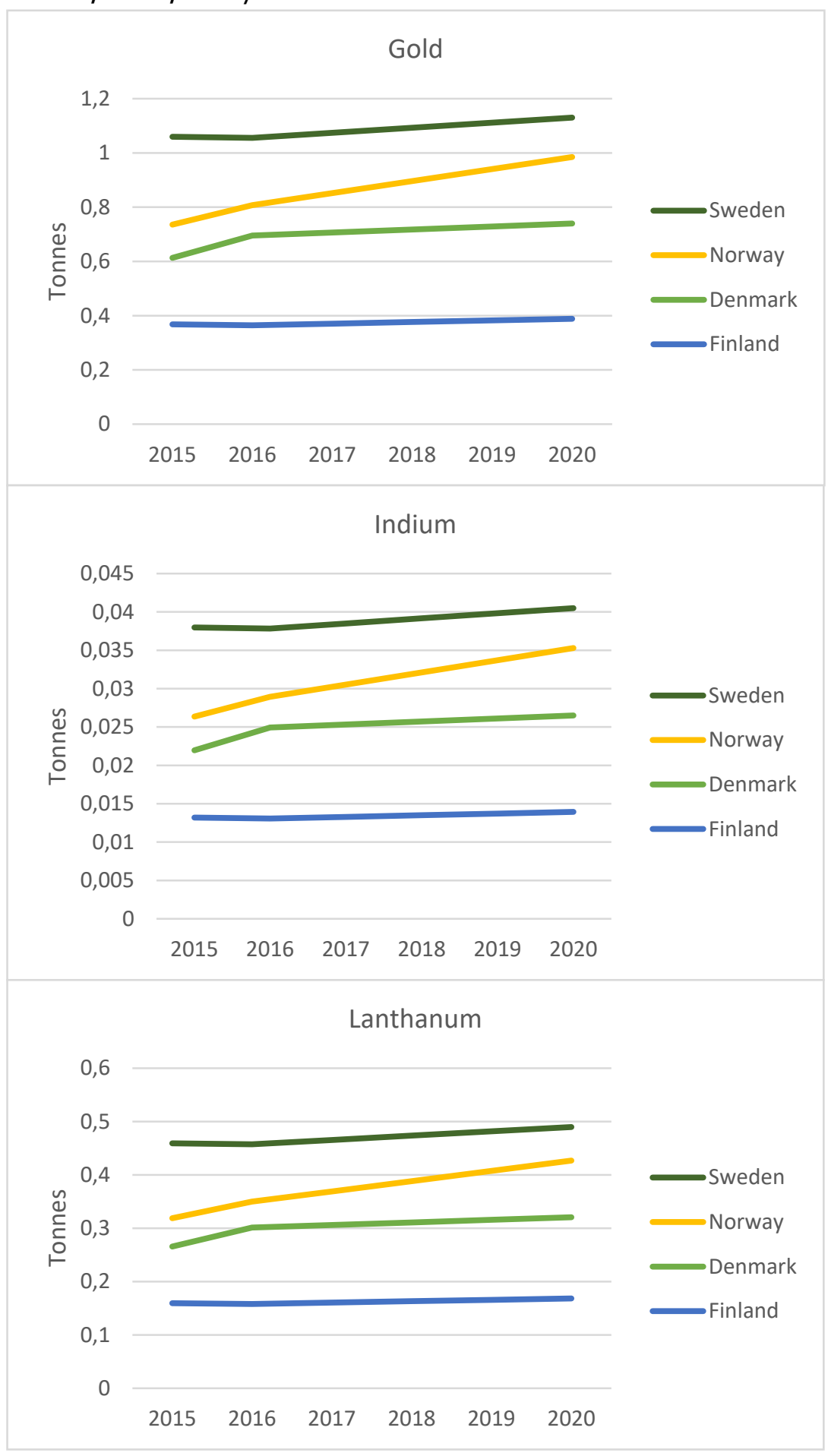


Figure 18: Total available quantities of lithium, neodymium and niobium in generated ELV in Denmark, Finland, Norway and Sweden

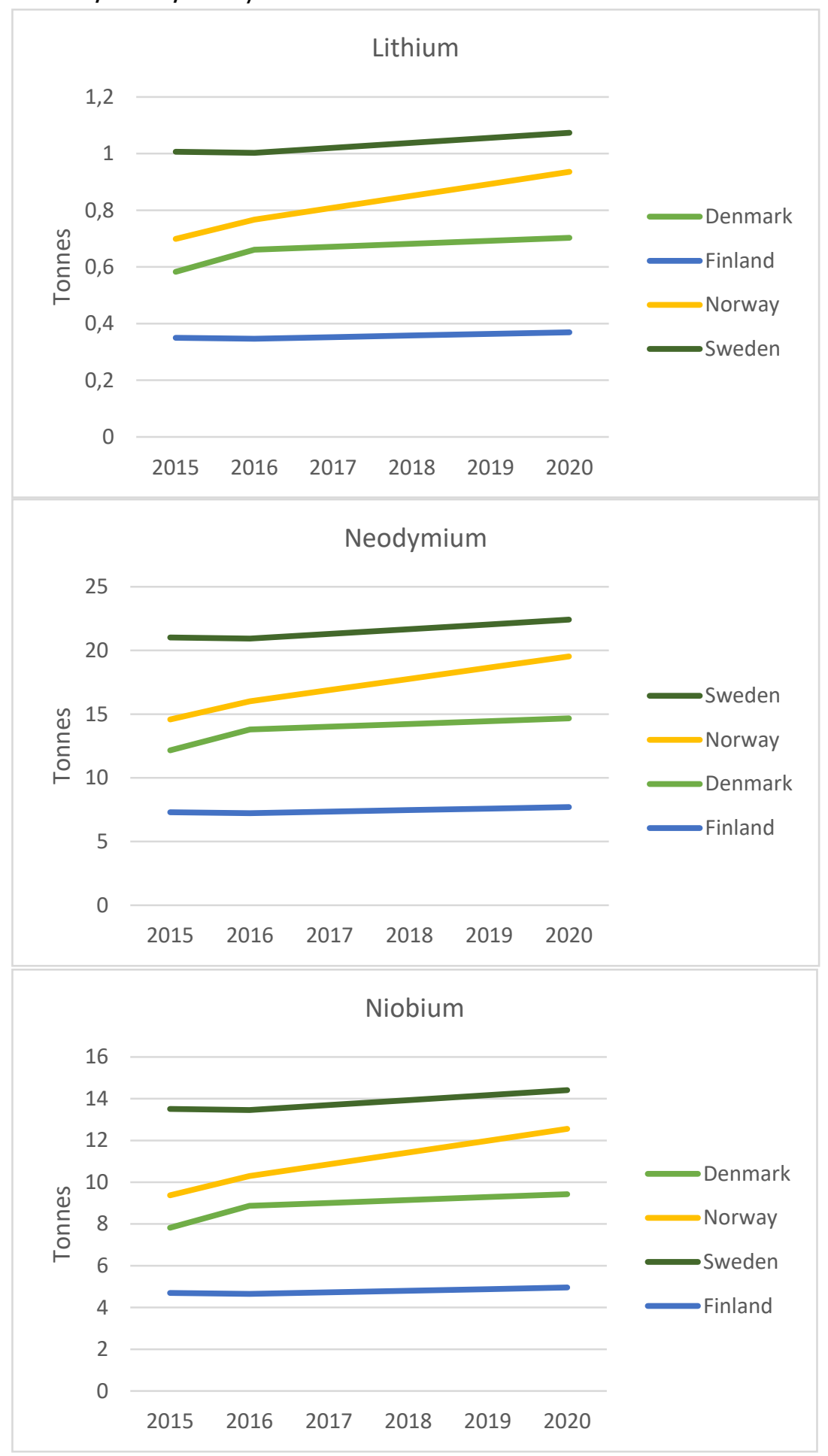


Figure 19: Total available quantities of palladium, platinum and praseodymium in generated ELV in Denmark, Finland, Norway and Sweden

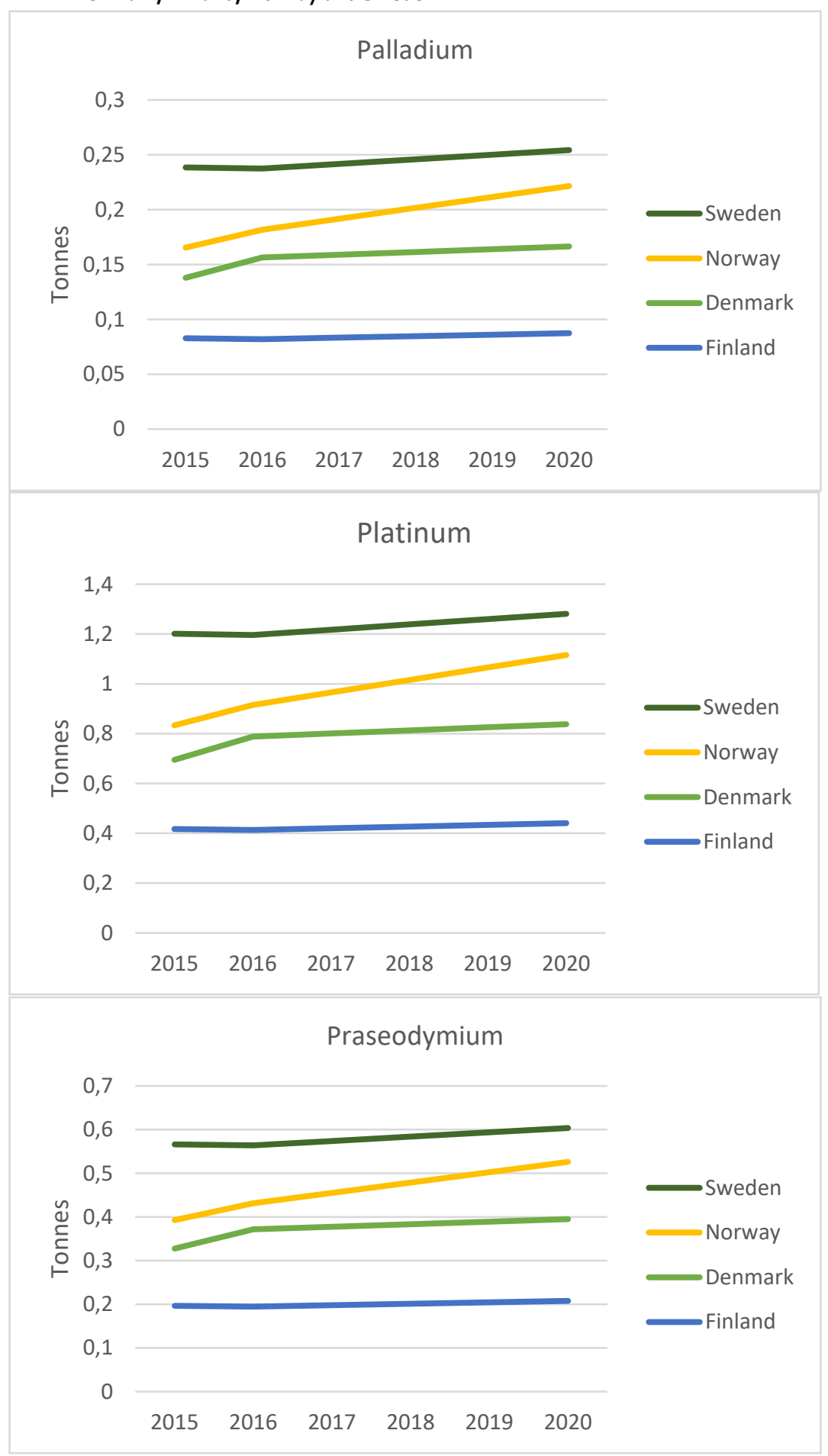


Figure 20: Total available quantities of samarium, silver and tantalum in generated ELV in Denmark, Finland, Norway and Sweden

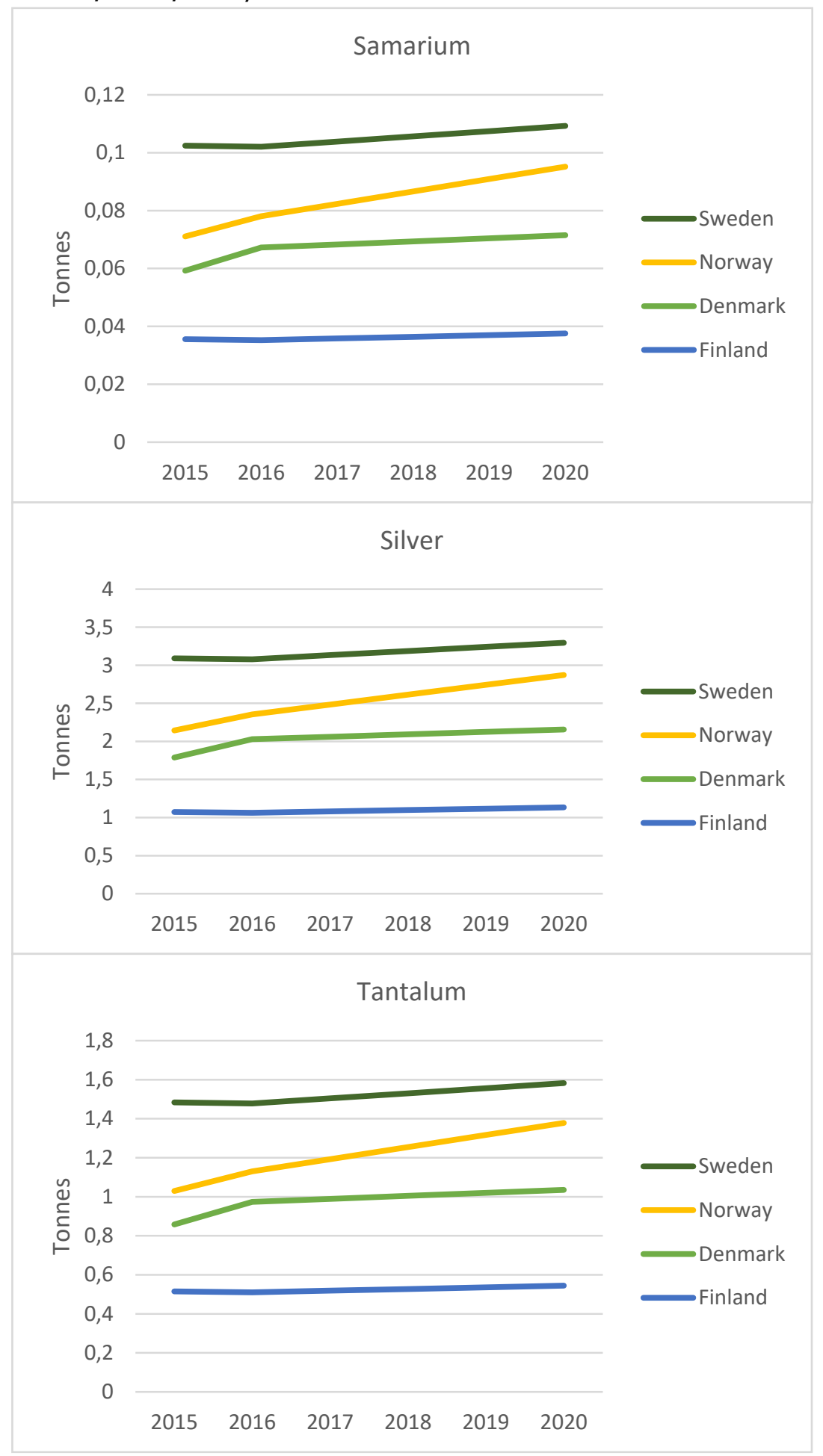


Figure 21: Total available quantities of terbium, rhodium and ytterbium in generated ELV in Denmark, Finland, Norway and Sweden

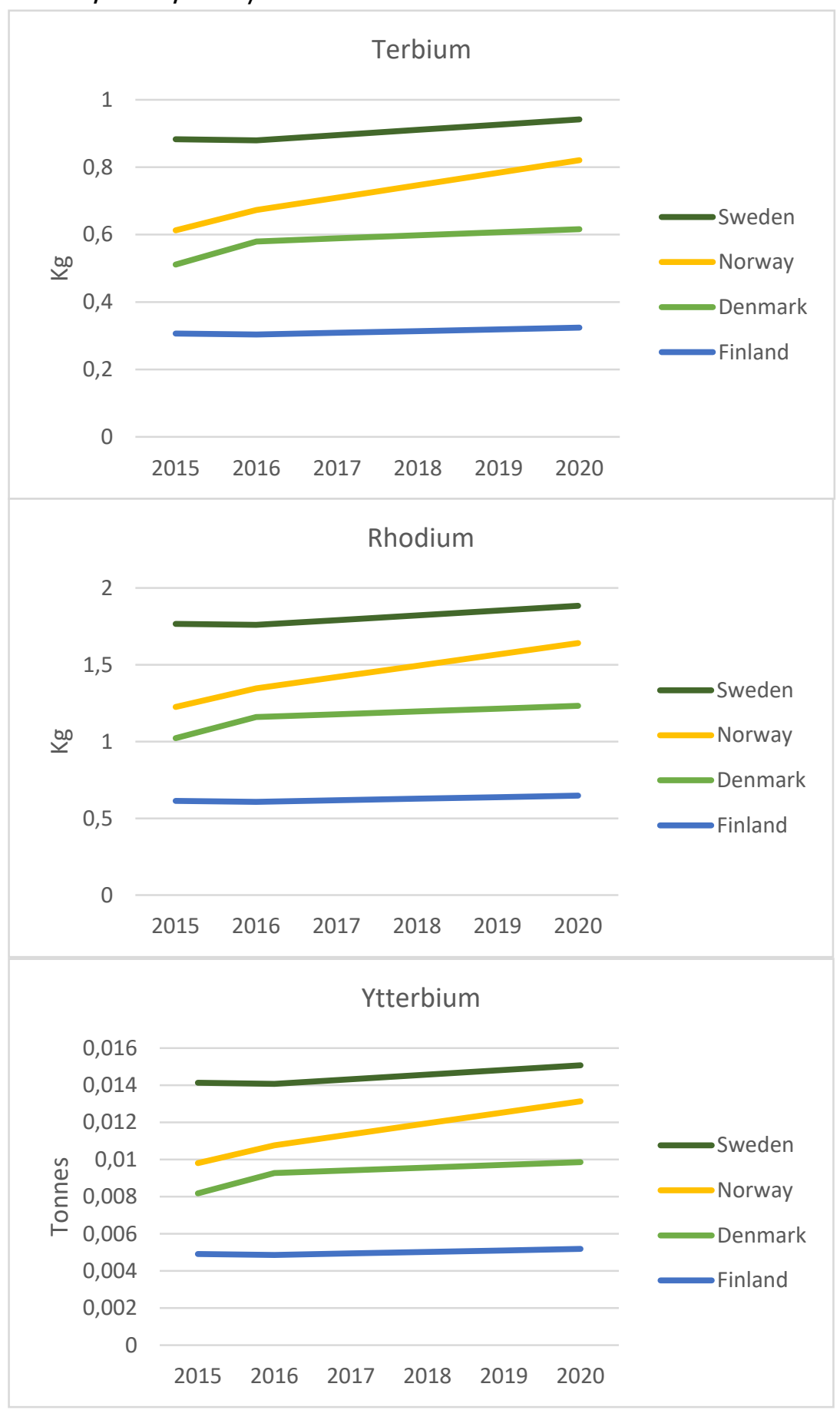


Figure 22: Total available quantities of yttrium in generated ELV in Denmark, Finland, Norway and Sweden

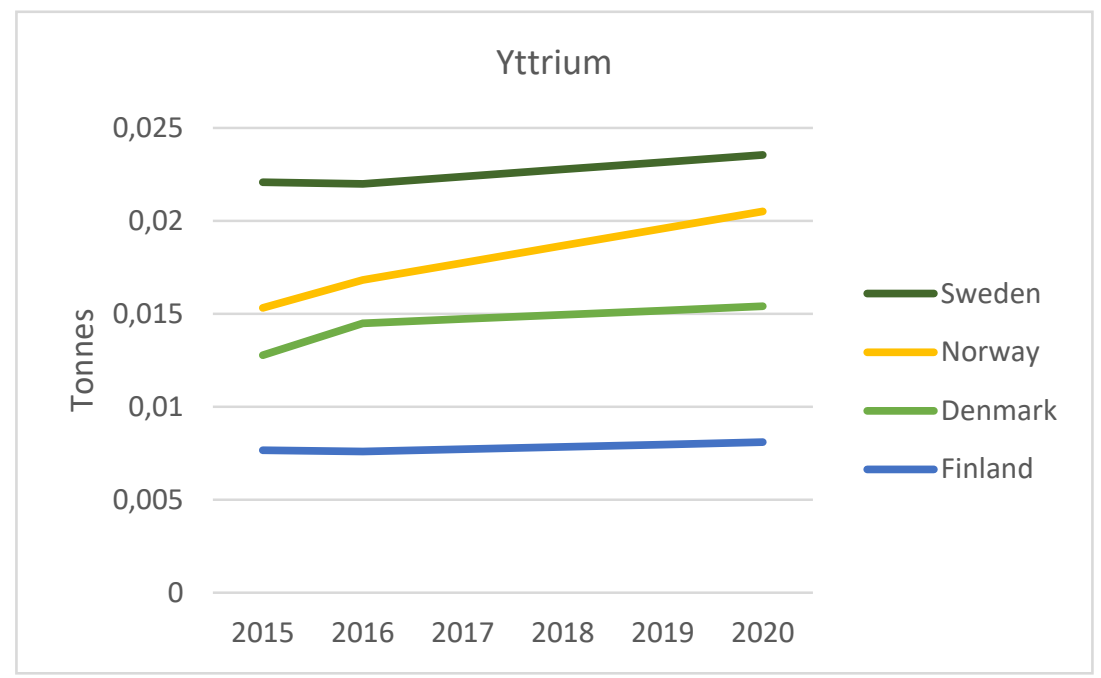




\section{Appendix 3: Identified bottlenecks for increased ELV recycling according to NEW_InnoNet and other sources}

Identified bottlenecks for increased ELV recycling. Bottlenecks 1-5 are identified as most significant in terms of being obstacles for increased recycling. Table adapted from ARN (2016), complemented with other sources: Geological Survey of Sweden (2014); Söderman \& Ingemarsdotter (2014); Ciacci et al. (2015); Andersson (2016).

Table 21: Identified bottlenecks for increased ELV recycling. Bottlenecks 1-5 are identified as most significant in terms of being obstacles for increased recycling. Table adapted from ARN (2016), complemented with other sources: Geological Survey of Sweden (2014); Söderman \& Ingemarsdotter (2014); Ciacci et al. (2015); Andersson (2016).

\section{Type of Bottleneck}

Quantifiable

1. Inadequate performance of the separation, sorting and refining technology
2. Inadequate performance of vehicle dismantling and reuse application

Description

Bottleneck impact

This bottleneck is identified in the stage of mechanical processing and has to do with the material and vehicle innovation taking place in the vehicle construction phase. As lighter components with the same operational performance are required, more complex materials are used, i.e. intermingled, alloyed or glued material particles. Thus, a variety of materials with overlapping properties is used causing difficulties in the current recycling practices.

According to Andersson (2016): CRMs are used in small amounts and in many components making them difficult to recover due to high related costs. There is a lack of recycling systems that regards the complexity of ELVs and strategies for the recycling of specific metals. The materials used in ELVs are not only many and complex, but the composition also changes rapidly over time contributing to unstable recycling markets. It is therefore necessary that long-term policies take this into consideration. Lack of industrial scale technologies for functional recycling regarding ELVs (Söderman \& ingemarsdottir, 2014; Geological Survey of Sweden, 2014)

In the dismantling phase, dismantling components for reuse requires great effort due to construction complexity and smart connected parts. A higher level of safety measures is also required for high-voltage components. Dismantling parts for material recycling is less viable when the value of the material is low.
Technical: Difficulty in separating the materials regarding both quantity and quality. Economic: Higher contamination levels in the secondary material.

Regulatory: Hindering meeting recycling targets.

Economic: More time required means reduced feasibility for reuse and recycling of potentially high-value components.

Societal: Increased use of high-voltage batteries in vehicles leads to higher safety risks for in the dismantling process.

Economic: No technical opportunity to extract limited, high-value materials such as rare earth metals.

Organizational: Parts that are softwareconnected are difficult to reuse in the market. 
3. Limited and low-quality application outlets of nonmetallic ELV materials

Inadequate performance of ELV collection and monitoring recovery and landfilling alternatives compared to material recovery
As "shredder waste" is of heterogeneous character, the technical and economic feasibility to sort, separate or refine non-metals is low. Due to the low economic value, materials that are sorted are recycled in low-grade application.

In collection, many factors have an impact on the interpretation of what an ELV is, how it should be recycled, and how the recycling subquota should be judged and monitored. The vagueness this causes may lead to substandard treatment. It also leads to a lack of reliable data availability on vehicle registration and composition, ELV collection and trade of vehicles/ELVs.

Overcapacities and competition in incineration and landfill facilities as well as low taxation rates lead to low gate fees in some EU Member States, thus making it difficult for material recycling to compete with alternative treatment. The operational costs of material recycling are usually higher than for incineration and disposal.
Economic: As no projection on business cases can be made, the willingness to invest is low. Societal: Material resources leave the material chain through incineration and disposal. Technological: Need for more innovation in terms of decontamination and immobilization.

Economic: Recycling targets are only possible by negative costs.

Societal: Gaps in sound and environmental processing.

Organizational: Information is invalid and monitoring and enforcement insufficient.

Economic: Reduced economic feasibility for recycling and investing in recycling of nonmetallic materials and minor metals. Societal: Only low-quality recycling can compete with incineration and disposal. Regulatory: The bottleneck causes substandard and shady operations for the disposal of waste.

\section{Not quantifiable}

6. Lack of accreditation and standardization for ELV recycling operators improvement of recycling

8. Lack of Europe-wide harmonization in regulation, poor governance and ineffective enforcement of regulation

Presence of unwanted substances prohibiting further qualitative application
Licensing, education, reporting and other requirements needed to start an ELV business are low. At the same time, cooperation often only occurs between ELV operators and operational standards vary between stakeholders. Trust and confidence of contractors are sometimes threatened by involvement in criminal practices. Need for enhanced coordination of research which today is fragmented. Industry, academi and authorities need to cooperate and exchange knowledge and experience in order to further stimulate economically viable recycling solutions and methods for recycling (Geological Survey of Sweden, 2014).

In sorting, higher requirements for raw material production, for example, through $\mathrm{REACH}$ secondary materials face new challenges as they in general contain higher levels of contamination and impurities.

There is a significant variety in the implementation levels of the current regulations between the Member States, thus making it difficult to understand the requirements set for legal operators. As enforcement is regarded insufficient, illegal operators can easily hide.

Hazardous substances accumulate in waste materials such as mercury, hydrocarbons and PCBs in the case of ELVs. Waste is often comingled with other scrap metals in ELV processing.
Organizational: Contracting partners may have difficulties in selecting the right partners.

Economic: Effort and costs are high for producers and extended producer responsibility systems.

Economic: Recycling applications are costly to develop.

Regulatory: Operators may be tempted to avoid regulations by illegal operations.

Regulatory: Recyclers work in an uneven playing field, unfair trade competition, different taxation and standards on waste management, substandard practices in the ELV-chain and lack of insight in vehicle registration flows.

Organizational: Increased contamination rates of heavy metals, persistent organic pollutants, PCBs and oils in metallic and non-metallic fractions. 

is benchmarked against primary material prices

Rapidly changing vehicle designs (model updates) technical compositions and higher contribution of consumers in vehicle design

12. Transportability of goods and materials. High share of small regional operating companies in the vehicle end-of-life chain

13. Lack of stability (volume / economic) in secondary material supply chain, is not motivational for material producers to integrate recyclate streams

14. No incentive for manufacturers to develop "recyclable" products, as vehicle use phase emissions are dominant design choice in total environmental performance

15. Total arising from ELVs is dropping and ageing, due to "fewer accidents", higher safety measures and vehicle exports to foreign destinations
The high environmental value of secondary material is not reflected in the financial pricing compared to primary materials. The virgin materials and especially the oil-based ones predominantly set the prices. For example, the recycling of plastic is economically challenged when oil prices are weak.

Product functionality and material composition is increasingly difficult to comprehend as the speed of product adaptation increases. Material use is not communicated between manufacturers and end-of-life operators; thus, the end-of-life operators have to investigate this by themselves.

Ciacci et al. (2015) points out the lack of designing vehicles for scarce metal recycling.

Whether or not the collection of ELVs is adequately performed is to a high degree decided on the transportation costs. This is especially true for less populated areas with low levels of generated ELVs. This is regarded as a key obstacle in international cooperation.

There is a lack in quality standardization agreed by secondary material producers caused by relatively low volumes of secondary materials.

The manufacturing chain in the automotive industry is judged by the final exhaust emissions of their products rather than on the recyclability of their products. Besides the producers' responsibility, the incentives to develop recyclable components are limited.

Due to the high secondhand value and improved safety features, many vehicles are exported instead of scrapped, and young damaged vehicles are getting scarcer which impacts the dismantling companies.
Economic: Material pricing does not reflect the total environmental and societal benefits brought by recycling.

Organizational: Producers driven mainly by cost will focus on the primary materials in their production.

Organizational: Knowledge gaps and depleting feasibility for component reuse and material recycling.

Societal: Lack of international operations, wide array of absent warranty product and operational standards, lack of capacity in investing, unstable long-term forecasts, lack of business-to-business cooperation and lack of innovation capacity.

Organizational: Insufficient organizational and technological effort by manufacturers to secure secondary materials as part of raw material chains.

Regulatory: As the use phase in vehicles is the leading factor, manufacturers are developing more complex products less convenient for recycling.

Economic: High level of competition to acquire valuable ELVs and less opportunity to fulfil the demand on some parts. 
Nordic Council of Ministers

Ved Stranden 18

DK-1061 Copenhagen K

www.norden.org

\section{CRITICAL METALS IN END-OF-LIFE PRODUCTS}

Critical raw materials (CRM) are used in various applications in different sectors, and their consumption will likely further increase in future. The threats caused by their limited availability and high prices have led to discussion on more efficient use of the resources available. The enhanced recycling of critical raw materials could be a significant opportunity for the Nordic countries.

This report focuses on the recycling potential of wastes containing CRMs, analyses of the bottlenecks of recycling, and identifies potential policy instruments to eliminate the barriers or reduce their impact. In order to enhance sustainable recycling, the Nordic countries should improve knowledge of CRM availability, develop new recycling strategies, support demonstration and selected R\&D actions, and strengthen Nordic influence on the development of European legislation and standards.

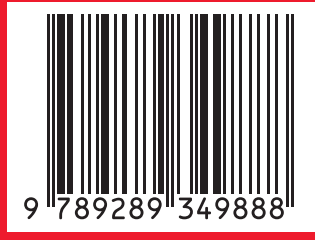

